NOTE TO USERS

This reproduction is the best copy available.

UMI 



\title{
Implicit Contracts and Immigrant Wages in Canada
}

\author{
by
}

\section{Yue XING}

A thesis submitted to the Faculty of Graduate Studies and Research in partial fulfillment of the requirements for the degree of

Doctor of Philosophy

Department of Economics

Carleton University

Ottawa, Canada

(C) Copyright 2010.

Yue XING 


\section{Library and Archives \\ Canada}

Published Heritage

Branch

395 Wellington Street Ottawa ON K1A ON4

Canada
Bibliothèque et

Archives Canada

Direction du

Patrimoine de l'édition

395 , rue Wellington

Ottawa ON K1A ON4

Canada
Your file Votre référence

ISBN: 978-0-494-67883-1

Our file Notre référence

ISBN: 978-0-494-67883-1
NOTICE:

The author has granted a nonexclusive license allowing Library and Archives Canada to reproduce, publish, archive, preserve, conserve, communicate to the public by telecommunication or on the Internet, loan, distribute and sell theses worldwide, for commercial or noncommercial purposes, in microform, paper, electronic and/or any other formats.

The author retains copyright ownership and moral rights in this thesis. Neither the thesis nor substantial extracts from it may be printed or otherwise reproduced without the author's permission.
AVIS:

L'auteur a accordé une licence non exclusive permettant à la Bibliothèque et Archives Canada de reproduire, publier, archiver, sauvegarder, conserver, transmettre au public par télécommunication ou par l'Internet, prêter, distribuer et vendre des thèses partout dans le monde, à des fins commerciales ou autres, sur support microforme, papier, électronique et/ou autres formats.

L'auteur conserve la propriété du droit d'auteur et des droits moraux qui protège cette thèse. $\mathrm{Ni}$ la thèse ni des extraits substantiels de celle-ci ne doivent être imprimés ou autrement reproduits sans son autorisation.
In compliance with the Canadian Privacy Act some supporting forms may have been removed from this thesis.

While these forms may be included in the document page count, their removal does not represent any loss of content from the thesis.
Conformément à la loi canadienne sur la protection de la vie privée, quelques formulaires secondaires ont été enlevés de cette thèse.

Bien que ces formulaires aient inclus dans la pagination, il n'y aura aucun contenu manquant.

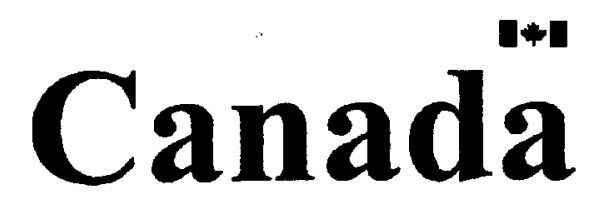


Acceptance 


\begin{abstract}
This thesis contains three research chapters concerning the determinants of wages of both the native born and immigrants in Canada. The role of implicit contracts on wages is examined both for the native born and for immigrants. Specifically, using panel data from the Survey of Labour and Income Dynamics (SLID), these chapters examine Canadian workers' response in their wage earnings to contemporaneous and past labour market conditions. In addition, the wages at arrival in Canada and the subsequent wage growth of the immigrants are analyzed by immigrant arrival growth using the native born as a comparison group.

In the first research chapter, we investigate whether the standard spot market view or the implicit contracting view dominates Canadian real wages for the native born. Using data taken from several SLID panels for the years 1993 to 2006, we found evidence that an implicit contract model with costless mobility is more consistent with the wage outcomes than is either the spot wage model or an implicit contract model with costly mobility in determining wages in the Canada labour market. By introducing differences by gender, industry and age into the wage model, evidence suggests that labour market conditions have differing impacts on wage dynamics between males and females, across industry groups and by age. Compared to men, women are found to be more affected by current macroeconomic conditions than by past macroeconomic conditions. Differing magnitudes of the implicit contracting effect are witnessed in the wage movements across industries. We also find that, unlike non-union workers who have wage responses consistent with an implicit contract model with costless mobility,
\end{abstract}


union workers seem to be insulated from most of the wage effects of macroeconomic variation.

The second research chapter focuses on analyzing the role of macroeconomic risk on earnings outcomes of immigrants within the context of an implicit contracts model. Again, using a pooled sample of data from the SLID over the period 1993 to 2006, we investigate the labour market performance of immigrants in Canada taking into account both current and past business cycle fluctuations. Three macroeconomic measures are incorporated into the standard wage models to test whether immigrants' wages follow a spot market view or an implicit contracting view. For the first time not only the implicit contract effect on the immigrant group is examined but also extensions have been made to test for differences in the wage responses to business cycles between immigrants and the native born. The empirical evidence suggests that an implicit contract model dominates the spot market model in terms of explaining immigrant wage outcomes. Further, the contract wage effect differs by gender among immigrants. Female immigrants are found to be less sensitive to the labour market conditions than are male immigrants. We also explore the role for job tenure on the wages of immigrants using the longitudinal nature of the data to control for unobserved heterogeneity.

In the third research chapter, we investigate the earnings outcomes of nine cohorts of immigrants arriving between 1960 and 2004, to see whether these groups of immigrants have experienced wage differences compared to their native-born counterparts at the time of immigration, and whether they will eventually integrate into the local labour market with time. The empirical results show a decline in cohort quality (captured by weaker wage performance) and little evidence of wage assimilation. Using 
age as a proxy for actual work experience leads to an enlarged immigrant-native wage gap relative to analyses that employ actual reported work experience. In models that include controls for job tenure, we find a decline of approximately two to three percent of the entry wage gap between immigrants and their native-born counterparts, as well as a drop in the wage growth rate. Therefore, failing to control for tenure, results in biased estimates of both cohort effects and the rate of assimilation. Moreover, we extend the model to include controls for macroeconomic conditions at different stages of the job tenure. The innovative approach by integrating the implicit contract literature into the immigrant wage cohort-assimilation literature enable us to test not only the impact of business cycle on immigrants' wage growth paths, as well as immigrant-native differentials in wage returns to various macroeconomic measures. Again, we find support for the implicit contract view as well as a poorer economic performance of immigrants in comparison with that of the native born in business downturns. In addition, the cohort wage effect is found to differ by gender among immigrants: male immigrants are at a greater wage disadvantage (relative to the native born) than are female immigrants. 


\section{Acknowledgements}

My most sincere gratitude goes to my supervisor Professor Christopher Worswick who guided me all the way through my thesis with patience, support and encouragement. I have benefited substantially from his knowledge and expertise, which I believe I will be able to carry forward into my future research and career. I would like to thank Professor Pierre Brochu, Professor Marcel Voia, Professor Saul Schwartz and Professor LouisPhilippe Morin for their feedback and constructive advice; in particular I would like to thank Professor Pierre Brochu for all his time and instructions in assisting me to improve my knowledge about the data management and structure. Thank you to Jean-Michel Billette for providing guidance in using data from Statistics Canada. I am extremely grateful to my external examiner Professor Tony Fang who provided detailed and insightful feedback regarding the theoretical issues and the methodology of my thesis.

I am deeply indebted to Professor Lynda Khalaf for sharing her rich knowledge in econometrics, for referring me to many job opportunities and for acting as a mentor. I will always remember her kindness, unlimited support and encouragement.

I am also grateful to Marge Brooks and the staff in the economics department at Carleton University for their assistance throughout my study in the program. I will never forget Dr. Wichayayuth Boonchit and Dr. Eng Kooi Lim for going through together the comprehensive exam days. I would like to express my greatest appreciation to Linlan Xiao for standing by me during a special time in 2009.

Last, I would like to dedicate this thesis to my dearest mother Yuqiu Wang and my late father Wanghui Xing. They are my true inspiration. 


\section{Table of Contents}

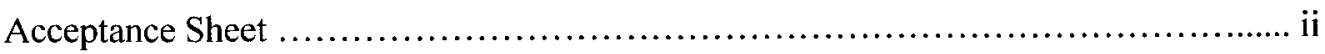

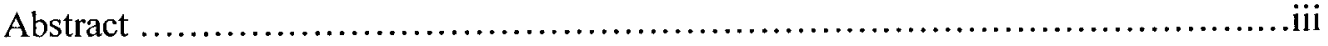

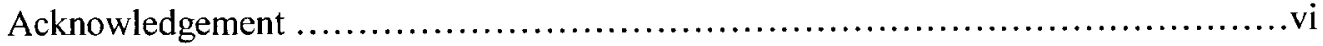

Table of Contents ............................................................ vii

List of Tables ......................................................................

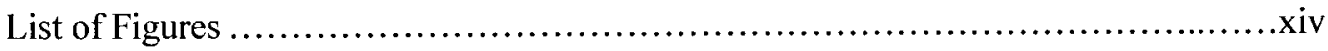

Chapter 1 Introduction

1. Implicit contract model vs. spot market model ...................................

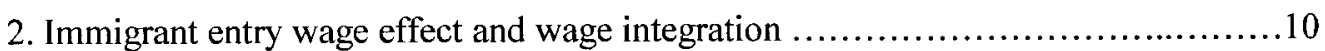

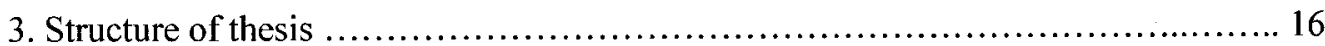

Chapter 2 Literature review





Chapter 3 The data

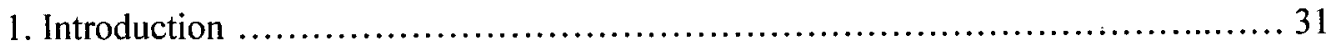

2. Sample restrictions and imputation methodology ............................. 33

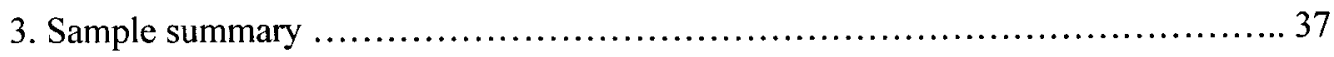


Chapter 4 Implicit contracts and wage outcomes of the native-born

1. Sample statistics

2. Empirical Results

3. Gender differences in implicit contract effect on wages ........................... 49

4. Introducing into the wage model differences by industry in the contract effect ...... 51

5. Introducing age differences in the contract effect on wages ...................... 55

6. Controlling for union status in explaining wage contract effects .................60

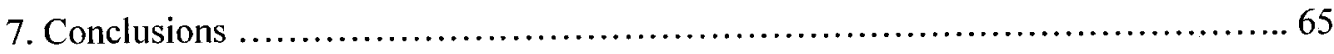

Chapter 5 Implicit contracts and immigrants wage determination

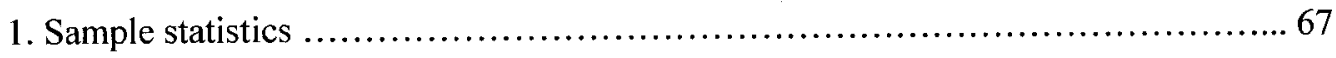

2. Testing the spot market view vs. the implicit contract view ........................ 69

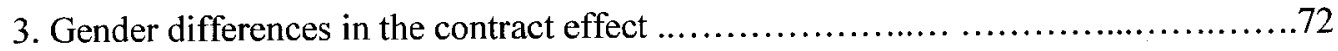

4. Immigrant-native born differences in wage response to macroeconomic conditions .. 75

5. Tests for immigrant-native differentials in the wage response to job tenure $\ldots \ldots \ldots \ldots . .82$

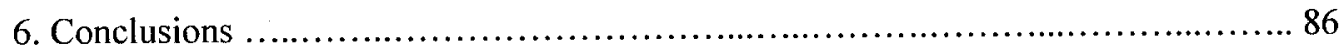

Chapter 6 Immigrant wage: macroeconomic conditions and job tenure

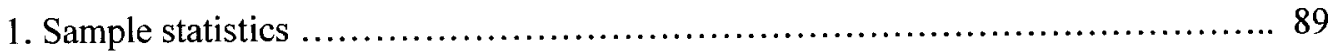

2. Immigrant wage disadvantage upon entry and the wage integration process .......... 92

3. Tests for the sensitivity of cohort differences and wage growth to the inclusion of

tenure controls ........................................................ 101 
4. Tests for differences by gender in entry wage differentials and wage assimilation... 105

5. Introducing initial and contemporaneous macroeconomic conditions into wage

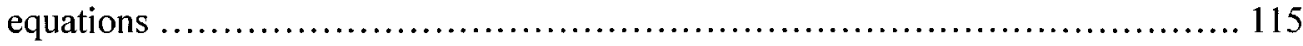

6. Fixed Effects Estimation ................................................ 125

7. Conclusions ............................................................... 133

Chapter 7 Conclusions ............................................................. 135

Appendix A:

Tables

Appendix B:

Consumer Price Index, historical summary (1993 to 2006)

Appendix C:

Tables with clustered standard errors (three examples from each research chapters) ...144

Appendix D:

Tables with regression results from using average hourly wage rate on the main job (three examples from each research chapters)) 147

Appendix E:

Tables with implicit contracting estimates obtained from random effects estimation... 150 


\section{Appendix F:}

A table with estimates representing individual characteristics..................... 152

References . 


\section{List of tables}

Table 4.1 Implicit contracts: sample means for selected variables (native-born group)

Table 4.2 Coefficient estimates of implicit contracting effects from fixed effects estimation (native-born group)

Table 4.3 Fixed effects: coefficient estimates of implicit contracting effects by gender

Table 4.4 Coefficient estimates of implicit contracting effects by industry 54

Table 4.5 Coefficient estimates of implicit contracting effects by age 58

Table 4.6 Fixed effects: coefficient estimates of implicit contracting effects after Controlling for Union Status

Table 4.7 Implicit contracting effects by union status from fixed effects estimation 63

Table 4.8 Implicit contracting effects by union status and gender from fixed effects

Estimation 64

Table 5.1 Implicit contracts: sample means for selected variables (full sample and immigrant sub-sample) 34

Table 5.2 Implicit contracting effects from fixed effects estimation: immigrant man and women

Table 5.3 Contracting wage effect for immigrants by gender: results from the the Pooled Panel 93-06

Table 5.4 Estimates representing immigrant-native differentials in contracting 
wages: men and women

Table 5.5 Immigrant-native differentials in contracting wage effects by gender

Table 5.6 Estimates representing immigrant-native wage differentials to job tenure: men and women

Table 5.7 Immigrant-native wage differentials to job tenure by gender

Table 6.1 Immigrant wage cohort effect and assimilation effect: sample means for selected variables: SLID, 1993 through 2006

Table 6.2 Mean age at immigration

Table 6.3 Coefficient estimates of immigrant variables (without tenure controls): men and women

Table 6.4 Coefficient estimates of immigrant variables (with tenure controls): men and women

Table 6.5 Coefficient estimates of immigrant variables by gender (with and without tenure controls)

Table 6.6 Coefficients from immigrant variables when macroeconomic controls are included in the model (with and without tenure controls): men and women

Table 6.7 Coefficients from immigrant variables by gender when macroeconomic controls are included in the model

Table 6.8 Coefficients of immigrant variables after controlling for fixed effects: men and women

Table 6.9 Coefficients of immigrant variables by gender after controlling for fixed 


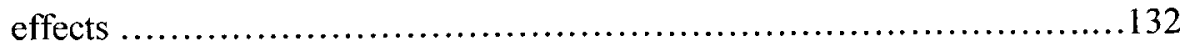




\section{List of figures}

Figure 4.1 Real wages against the unemployment rates $\ldots \ldots \ldots \ldots \ldots \ldots \ldots \ldots \ldots \ldots . \ldots 6$

Figure 4.2 Effect of the current unemployment rate by age ........................59

Figure 4.3 Effect of the initial unemployment rate by age ......................... 59

Figure 4.4 Effect of the minimum unemployment rate by Age .................... 60

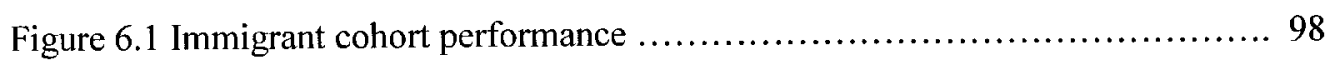

Figure 6.2 Assimilation process of the cohorts (with actual work experience)......... 100

Figure 6.3. Assimilation Process of the cohorts (with age proxy) ................... 101

Figure 6.4 Comparison of immigrant cohort quality with and without tenure

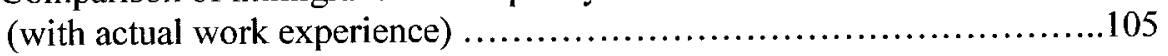

Figure 6.5 Comparison of immigrant cohort quality with and without tenure (with age proxy) ....................................................... 105

Figure 6.6. Assimilation Process of the 1980-84 cohort using actual work experience

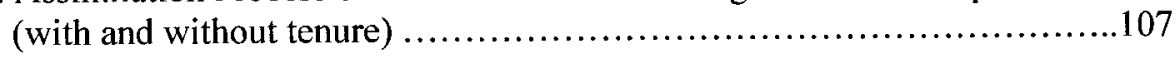

Figure 6.7 Tenure-wage profiles for native-born workers and for immigrants.......... 109

Figure 6.8 Assimilation process of the male cohorts (without job tenure) ..............112

Figure 6.9 Assimilation process of the female cohorts (without job tenure)............112

Figure 6.10 Assimilation process of the male cohorts (with job tenure)............... 113

Figure 6.11 Assimilation process of the female cohorts (with job tenure)............. 113

Figure 6.12 Immigrant wage differentials by gender (without tenure) ................ 114

Figure 6.13 Immigrant wage differentials by gender (with tenure) ................. 114

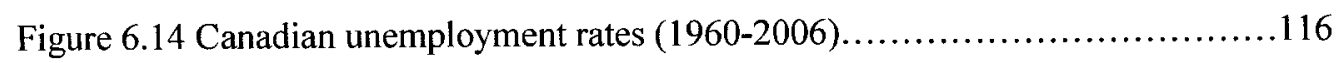




\section{Chapter 1}

\section{Introduction}

\section{Implicit contract model vs. spot market model}

Economists have found contradicting evidence on the issue of whether macroeconomic conditions affect wages in a manner consistent with a spot market model or an implicit contract model of the labour market. Empirically, three wage modeling frameworks stand out in terms of interpreting the role of past and contemporaneous labour market conditions in determining wages (see Beaudry and Green, 1991). Three indicators of macroeconomic measures are introduced separately and jointly into standard real wage models including the current unemployment rate, the unemployment rate at the time when an individual starts his job and the minimum unemployment rate over this individual's entire job tenure.' Under the standard spot market model, only the current macroeconomic condition affects current wages. Historical labour market conditions do not matter. Employers and workers renegotiate wages every period and thus wages vary with the marginal product of labour and the contemporaneous labour market conditions. On the other hand, the implicit contract framework allows for the possibility that the firm may be able to negotiate more stable real wages for the employees and thus reduce the impact of macroeconomic shocks on workers. Past labour market conditions play a more important role in determining current wages and not just the contemporaneous macroeconomic conditions. Two main forms of the implicit contract wage model are

\footnotetext{
${ }^{1}$ The measure of one minus the employment to population ratio is not adopted in this thesis. Due to the fact that this variable could not be generated prior to 1976 using Statistics Canada data, we were unable to carry out the research with this ratio. The unemployment rate is solely used here as a proxy for the macroeconomic condition.
} 
considered based on underlying assumptions related to the mobility of workers. If workers are not forced to commit to the contract, workers have costless mobility and are able to move to higher paying jobs in good times. With a binding contract instead, workers commit to the contract and their mobility between firms will be costly and prohibitive.

An extensive literature exists in Economics on the theoretical implications of implicit contracts models and their empirical implications for labour market outcomes such as wage rates and unemployment. The central idea revolves around risk neutral firms offering employment contracts that attempt to offer either insurance to their workers from the effects of business cycle fluctuations. Baily (1974) tries to explain wage rigidity with pre-announced contract enforcement. Azariadis (1975) studies firms' contractual strategies within the context of demand uncertainty in comparison with a layoff decision and concludes that an implicit contract represents a firm's optimal arrangement under different labour market conditions. Harris and Holmstrom (1982) characterize implicit contract wages as an outcome under an incomplete but symmetric information circumstance. Rosen (1985) gives a full picture of the advantages and disadvantages of adopting a contract wage approach to explain macroeconomic fluctuations in an imperfect market.

The recent literature has focused primarily on the implications of implicit contracts on wage outcomes of workers. Beaudry and DiNardo (1991) develop an empirical framework based on the Harris and Holmstrom (1982) theoretical model. Embedded within a human capital wage equation, they introduce three contract variables designed to proxy for the impact of current and past macroeconomic conditions on the 
current wage outcomes of workers. Therefore, three scenarios are built by them taking into account workers' mobility levels when facing labour market risks. More specifically, they define that only the current unemployment rate influences workers' current wages in the spot market model. Under implicit contract models, workers are impacted the most by the minimum unemployment rate over their job spells when the workers cannot commit to the contracts and workers are able to move between firms. When workers can commit to the contracts, the initial unemployment rate at the time of hiring should have the largest effect in determining the wage movements. Using US data taken from the Panel Study of Income Dynamics (PSID), the National Longitudinal Survey of Youth (NLSY) and the Current Population Survey (CPS), they find strong empirical evidence of implicit contracting effects in the US labour market. According to their study, a one percent reduction in the minimum unemployment rate is linked to a 4.5 percent wage increase, compared with a two percent wage increase influenced by a one percent drop in the current unemployment rate, and a three percent wage increase associated with the initial unemployment rate. When all three contract variables are combined in the same wage equation, they find that it is the minimum unemployment rate which is statistically significant. They also repeat the implicit contract analysis having unobserved individual attributes removed, and they still find that implicit contract with costless mobility dominates other modeling implications.

The first study to replicate the Beaudry and DiNardo (1991) results was carried out by McDonald and Worswick (1999) using Canadian data. By following the Beaudry and DiNardo framework and applying Canadian cross-sectional data over 1980s and early 1990s, McDonald and Worswick (1999) find similar results to support the implicit 
contractual view. However, the implicit contract effect they find has much lower magnitude than Beaudry and DiNardo's. The McDonald and Worswick estimates of the current and past macroeconomic measures range from approximately 0.1 percent to 0.6 percent, compared with the 2 to 4.5 percent impact of labour market conditions on current wages as shown by Beaudry and DiNardo. Despite the significantly smaller estimates found by McDonald and Worswick, the implicit contract framework still dominates the spot market view. McDonald and Worswick also extend the model to include age cohorts and find a hill-shaped distribution of the age effect.

Grant (2003) employs six cohorts of the National Longitudinal Surveys to replicate the Beaudry and DiNardo framework and presents mixed results in terms of the importance of implicit contract effects on wages. He also extends the model to allow for differences by gender and union status within the contract wage model. Weak gender differences are found when testing the effect of implicit contracts on wages. The empirical results also suggest that the union sector has the strongest implicit contracting effect. The study by Devereux and Hart (2005) suggests that the British labour market is more consistent with the spot wage model than contracting models.

The most recent research by Green and Townsend (2010) focuses on Canadian male workers with high school education or less. Evidence is presented of a long downward trend in the real wages of less-skilled workers. They argue that the stationary AR (1) process for unemployment rates and worker productivity assumed by Beaudry and DiNardo (1991) will not sustain in analyzing the wage dynamics of low-skilled workers over the business cycle. In a recent paper, Green and Townsend took a different approach to allow for ratchet effect in an attempt to proxy for the best labour market 
conditions during a worker's job spell. Instead of including past and current unemployment rates as explanatory variables in the wage model, Green and Townsend employ rates of change in wage patterns to capture implicitly the effect of business cyclicality on wages. They focus on a specific labour group and find that implicit contract with costless mobility provides a better explanation for the wages of low-skilled workers.

Many researchers also carry out disaggregate analyses to see if the wages of certain groups of workers are more likely to be affected by implicit contract effects. Beaudry and DiNardo (1991) find strong evidence of implicit contracting effects across most industries, as well as cross-industry differentials in real wage cyclicality to historical macroeconomic variables. Devereux and Hart (2005) find strong support for the spot market view for manual labour and weak evidence that implicit contracts are important in professional jobs. Grant (2003) extends the empirical model to allow for gender differences and the impact of unions in the contract wage model. A weak gender difference is found when testing the effect of implicit contracts on wages. He also suggests that union sectors reveal the strongest implicit contracting effect. McDonald and Worswick (1999) include age cohorts into the wage model to test whether workers at different age groups have differing wage responses to macroeconomic conditions. They find that both younger workers and workers near retirement are affected the most by the macroeconomic conditions. They thus present a hill-shaped distribution of the age effect in terms of wage variations to the minimum unemployment rate over individuals' job tenure. 
In Chapter 4, we test whether the contracting effect is present in Canadian longitudinal earnings data when fixed effects regression methods are employed. The substantially smaller impact of unemployment rates on wages in the Canadian labour market as shown in the earlier literature gives us further motivation to explore the implicit contract issue through employing more recent data sets. Unlike McDonald and Worswick (1999) who did not have access to longitudinal data, we are able to control for unobserved heterogeneity through fixed effects estimation using the SLID (Survey of Labour and Income Dynamics) data. This is an important advantage in that it allows us to eliminate the possibility of fixed unobserved heterogeneity that may be correlated with the contract variables potentially lead to biased coefficients. Another important advantage of this chapter over many previous implicit contract studies is the availability of actual years of work experience and, especially, job tenure information. Due to data limitations, potential experience (age - schooling -5 or 6 ) is adopted as a proxy for actual labour market experience in many earlier studies (for example, McDonald and Worswick, 1999, and Grant, 2003). In addition, job tenure is either expressed in grouped categories (for example, McDonald and Worswick, 1999) or partially constructed (for example, Beaudry and DiNardo, 1991). ${ }^{2} \quad$ Job tenure measures an individual's work experience in the job. It is a key variable in the analysis of this thesis since it is used when deriving the labour market conditions at the time when a worker starts his job, as well as the best labour market conditions over the worker's job spell. Using actual

\footnotetext{
${ }^{2}$ The Survey of Consumer Finances (SCF) used in McDonald and Worswick's analysis classifies job tenure into five categories. Beaudry and DiNardo employ the Panel Survey of Income Dynamics (PSID) in their implicit contract studies. Job tenure in the PSID is either not recorded in some years or not defined clearly whether it is tenure in the job or tenure with the employer. They are forced to adopt methodologies proposed by Altonjoi and Shakatko (1987) and Topel (1989) to construct job tenure.
} 
experience and job tenure in this thesis allows us to avoid measurement errors that have been present in previous studies. ${ }^{3}$

We not only employ the pooled SLID data sets to examine the implicit contract effect on the wages of native-born Canadians, but also make an extension by including group-specific implicit contract effects in the empirical work. The regression results support the previous findings by Beaudry and DiNardo (1991) and McDonald and Worswick (1999) in which the implicit contract with costless mobility is found to have the strongest influence on wage outcomes. When testing wage variations in the of facing changing current labour market conditions, the evidence found in this chapter implies a slight upward trend of real wages which can be interpreted as an outcome of non-binding implicit contracts. In addition, the empirical results suggest that labour market conditions have differing impacts across groups. The group effect by gender suggests that the wages of female workers react slightly more to current labour market conditions than is the case for male workers. The minimum unemployment rate over an individuals' job tenure, on the other hand, seems to have a larger impact on the wages of men when compared to the effect on the wages of women. Moreover, by introducing age groups into the empirical model, we found that workers in their early thirties are more sensitive to the past macroeconomic conditions than both younger and older workers. Unlike a hill-shaped implicit contracting effect found in the earlier literature, there is no clear pattern in the manner in which past labour market conditions affect the wages of different age groups;

\footnotetext{
${ }^{3}$ Altonji and Shakotko (1987) employ an instrumental approach to correct for individual heterogeneity and job match heterogeneity. They conclude that general human capital is more important than job tenure in affecting wages. Parent (2000) adopts the same instrumental method and further controls for industry tenure besides general human capital and firm tenure. They find that it is industry-specific capital other than firm specific capital that affects wages. An exploration of the endogeneity of job tenure is left for future work.
} 
however, variation in the magnitude of this affect by age groups is found. In summary, the evidence found in Chapter 4 gives further support to the implicit contracting view of wage determination in Canada and in terms of the importance of past macroeconomic conditions in determining current wages.

In Chapter 5, the analysis of the effect of implicit contracts on wages in Canada is extended to the case of immigrants. The SLID contains detailed demographic characteristics and information on immigrant status and year of arrival in Canada, which allow us to fill the void in the implicit contract literature related to immigrants. We adopt the same empirical approach in this chapter as in Chapter 4 but focus on immigrant/Canadian-born differences. We investigate the importance of implicit contract models both with and without costless mobility, and compare the results from these versions of the model to what would be found from a traditional spot market model of the labour market. When studying wage returns to macroeconomic variables, some studies have found that wages are more affected by current than past labour market conditions (Devereux and Hart, 2005). While others have found that historical macroeconomic status has permanent or 'scarring' effects on wages (Beaudry and DiNardo, 1991, and McDonald and Worswick, 1999). However, all previous studies are based on either a non-immigrant sample or a combined sample of both the native born and immigrants without allowing for the magnitude of the contract effect to vary by immigrant status. No studies have focused directly on the implicit contracting effect on immigrants. Therefore, another important contribution of this thesis is to integrate the implicit contract literature into the immigrant earnings literature. The wage performance of immigrants in business cycles is investigated as well as differences in immigrant wage response to market 
fluctuations compared to that of native-born Canadians. Current and past macroeconomic measures are included as control variables in the wage models to investigate the impact of business cycle patterns on the wages of immigrants. Interactions of immigrant status with the labour market indicators are also included as controls to examine the sensitivity of immigrant earnings relative to native-born earnings to business cycle fluctuations operating through contract effects.

Estimation using a pooled sample drawn from several panels of the SLID yields strong evidence is found that wages of immigrants are affected by past macroeconomic conditions in a manner that is consistent with an implicit contract model with costless mobility. The analysis also allows the impact of the contracting variables to differ by gender among immigrants. The wages of female immigrants are less sensitive to the fluctuating labour market conditions than are the wages of male immigrants. Further extensions have been made to investigate immigrant-native wage differentials to current and past labour market conditions and to job tenure. Regression results suggest that immigrants face a less favourable position than their native-born counterparts in terms of labour market earnings.

The implicit contracting view supported in our analysis sheds light on the nature of the employment relationship and the way in which employees and firms act under labour market uncertainty and the possibility of worker mobility. During an economic downfall, risk-neutral firms offer risk-reducing contracts to risk-averse workers so that workers are at least partially insured against wage variation due to business cycle fluctuations. During a boom, firms need to raise the wage to keep workers from leaving the firm. 
Immigrant-native differences in terms of implicit contract effects found in this thesis may provide insights into immigrants' economic status in the hosting country and lead to policy inclination or adjustment. For example, it may suggest that government policies lean towards greater financial assistance targeting certain groups of workers during recessions, as well as suggest that immigration-adjustment programs be instituted by policy makers according to the economic environment. In addition, the analysis of this thesis indicates that both current and past labour market conditions must be factored into analyses of immigrant wages if the goal is to evaluate the performance of immigrants in the labour market since ignoring macroeconomic conditions may lead to a biased interpretation of the success of a particular group of immigrants.

\section{Immigrant entry wage effect and wage integration}

Immigrants today account for a large and increasing proportion of labour force growth in immigrant-accepting countries. The economic impact of immigration has been an important issue in immigrant-accepting countries, for example, the United States, Canada and Australia. Economists have tried to infer social and economic implications from analyzing immigration data. They specifically focus on the issues of: whether there are initial wage discrepancies between immigrants and native-born workers, whether immigrants will eventually catch up economically, how the employment opportunities of native-born workers are affected by the economic performance of immigrants, and what policy issues are implied in immigration studies. In his pioneering work, Chiswick (1978) studied the earnings performance of immigrant and native-born men. He employed the 1970 Census data from the United States to test the hypotheses of wage assimilation of 
foreign-born men. Through comparisons of immigrants with their native-born counterparts, by English-speaking and non-English-speaking source countries, and years spent in the United States since immigration, Chiswick found that immigrants have initial earnings disadvantages when compared to native-born men; but in 10 to 15 years of residence in the US, they catch up and even exceed their native-born counterparts in terms of earnings.

Following the framework and methodology of Chiswick (1978), many immigrant earnings studies based on cross-sectional analysis have found similar results (Lalonde and Topel, 1990; Abbott and Beach, 1993; and Duleep and Regets, 1997). Meanwhile, many others have shown mixed results in analyzing the immigrant wage assimilation process.

Many studies in this literature have analyzed differences in immigrant earnings performance by source country (see Borjas, 1982; Butcher, 1994; Borjas, 1996; Allensworth, 1997; Miller, 1992), gender (Long, 1980; Beach and Worswick, 1993; Cobb-Clark, 1993) and generations (Carliner, 1980; Hum and Simpson, 2004). Borjas (1985) employed both the 1970 and 1980 US Census files allowing for the introduction of a set of immigrant arrival cohort variables and found evidence of a cohort quality gap for more recent arrival cohorts as well as lower speed of earnings convergence. Baker and Benjamin (1994) used three Canadian Census data (1971, 1981 and 1986 census) to test the entry cohort effect and the subsequent assimilation effect. Prolonged cohort differences and little evidence of catching-up are supported in their empirical findings. While Grant (1999) examined 1991 Canadian census and found that Canadian 
immigrants who arrived in the early 1980 s cohort catch up to their native-born counterparts at a faster rate than earlier cohorts.

Later, the availability of longitudinal data sets enable economists to overcome the limitation of the cross-sectional nature of data sets such as the Census, and analyze the economic performance of each individual immigrant over time (see Hu, 2000; Hum and Simpson, 2002; Hum and Simpson, 2004). Evidence suggests that the assimilation rate is not as fast as is found in most census-based studies.

Modeling specification bias has also been discussed to evaluate the true economic performance of immigrants compared with native-born workers. McDonald and Worswick (1998) discuss the importance of including job tenure and macroeconomic conditions to derive the true estimates of cohort performance and the degree of assimilation. They find evidence of biases arising from the exclusion of those variables. Hum and Simpson (2004) find support for an upward bias in their estimates of the initial earnings disadvantage of immigrants at arrival as well as an upward bias in the earnings assimilation rate, due to the use of potential labour market experiences. They also suggest that unobserved heterogeneity is an important factor in immigrant earnings models that can lead to omitted variable biases.

One issue that has drawn much attention is the imperfect transferability and under-utilization of the human capital of foreign-born workers acquired prior to migration. Reitz (2001) finds evidence that immigrants' pre-migration professional skills are discounted and not fully utilized in the Canadian labour market. Hum and Simpson (2004) argue that the imperfect transferability of immigrant education and labour market experience obtained before they migrated to the destination country results in biased 
estimates of the economic return to human capital. Using the 1999 Canadian Workplace and Employee Survey, Wald and Fang (2008) find that high skills are underutilized and the job mismatch leads to an enlarged earnings gap between immigrants and the native born. Chiswick and Miller (2007) estimate an inverse relationship between pre-migration labour market experience and post-migration job match. However, post-migration human capital enables better occupational selectivity.

Using pooled data from the Survey of Labour and Income Dynamics (SLID), Chapter 6 mainly adopts the methodology of McDonald and Worswick (1998) in terms of the analysis of immigrant wage determination. Several wage models are regressed to test immigrant wage assimilation hypotheses for the case of Canadian immigrants. An important issue raised by McDonald and Worswick (1998) relates to the role job tenure plays in determining immigrant wage dynamics. Mincer (1958) and Becker (1964) introduced human capital theory into the modern neoclassical labour economic literature. Job tenure is generally considered to be a proxy for firm specific human capital since work experience is thought of as the best proxy for general human capital gained through working. A number of researchers have looked at the role of job tenure in a wage regression framework (see Mincer and Jovanovic, 1981, Altonji and Shakotko, 1987, and Topel, 1991).

A key contribution of this thesis chapter is the fact that a thorough investigation is carried out on the returns to job tenure for immigrants. McDonald and Worswick (1998) were the first to include tenure controls in their wage specifications to explain immigrant/non-immigrant wage differentials. To the best of our knowledge, this is only the second study of its kind to investigate this issue. Unlike McDonald and Worswick 
(1998) who did not have access to longitudinal data, we are able to control for

unobserved heterogeneity through fixed effects estimation using the SLID data. This is an important advantage in that it allows for us to eliminate the possibility that fixed unobserved heterogeneity across individuals that is correlated with job tenure may be the underlying cause of a positive return to job tenure in a wage regression. For example, if firms tend to retain workers with higher ability through offering higher wages, workers in our data with higher average wages will have higher job tenure, ceteris paribus, in the absence of controls for unobserved heterogeneity. Without using fixed effects methods, this assumed relationship would introduce an upward bias in our estimates of the returns to job tenure since the coefficients would capture both the hypothesized positive relationship due to firm specific human capital as well as the fact that the workers with higher job tenure having higher unobserved ability.

Similar to McDonald and Worswick (1998), job tenure has been found to be an important factor in analyzing immigrant wage dynamics. Biases arising from omitted tenure variables are suggested. Using age as a proxy for actual years of work experience leads to exaggerated estimates of wage differentials between immigrants and nonimmigrants. This may provide a tenable explanation for the higher magnitude of cohort effect found in earlier studies that use conventional proxies for the missing experience variable. Furthermore, extensions have been made to examine gender differences in the initial economic state of immigrants. Wage disparity has been found to be less severe between female immigrants and natives than between male immigrants and natives. Another major issue concerns the impact of macroeconomic conditions on immigrant wages. Many previous immigration studies focused on the labour market 
outcomes of immigration. Little attention has been contributed to the other side of the issue, namely, the effect of labour market conditions on immigrant wage outcomes. McDonald and Worswick (1998) study eleven cross-sectional data sets covering 1981-92 and control for the macroeconomic conditions in the conventional wage setting. They provide evidence that links the poor performance of immigrants to the worsening labour market conditions. Following their approach, we introduce current macroeconomic variables into the immigrant wage studies and find declines in the estimated cross cohort in entry earnings. Moreover, we incorporate the implicit contract literature into the immigrant wage assimilation equation. This is an important innovation in that it allows us to track workers' wage reaction to macroeconomic shocks at various stages of the entire job tenure, as well as immigrant-native wage differentials in facing macroeconomic variations along the earnings convergence paths. We find that the minimum unemployment rate since the time of hiring has the largest influence on workers' wage outcomes relative to the effect of the current unemployment rate or the unemployment rate at the start of employment at the firm. Immigrants typically perform poorer economically than the native born in worsening labour market conditions.

A number of other studies have analyzed the issue of whether the labour market performance of immigrants is especially sensitive to the macroeconomic conditions. (see, for example, Nakamura and Nakamura, 1992, and Chiswick and Miller, 2002). Chiswick, Cohen and Zach (1997) incorporated into the wage model the unemployment rate at the time of arrival in the U.S. labour market. They tried to derive the inference of business cycle on the unemployment incidence. The empirical results show support for the adverse effect of poor labour market conditions on the employment probabilities. 
MacDonald and Worswick (1997) find similar results for Canada but focus primarily on the unemployment rate at the time of the survey finding it to be more important than the unemployment rate at landing in terms of explaining the current unemployment probability of immigrants. McDonald and Worswick (1998) examine the economic return to the current unemployment rate and found evidence that macroeconomic conditions account for a part of immigrants' assimilation effect. Using 19 cross-sectional data sets of Survey of Consumer Finances, Aydemir (2003) adopted both current unemployment rate as well as the unemployment rate at the time of immigration, and found significant interactions of business cyclical pattern with the cohort quality characteristics and integration effect on immigrants.

\section{Structure of the thesis}

In this thesis, we aim to investigate the implicit contracting effect using Canadian Panel survey data. The sample data set is divided into two subgroups.

The thesis is organized as follows. The second chapter focuses on the literature review of the implicit contract models, the key issues associated with immigrant wage studies, the modeling framework capturing the implicit contracting effect facing Canadian workers, and the immigrant initial wage performance upon arrival, as well as the assimilation effect through their post-immigration employment. Chapter 3 contains the data description for the SLID data. Selected statistics are presented in each of the following research chapters. In Chapters 4 and 5, the models with different macroeconomic measures are examined and the key modeling inferences for implicit contracting effects facing both the native born and immigrants are presented. The group 
effects by gender, industry and age are investigated. Immigrant-native earnings differentials to current and past macroeconomic variations as well as the role of job tenure in terms of earnings determination are discussed. More issues examined in Chapter 6 include the immigrant wage hypotheses, the role of tenure controls, age proxy versus actual work experience, an extension with gender differences, the introduction of macroeconomic controls, the fixed effects estimation results and the discussion of unobserved heterogeneity bias. In Chapter 7, major findings and policy implications in this thesis are presented. 


\section{Chapter 2}

\section{Literature Review}

\section{Implicit contract models and the empirical approach}

This chapter aims at exploring how current and historical labour market conditions affect wage outcomes. More specifically, the impact of current and past labour market conditions on wages is analyzed by employing the Beaudry and DiNardo (1991) specification of the human capital wage equation and augmenting it to include variables typically employed in an analysis of wages. By testing the empirical predictions of three competing models, namely, the spot wage model, the implicit contract model with costless mobility and the implicit contract model with costly mobility, important effects of the implicit contracts on wage earnings will be presented.

In the early 1920s, Frank Knight (1921) published his work "Risk, Uncertainty, and Profit" introducing the distinction between risk and uncertainty in an economic sense. The concepts spread widely in the insurance and finance circles in the 1970s and 1980s, and were developed scientifically in both quantitative and qualitative approaches.

The relationship between wage and employment has been a critical issue in economic theory (i.e. Phillips, 1958, vs. Friedman, 1966), and leads to different schools of economic thought (Keynesian vs. Classical) and different treatment in the modeling tradition of the demand theory of the business cycle.

Baily (1974) and Azariadis (1975) are among the first to propose the idea of implicit contract wages in an effort to explain how the long-run risk-reducing insurance policy offered by the firm affects wages and employment variations. In their framework, 
risk neutral firms offer binding insurance contracts to risk-averse workers to smooth stochastic labour market fluctuations.

Since the 1970s, theories and empirical studies have presented contrasting results regarding contract wages. Harris and Holmstrom (1982) explain contract wage profiles under incomplete but symmetric information circumstances. They derive equilibrium contract wages under the condition of workers' risk-averse behaviour and firms' riskneutral preferences in the absence of insurance markets that would allow workers to insure themselves against macroeconomic variation in wages. Rosen (1985) elucidates the pros and cons of adopting a contract wage approach to explain macroeconomic fluctuations in an imperfect market.

Beaudry and DiNardo (1991) are the first to construct a complete methodology by integrating implicit contract theory into an empirical model of wage outcomes and then show strong evidence of the implicit contracting effect on wages. They link past labour market conditions with current wages through a contract wage framework. The key ideas of their studies are presented below.

1.1 Major assumptions about the behaviour of employees and firms under labour market uncertainty

One of the key assumptions that has been made in the contract wage model is about the risk taking behaviours of firms and workers under demand uncertainty. It is assumed that employees are risk-averse and firms are risk-neutral when facing business cycle shocks. Firms are assumed to be better at bearing macroeconomic shocks than workers. In the absence of a perfectly insured labour market, firms maximize their 
expected profits and at the same time offer risk-reducing contracting policies to riskaverse workers.

1.2 Mobility level of workers between employers

Earlier implicit contract studies state that firms will incur mobility and turnover costs when workers are mobile and are able to move from one firm to another. Firms must offer a risk-reducing insurance contract to guard workers against employment variations so as to prevent workers from quitting. Beaudry and DiNardo (1991) extend the idea by allowing both limited and unrestrained mobility of labours between firms, which means that implicit contract may or may not be binding on the employees. With a non-binding contract, workers have costless mobility and are able to change jobs in good times. Contrarily, workers with a binding contract commit to the contract and their mobility between firms will be costly and prohibitive. Devereux and Hart (2005) further control for the maximum unemployment rate over the job tenure to capture the possibility of non-binding wage contracts on firms.

\subsection{Contract wage vs. Current wage}

Economists in the earlier literature have developed in many ways a complete framework regarding dynamic models of implicit contract wages. Enormous effort has been made to explain the dynamic movements of wages and unemployment. Beaudry and DiNardo (1991) adopt the contract wage methodology and synthesize it with the existence of labour market risks as well as level of mobility in the wage profile. Wages in this contracting framework are pre-announced and may or may not be stochastic depending on whether the workers' mobility is costly or costless. 
If one combines the aforementioned key points into the contracting wage profiles, it yields the basis of the following regression models. The basic spot market model and implicit contract wage models are defined in (2.1.1) according to the macroeconomic measures employed. ${ }^{4}$

$$
\ln w(i, t)=X_{i, t} \Omega_{1}+\left\{\begin{array}{l}
\beta_{1} u c_{t}+\varepsilon_{1, i t} \\
\beta_{2} u s t r_{i, t}+\varepsilon_{2, i t} \\
\beta_{3} u l o w_{i, t}+\varepsilon_{3, i t} \\
\beta_{4} u c_{t}+\beta_{5} u s t r_{i, t}+\beta_{6} u l o w_{i, t}+\varepsilon_{i, t}
\end{array}\right.
$$

where $\ln w(i, t)$ is the $\log$ real wages of individual $i$ at time $t$. The independent variables include a vector of individual characteristics $X_{i, l}$, and different measures of labour market conditions which enter the model individually or jointly. The vector $X_{i, t}$ contains explanatory variables including years of schooling, years of experience, years of tenure with the firm, and controls for industry, marital status, region of residence and urban/rural status. The contract variables, $u c_{i}, u s t r_{i, t}$, and $u l o w_{i, t}$ are the three contract variables which stand respectively for the current unemployment rate, the unemployment rate at the time of hiring and the minimum unemployment rate since the time when the individual was hired. To construct $u s t r_{i, t}$ and $u l o w_{i, t}$, we first determine each worker's main job in each survey year and calculate the worker's tenure for that job. We then calculate both the unemployment rate at the start of that job and the minimum unemployment rate since the start of that job and those are the values of $u s t r_{i, t}$ and $u l o w_{i, t}$ for that worker in that reference year. With each single measure of the labour market

\footnotetext{
${ }^{4}$ The pair-wise combinations taken from the set of 3 macroeconomic measures are omitted here for simplicity.
} 
conditions, we test whether the immigrant wage profile follows the spot market model or the implicit contract model. By combining the three measures together, we can investigate which contract variable has the greatest influence on wages.

To correct for possible unobserved heterogeneity, fixed effects estimation is carried out through most parts of this chapter. Fixed effects analysis is superior to random effects analysis in the sense that it has the orthogonal design between individual specific characteristics and the covariates of the wage model. The individual specific mean is subtracted from the left and right-hand-side variables of model (2.1.1), and the fixed effects models take the following form: ${ }^{5}$

$$
\ln w(i, t)-\overline{\ln w(i)}=\left(\Psi_{i, t}-\overline{\Psi_{i}}\right) \Omega_{2}+\left\{\begin{array}{l}
\rho_{1}\left(u c_{t}-\overline{u c_{i}}\right)+\left(e_{1, i t}-\overline{e_{1, i}}\right) \\
\rho_{2}\left(u s t r_{i, t}-\overline{u s t r_{i}}\right)+\left(e_{2, t}-\overline{e_{2, i}}\right) \\
\rho_{3}\left(u l o w_{i, t}-\overline{u l o w_{i}}\right)+\left(e_{3, t}-\overline{e_{3, i}}\right) \\
\rho_{4}\left(u c_{t}-\overline{u c_{i}}\right)+\rho_{5}\left(u s t r_{i, t}-\overline{u s t r_{i}}\right)+\rho_{6}\left(u l o w_{i, t}-\overline{u l o w_{i}}\right) \\
+\left(e_{i, t}-\overline{e_{i}}\right)
\end{array}\right.
$$

The regression model sheds light on how different measures of macroeconomic conditions affect the real wage movements. In a spot market view, only the current unemployment rate $\left(u c_{t}\right)$ affects current wages. On the other hand, if the contract is

\footnotetext{
${ }^{5}$ The current unemployment rate $u c_{t}$ does not have a subscript $i$ since each individual respondent $i$ face the same labour market condition at time $t$. The individual specific mean value of the current unemployment rate $\overline{u c_{i}}$, however, captures the idea that each individual respondent may stay different lengths of years across the whole survey period, and therefore the mean of current unemployment rates varies across individuals.
} 
binding on both employers and workers, the unemployment rate at the time of hiring $\left(u s t r_{i, t}\right)$ affects wages. When the firms can commit to the contract but workers are not bound to the contracts and are able to move costlessly to another firm, it is the minimum unemployment rate over the worker's entire job spell $\left(u l o w_{i, t}\right)$ that affects current wages and not the other two possible macroeconomic variables.

Our research focuses on the possible scenarios that are derived from the implicit contract model, namely, whether the spot market view explains the wage dynamics better, or whether the historical labour market conditions dominates the spot market model in determining current wages, or whether both play roles on current wages. In addition, we examine whether macroeconomic conditions have differing impact on wages by gender, industry and age.

The above regression models are estimated not only for the native born, but also for immigrants. Macroeconomic controls are seldom incorporated into immigrant wage studies. For the first time, this study selects immigrants as an independent target group for the consideration of the impact of macroeconomic variables on wages operating within an implicit contract framework. Not only is the implicit contract effect on the wages of immigrants examined but also extensions are made to test for differences between immigrants and the native born in terms of the wage response to business cycle fluctuations. As shown in equation (2.1.3), interactions of the immigrant status indicator variable with the variations of different macroeconomic measures are added:

$$
\ln w(i, t)-\overline{\ln w(i)}=\Pi_{i, t} \Omega_{3}+\left(F B_{i}\right)\left(U_{i, t}-\overline{U_{i}}\right) \Psi_{1}+\left(\omega_{i, t}-\overline{\omega_{i}}\right)
$$


where $\pi_{i, t}$ contains the right-hand-side control variables from model (2.1.2). $F B_{i}$ is an immigrant status indicator. For simplicity, $U_{i, t}$ stands for a vector of macroeconomic variables, entering the wage model either separately or jointly as shown in model (2.1.2).

One major issue to be addressed in immigrant wage analysis relates to differences in returns to job tenure between immigrants and the native born. Following McDonald and Worswick (1998), interactions of an immigrant status indicator variable with job tenure variables are introduced into the wage regression to control for the possible different returns to firm specific human capital between immigrants and the native born:

$\ln w(i, t)-\overline{\ln w(i)}=\Xi_{i, t} \mathbf{\Omega}_{4}+\left(F B_{i}\right)\left(\left(T_{i, t}-\overline{T_{i}}\right)+\left(T_{i, t}^{2}-\overline{T_{i}^{2}}\right)\right) \Psi_{2}+\left(v_{i, t}-\overline{v_{i}}\right)$

where $\Xi_{i, t}$ contains the right-hand-side control variables from model (2.1.3). $T_{i, t}$ and $T_{i, t}{ }^{2}$ represents the linear and quadratic form of the individual's job tenure variable. ${ }^{6}$ $\Psi_{2}$ captures wage differentials between these two groups of workers arising from firmspecific capital acquisition.

Many wage-tenure studies have found evidence regarding the important role of job tenure on wage dynamics. Investment in firm-specific human capital may affect individuals' wages if firms are forced to raise the workers' wages after training in order to avoid losing them to jobs at other firms. Topel (1991) found that 10 years of job tenure leads to a 25 percent increase in wages. Juhn, Murphy and Pierce (1993) examined wage inequality for males between the years of 1963 and 1983. They found a large wage rise for skilled workers and a moderate wage decline for unskilled workers. Altonji and

\footnotetext{
${ }^{6}$ The tenure and tenure squared variables also appear on their own in $\Xi_{i, r}$.
} 
Williams (2005) suggested that the net return to 10 years of tenure to be 11 percent. Green and Townsend (2010) studied the wage-tenure profiles for unskilled workers and found that workers with higher job tenure are less impacted by economic variations. McDonald and Worswick (1998) introduced tenure variables and the interaction of job tenure with immigrants' cohorts to allow for the job tenure effect in immigrant wage studies. Based on cross-sectional survey data, they presented evidence on a positive impact of job tenure on earnings outcomes. Immigrant-native differentials in wage returns to tenure accumulation were also suggested. The magnitude of tenure effect in their analysis is similar to that of Topel (1991). One major advantage of this study over the McDonald and Worswick's (1998) approach in studying wage-tenure relationship is that employing longitudinal data allows us to control for unobserved heterogeneity through fixed effects estimation.

\section{Immigrant wage performance and the empirical approach}

One of the important hypotheses about immigrant wage performance relates to differences in earnings across immigrant arrival cohorts that cannot be fully explained by differences in other standard controls such as education and work experience. Borjas (1985) argues that external institutional parameters, such as labour demand, immigration policies, global political and economic environment, etc., play an important role in interpreting immigrants' post-immigration labour market performance. Borjas finds evidence of significant cross-cohort differences with earlier cohorts performing better economically than more recent cohorts. As cited above, numerous Canadian studies find 
similar cross-cohort differences in earnings of immigrants (see, for example, Baker and Benjamin, 1994).

Following the methodology of McDonald and Worswick (1998), we investigate the conventional initial wage disadvantage hypothesis and the convergence hypothesis for immigrants using SLID data spanning the period from 1993 to 2006 . Several modeling specifications are estimated to determine: 1) the impact of job tenure on immigrant wage dynamics; 2) the modeling inferences of using age proxies for actual work experience; 3 ) gender differences in the initial and later wage performance and 4) the effect of business cyclical fluctuations on the earnings of immigrants.

We employ the following empirical wage model:

$\ln w(i, t)=\mathrm{X}_{i, t} \Omega_{1}+\sum_{j=1}^{J} \lambda^{j} t_{0 i}^{j}+\alpha Y S M_{i, t}+\delta Y S M_{i, t}^{2}+\varepsilon_{i, t}$

where $\ln w(i, t)$ is the logarithm of the composite hourly wage earnings of individual $i$ at time $t$. $\mathrm{X}_{\mathrm{i}, \mathrm{t}}$ is a vector of individual characteristics including education, linear and quadratic variables for work experience, and dummy variables for marital status, industry, region of residence and rural/urban residence. $t_{0 i}^{j}$ is a set of $J$ cohort dummy variables for the period of arrival in Canada for immigrant i. $Y S M_{i, t}$ and $Y S M_{i, t}{ }^{2}$ are the linear and quadratic form of the number of years since immigrant $i$ landed in Canada. $^{7}$ The coefficients on these two variables capture assimilation and can be used to

${ }^{7}$ YSM is set to be zero for native-born workers. 
quantify whether immigrants have experienced faster growth in earnings over time than have otherwise similar native born.

With the empirical model defined, the following assumptions (based on the hypotheses and the evidence found in many earlier immigrant wage studies) can be tested.

1. $\lambda^{j}$ captures the wage gap between immigrant $i$ from cohort $j$ and the nativeborn comparables at the time of immigration. The cohort effect is predicted to be negative $\left(\lambda^{j}<0\right)$, meaning immigrants experience initial wage disadvantage in comparison to the native-born.

2. $\lambda^{j}-\lambda^{k}$ (for cohort $\mathrm{j}$ and cohort $\mathrm{k}$ where $j \neq k$ ) measures the extent of quality differences between cohort $\mathbf{j}$ and cohort $\mathbf{k}$. For any $\mathrm{n}$ and $\lambda^{n}<0, j>k$ and $\lambda^{j}-\lambda^{k}<0$ indicates that immigrants from the more recent cohort $\mathrm{j}$ perform worse economically than those from the earlier cohort $\mathrm{k}$. The hypothesis of declining cohort quality has been found by a number of authors (for example, Borjas, 1985, Baker and Benjamin, Green and Worswick, etc.) but also challenged by an alternative finding in which $\lambda^{j}-\lambda^{k}>0$, or equivalently, no evidence of worsening cohort quality has been witnessed (see, for example, McDonald and Worswick, 1998).

3. $\partial \ln w(i, t) / \partial Y S M_{i, t}$ measures the rate of wage growth with an additional year spent in Canada since arrival while holding work experience and other control variables constant. With a decreasing rate of wage growth predicted, we will have a negative derivative, $\delta$, i.e., $\partial \ln w(i, t) / \partial Y S M_{i, t}{ }^{2}=\delta<0$. The positive assimilation derivative $\alpha+2 \delta Y S M_{i, t}$ implies that immigrants will overcome the initial wage disadvantage and gradually integrate into the local labour market. 
The availability of tenure data in the SLID allows us to examine the importance of tenure as an explanatory variable within the context of the following human capital wage model:

$$
\ln w(i, t)=\Lambda_{i, t} \Omega_{2}+\beta_{1} T_{i, t}+\beta_{2} T_{i, t}^{2}+e_{i, t}
$$

where $\Lambda_{i, t}$ includes all the independent variables from equation (2.2.1). The tenure variable $T_{i, t}$ serves as a proxy variable for individual $i$ 's firm specific human capital as of time $t$ and appears in both linear and quadratic form. In Chapter 6, results with and without tenure controls will be presented for comparison. ${ }^{8}$

The basic intuition behind using job tenure in immigrant wage studies is that immigrants may have less firm-specific capital on average than do native-born workers if the act of migration interrupts their employment spells. They may also experience labour market inactivity or a lower rate of labour force participation due to imperfect transferability of pre-immigration human capital accumulation, or lack of knowledge of the local labour environment. Therefore, introducing the tenure controls may lead to a reduction in the initial immigrant/native-born wage gap. McDonald and Worswick (1998) find evidence of biases arising from exclusion of tenure controls. With tenure controls, they show that the cohort estimates for all five immigrant cohorts in the full sample have dropped in magnitude (in terms of absolute value). For example, the coefficient estimates of $1976-80$ cohort are -0.2963 and -0.2345 before and after controlling for

\footnotetext{
${ }^{8}$ In addition, the model is expanded to interact the tenure variables with an immigrant indicator variable and the estimation results are shown in Table 6.2. The inclusion of the interaction term is aimed to examine the difference in wage returns to job tenure between immigrants and the native born.
} 
tenure variables, respectively, which implies this group of immigrants have earnings improved by approximately 21 percent. The "Years Since Migration" coefficient has also dropped from 1.17 percent to 0.84 percent.

Another key issue relates to the effect of labour market conditions on immigrant wage dynamics. McDonald and Worswick (1998) find that immigrant/native-born earning differences in their Survey of Consumer Finances data (1981 through 1992) can be explained in part by the decline in labour market conditions due to economic recessions. Aydemir (2003) examines the impact of labour market conditions both in the survey year and at the time of arrival in Canada on immigrant wages and finds evidence of a decrease in the cross-cohort differences in earnings once the macroeconomic controls are introduced into the earnings model. To allow for impacts of the macroeconomic conditions, equation (2.2.2) is expanded to include the current unemployment rate and the unemployment rate at the time of immigration, to test for wage variations due to both current and past labour market dynamics as well as measuring cohort effects and immigrant wage assimilation. ${ }^{9}$ More importantly, we integrate the implicit contract literature into the immigrant earnings cohort-assimilation literature. Two more macroeconomic indicators are incorporated into the wage model, i.e., the unemployment rate at the time when an individual is hired by the firm and the lowest unemployment rate over this individual's job tenure.

$\ln w(i, t)=\Psi_{i, t} \Omega_{3}+\sigma_{1} u c_{t}+\sigma_{2} u_{i m m_{i, t}}+\sigma_{3} u s t r_{i, t}+\sigma_{4} u l o w_{i, t}+v_{i, t}$

\footnotetext{
${ }^{9}$ The unemployment rate employed in this chapter is the annual national rate.
} 
where $\Psi_{i, t}$ represents all of the right-hand-side control variables from model (2.2.2). The variable $u c_{t,}$ uimm $_{i, t,} u s t r_{i, t}$, and $u l o w_{i, t}$, stand for the current unemployment rate, the unemployment rate at the time of immigration, the initial unemployment rate and the minimum unemployment rate, respectively.

To correct for possible unobserved heterogeneity, we later adopt fixed effects estimations in which the individual specific mean is subtracted from the left and righthand-side variables. The fixed-effects models including variations of both "Years Since Immigration" and tenure controls take the following form. ${ }^{10}$

$$
\begin{aligned}
\ln w(i, t) & -\overline{\ln w(i)}=\left(\mathrm{X}_{i, t}-\overline{\mathrm{X}_{i}}\right) \Omega_{4}+\phi_{1}\left(Y S M_{i, t}-\overline{Y S M_{i}}\right)+\phi_{2}\left(T_{i, t}-\overline{T_{i}}\right) \\
& +\phi_{3}\left(u c_{t}-\overline{u c_{i}}\right)+\phi_{4}\left(u s t r-\overline{u s t r_{i}}\right)+\phi_{5}\left(u_{l o w_{i, t}}-\overline{u l o w_{i}}\right)+\left(\omega_{i, t}-\overline{\omega_{i}}\right)
\end{aligned}
$$

${ }^{10}$ The variations of YSM-squared and Tenure-squared are omitted for simplicity. Also included in model (2.2.4) are interaction terms of the foreign-born indicator with both tenure and the macroeconomic variable. 


\section{Chapter 3}

\section{The Data}

\section{Introduction}

The data that employed in this analysis are the pooled data sets from the Survey of Labour and Income Dynamics (SLID) of Statistics Canada. There are other Canadian surveys that collect information on employment and labour market indicators (for example, the Labour Force Survey (LFS)). The limitation of those surveys is the crosssectional design of the sample which will not serve our purpose of following individuals over time as is possible with the SLID data. Other Canadian longitudinal data sets have tended to be much shorter, for example, the Workplace and Employee Survey (WES) follows employees for only two years, and the Labour Market Activity Survey (LMAS) has a maximum three-year panel design. Introduced in 1993, the SLID is the first Canadian comprehensive household survey that contains nationally representative data on labour market activity and income for a representative sample of Canadian households and individuals and tracks those individuals for up to six years. A new overlapping panel is introduced every three years. The sample individuals for the SLID are selected from the monthly Labour Force Survey (LFS) which is based on a stratified, multi-stage design that uses probability sampling. ${ }^{11}$ The SLID has four panels, each surveyed for a period of six consecutive years (five consecutive years available for panel 2002-2006 at the time of this study) and focuses on individuals aged 15 to 69 at the time of survey.

We employ data on individuals in the person file who are employed during the survey period. We have constructed a pooled sample of data from the SLID panels which

\footnotetext{
"A sample longitudinal weight variable is presented in the SLID data sets and is applied to all of the
} estimation in this study. 
covers the 1993-2006 period. Due to the relatively small number of immigrants in each SLID panel, this strategy of pooling panels was necessary in order to generate reliable results from the econometric analysis. ${ }^{12}$ It was unclear how best to handle the fact that the panels overlap and data from the same year is available in up to two of the panels. We decided to avoid this problem by selecting from the available SLID panels so that we would have as many complete, six-year panels as possible but without any overlap across the panels. Consequently, the panels selected are: 1993-1998, 1999-2004 and 2002-2006, with the first two panels covering six consecutive years and the last incomplete panel containing data from the only last two survey years (2005 and 2006). The years chosen allow us to have a single year from a single SLID panel in each of the years 1993 through 2006.

The sample we select includes both male workers and female workers, as well as both the native born and immigrants. We then control for gender in the analysis to see whether there are wage differences between male and female respondents, in terms of implicit contract effects, immigrant cohort effects and assimilation effects. The full sample is also divided into two subgroups: the native born and immigrants, for carrying out separate empirical implicit contract tests.

The main information that we use from the SLID for our analysis include workers' demographic characteristics such as age, immigrant status, province of residence, urban/rural status, level of education and marital status, as well as their labour market experience, job tenure, industry group classification, and wage earnings. The

\footnotetext{
${ }^{12}$ Skuterud and Su (2008) also choose to pool the panels from SLID for their wage analysis for immigrants.
} 
labour market data is selected from each worker's main job. ${ }^{13}$ For immigrants, we also employ the SLID information on period of immigration and length of time since immigration.

\section{Sample restrictions and imputation methodology}

We restrict our sample to workers that are 21 to 64 years of age and are not selfemployed. ${ }^{14}$ We also drop observations for which we could not "reasonably" impute the missing information. ${ }^{15}$ Finally, we drop individuals who have less than three years of SLID observations in the 1993-1998 and 1999-2004 panels. Since we select data from the last two survey years in the 2002-2006 panel, we drop individuals who have only one observation in this panel. In the next paragraphs, we justify our sample restrictions and explain our imputation methodology.

Following previous studies (for example, Beaudry and DiNardo, 1991, McDonald and Worswick, 1998, and McDonald and Worswick, 1999), the sample is restricted to individuals between 21 and 64 years of age. This age range is also chosen because those who are younger than 21 and older than 64 have relatively low labour force participation rates. Individuals who are self-employed were dropped because we want to focus on earnings from wage and salaries and investigate the role of implicit contracts.

Unlike previous studies which had access to job tenure and education information but only in grouped categories as well as only having potential labour market experience instead of actual work experience (for example, McDonald and Worswick, 1999), the

\footnotetext{
${ }^{13}$ SLID defines the main job according to the following criteria: 1) a job with the most scheduled hours; 2) The one with the greatest earnings if hours are identical; 3) The longest tenure if earnings are identical. ${ }^{14}$ For workers who are 18 years of age in the first survey year, we start following them in year four, or equivalently, when they turn 21 years of age.

${ }_{15}$ An observation is person-year specific. As such, there could be up to six observations per person.
} 
SLID has an obvious advantage in that it contains actual years of schooling, actual years of work experience and actual months of job tenure.

As with any panel, however, there are missing observations. For years of schooling, the rate of missing data is generally less than 10 percent for each survey year, with 2004 having the highest missing rate at 20 percent. We are able to impute some of the missing education data according to the following rules. First, when there is missing data, we obtain valid inferences from available schooling information and create imputations by either adding or subtracting the appropriate number of years. For example, say an individual has 18 and 20 years of schooling in 1993 and 1995, respectively. The missing schooling in 1994 can therefore be imputed as 19 . Second, for those who are at least 45 years of age in the survey year, their missing number of years of schooling in that survey year is imputed with the same value as that of the previous survey year. Approximately 25 percent of the missing schooling values could be imputed. For 2004 , the recovery rate was 36 percent.

Despite having very detailed job tenure data, the tenure information is missing (or incomplete) for some individuals in the SLID. For years other than 1995 and 1996, the average missing rate is around 30 percent. While 1995 and 1996 have significantly higher missing rates for job tenure (both at 85 percent). As with schooling, one can impute some of the missing tenure data for the panel 1993-1998. ${ }^{16}$ For the other two panels, the imputation approach did not lead to substantial improvement in tenure variable information. Therefore we decided against using it.

First, we use backward induction to impute missing tenure when the available accumulated tenure is equal to or larger than 72 months in the last survey year (60

\footnotetext{
${ }^{16}$ We only impute tenure for the 1993-1998 panel.
} 
months for the panel 2002-2006). ${ }^{17}$ For example, if tenure is 84 months in 1998, we interpret it as an indicator that this individual has been employed full time during the six survey years (1993-1998).

Second, when there is missing data among available data, and the subtraction of the known tenure between any two survey years is multiples of 12 , then the missing tenure is imputed by adding 12 or multiples of 12 . For example, say we have an individual that has 20 months of job tenure in 1994 and 56 months in 1997. Job tenure for 1995 and 1996 are missing. The 36 months of difference between 1994 and 1997 indicates a full-time worker's tenure accumulation since 1994 . So the missing tenure for 1995 and 1996 can be assigned values of 32 and 44, respectively.

Third, under the condition that job tenure in a particular survey year is 24 months, the job tenure variable is missing in the previous year, and the tenure two years before is larger than 24 months, then we interpret it as switching to new jobs and the missing tenure in between is set to 12 months.

Fourth, in cases where the two survey years are three years apart and the difference in job tenure between these two survey years is larger than 30 months and less than 36 months instead of multiples of 12 , we can still assign appropriate values where tenure information is missing based on the job start and end dates. For example, job tenure in 1994 and 1997 is 25 months and 60 months, respectively. The difference of job tenure is 35 months between these two survey years. To recover the missing tenure for 1995 and 1996, we need to check whether the start dates are the first day and the end dates are the last day of these two years. According to the SLID, it defines the following rules regarding the start and end dates. First, if the job begins prior to the reference year,

${ }^{17}$ Equal or larger than 60 (48 for the panel 2002-2006) for the second last survey year, and so on. 
the start date of the job will be January 1 of the reference year. Second, if the job is not ended, the end date of the job will be December 31 of the reference year. Therefore, if the available job start and end dates of 1995 and 1996 show that this individual works continuously from the first day until the last day of each reference year, the missing tenure for 1995 and 1996 can therefore be each added by 12 and 24 months, respectively.

The data imputation continues until all of the observations have consistent values over the survey period. After imputation, the rates of missing tenure for 1995 and 1996 dropped from 85 percent to 24 percent and 35 percent, respectively. Job tenure is later divided by 12 to be expressed in years.

Actual labour market experience is recorded in the SLID. The average rate of missing data for work experience is 14 percent. Approximately 27 percent of the missing experience data can be imputed by calculating the gap between the two available tenure values in any two survey years, then assigning appropriate values to the unknown data. For example, an individual respondent has years of work experience assigned in 1994, but not in 1995. Consider the case where based on the available tenure information in 1994 and 1996, the difference between the two given tenure values is 24 months. We then divide 24 by 12 and assume that this respondent has accumulated labour market experience continuously over the two-year period. Therefore, in this case, we assign one more year of experience in 1995, as compared to 1994 .

We also control for industry in the analysis as other authors have done (see, for example, Beaudry and DiNardo, 1991, and McDonald and Worswick, 1999). We use the 21 industry groups as defined in the North American Industry Classification System 
(version of 2002). ${ }^{18}$ The missing rate for industry information in the SLID is very low. Some of the missing values are imputed by the rule that individuals work in the same industry group if the individual's job tenure information implies that $\mathrm{s} / \mathrm{he}$ was employed continuously at the same firm across the contiguous survey years.

The reason we keep individuals with a minimum of three observations for estimation (two observations for the panel 2002-2006) is mainly due to the fixed effects estimation that we later adopt in our analysis - we need at least two observations per respondent. In addition, we consider three years of observations to be a compromise choice. It allows us to retain individuals with strong coverage in the panel in terms of number of survey years; however, at the same time, it does not require us to drop many respondents (which would be the case if we were to require each respondent to be observed in all six survey years).

Sample individuals between 21 and 64 years of age in the first survey year of each panel account for approximately 58 to 59 percent of the whole sample among which, 58 to 68 percent are employed part-year or all year. The attrition rate for the working-age respondents is approximately 14 to 20 percent in the second wave of each panel. After sample restrictions, our regression samples have approximately four years of observations on average for each individual respondent. The attrition rate is less than one percent in the second and third wave, and approximately two percent in the sixth wave of each panel. $^{19}$

\section{Sample summary}

\footnotetext{
${ }^{18}$ See Appendix A for detailed classification.

19 Using the SLID, Skuterud and Su (2008) obtain a sample with 3.9 and 3.8 years of observations on average for the native-born men and women, which is similar to ours.
} 
We start with approximately 40,000 individuals in each panel. The 1993-1998, 1999-2004 and 2002-2006 SLID panels contain 40,155 individuals, 43,683 individuals and 42,232 individuals, respectively. In the first survey year of each panel, the number of individuals aged between 18 and 59 is 23,220 (in 1993), 25,718 (in 1999) and 24,522 (in 2002) after excluding the missing data. ${ }^{20}$ The number of available immigrant respondents is 2,357 for the 1993-1998 panel, 2,332 for the 1999-2004 panel, and 2,332 for the 2002-2006 panel, accounting for approximately 10 percent of each sample panel data set. After sample restrictions and data imputation, we obtain samples of 18,320 individuals and 80,925 person-year observations for implicit contract estimation among which, 16,776 individuals and 74,038 observations target the native born as shown later in Table 4.1, 1,544 individuals and 6,887 observations target immigrants as shown in Table 5.1. For the research chapter testing immigrant wage cohort effect and assimilation effect, the total number of individuals and observations is 23,819 and 96,927 , respectively. Among them, the native-born sub-sample contains 21,975 individuals and 84,455 observations. 1,844 individuals and 7,472 observations are included in the immigrant sub-sample.

In terms of other variables, marital status is classified into six categories: married, common law, separated, divorced, widowed and single (never married). We merge the last five categories and simply define the marital status as married and not married.

The provinces of residence are Newfoundland, Prince Edward Island, Nova Scotia, New Brunswick, Quebec, Ontario, Manitoba, Saskatchewan, Alberta and British Columbia. Ontario is set as the default province of residence. Urban and rural residence

\footnotetext{
${ }^{20}$ Considering the age restriction of the thesis which is between 21 and 64, and the minimum number of observations for each individual (three for panel 1993-1998 and 1999-2004, and two for 2002-2006), we set the age limit between 18 and 59 in the first survey year of each panel.
} 
is also controlled for mainly due to the distinctive demographic characteristics between these groups.

The wage measure employed is the composite hourly wage rate which is calculated based on the derived hourly wage for all paid-worker jobs, weighted using total hours paid for each job. ${ }^{21}$ The reason we chose to work with an hourly wage instead of a weekly wage is due to the existence of outlying observations in the hour and week variables. Therefore a weekly wage may not be as accurate as an hourly wage in terms of representing an individual's real reward from labour input. Also, variation in hourly wages rates across individuals is unlikely to be affected by labour supply choices unlike either a weekly wage or an annual earnings measure.

One could argue that the wage rate for the main job should be used in place of the composite hourly wage rate. Our job tenure information relates to the worker's main job and so in some ways it would be natural to employ the hourly wage rate from the main job in the parts of the analysis that employs job market information. However, the composite wage rate is provided in the SLID data as capturing the hourly return to the worker across possibly different jobs. The decision was made to employ this measure since it relates to more than just the main job and may be a more accurate reflection of the valuation of the individual's time in the labour market. Also, after data restrictions, the sample size of workers with multiple jobs is very small (less than one percent). However, we have carried out a sensitivity analysis to see if the main results would differ

\footnotetext{
${ }^{21}$ Non-wage benefits such as pensions, dental insurance and disability insurance that are contributed or offered by employers may result in lower turnover rates and longer job tenure, which potentially provides a theoretical ground for the implicit contract view with costly mobility. Since the SLID only provides flag indicators of those non-wage benefits starting from 1999, we have a limited source to link non-wage benefits to our analysis. Consequently, we decided to follow the previous literature and focus on wages only.
} 
had we employed an hourly wage rate based on the main job instead of the composite hourly wage rate. By using the total earnings in the main job divided by the product of usual number of weeks and usual weekly hours, we obtain qualitatively similar results as presented in the thesis chapters. The examples of regression results are shown in Appendix D.

The unemployment rate employed in this thesis is the annual national rate. We considered using a more disaggregate rate matched to the individual's gender and province. However, unemployment rate data for Canada are only available by province and gender since 1976. For workers with high levels of job tenure, this would mean that we would not know the actual unemployment rate that was relevant for the person at the time of starting the job. Consequently, we decided to follow much of the literature and focus on the annual national unemployment rate (see, for example, McDonald and Worswick, 1999).

The detailed data summary statistics are presented in each research chapter. 


\section{Chapter 4}

\section{Implicit Contracts and Wage Outcomes of the Native Born}

In this chapter, we analyze the importance of implicit contracts on the hourly wage rates of Canadian-born workers. Extensions are also made to test for differences in the wage responses to business cycles between male and female, across industries and age groups. To examine the impact of the current and past labour market conditions on wage variations, we apply three key macroeconomic contract variables: the current unemployment rate, the unemployment rate at the time of hiring and the minimum unemployment rate over an individual's job spell. We not only test the individual effect of each macroeconomic variable when they enter the wage model as a single measure, but also nest the three contract variables into the same wage model to investigate which one has the largest magnitude of impact on wage outcomes of the native-born Canadians. Previous findings show mixed results in terms of the importance of the contract variables. For example, Beaudry and DiNardo (1991), and McDonald and Worswick (1999) find that wage movements follow an implicit contract view with costless mobility more than a spot market view. The minimum unemployment rate takes the lead in determining wage outcomes than the other two macro indicators. On the contrary, Devereux and Hart (2005) find evidence of the importance of spot wage model against contracting models in the British labour market. Unlike McDonald and Worswick (1999) who suffer from limitations of the cross-sectional type of data as well as data inaccuracy of the tenure variables, we are able to overcome these problems by using the SLID panel data sets. 
The chapter proceeds as follows. Section 1 reports the sample statistics. In Section 2, the models with different macroeconomic variables are examined and tests are carried out of the statistical significance of the different contract variables. In addition, we investigate whether these implicit contract effects on wage rates differ by gender, industry and age group, respectively, in Sections 3,4 and 5. The main findings and policy implications are present in Section 6.

\section{Sample statistics}

The summary statistics on wages, employment, labour market conditions and other demographic variables for this research chapter are presented in Table 4.1. There is evidence of differences in individual characteristics between the native-born male group and the native-born female group. Male workers earn roughly 24 percent higher hourly wages than female workers. They have approximately four more years of work experience and one and a half more years of job tenure as well as slightly lower education compared to females. 
Table 4.1

Implicit Contracts: Sample Means for Selected Variables (Native-born Group)

\begin{tabular}{lccc}
\hline \multirow{2}{*}{\multicolumn{1}{c}{ Variable }} & \multicolumn{3}{c}{ Mean } \\
\cline { 2 - 4 } & Total & Male & Female \\
& $\mathrm{N}=74,038$ & $\mathrm{~N}=37,863$ & $\mathrm{~N}=36,175$ \\
\hline Demographic Characteristics & 20.18 & 22.27 & 17.99 \\
Composite Hourly Wage & 2.90 & 3.01 & 2.78 \\
Log Composite Hourly Wage & 40.77 & 40.77 & 40.77 \\
Age & 0.51 & - & - \\
Male & 0.66 & 0.68 & 0.63 \\
Married & 0.73 & 0.72 & 0.73 \\
Urban & 13.80 & 13.61 & 14.00 \\
Years of Schooling & 17.61 & 19.77 & 15.36 \\
Years of Work Experience & 10.48 & 11.26 & 9.66 \\
Years of Job Tenure & & & \\
& & & 8.52 \\
Macroeconomic Indicators & 8.11 & 8.16 & 8.07 \\
Current Unemployment Rate & 8.43 & 8.34 & \\
Initial Unemployment Rate & 7.02 & 6.97 & \\
Minimum Unemployment Rate & & & \\
\hline
\end{tabular}

Note: $\mathrm{N}$ stands for the number of observations.

\section{Empirical results}

Table 4.2 presents the fixed effects coefficient estimates from the human capital wage equation 2.1.2 capturing the effect of each of the three contracting variables. ${ }^{22}$

\footnotetext{
${ }^{22}$ We also employ the random effects approach for comparison. The estimates of contract variables are reported in Appendix E. All other estimates representing individual characteristics are presented in Appendix F for readers' information. Using weighted least squares estimations leads to qualitatively similar results in that the minimum unemployment rate is the determinant factor in affecting the wage outcomes of Canadian workers.
} 
Columns 1 to 3 contain the estimates from wage equations which contain the different current and past macroeconomic contract variables. In Column 1, the current unemployment rate is examined separately and the coefficient estimate is not only significant at the 5 percent level of significance but it is also positive. ${ }^{23}$ Although the magnitude is quite small, the result still indicates a positive impact of unemployment rates on real earnings. The statistically significant positive effect of the current unemployment rate on current wages differs from the findings in the previous literature in which Beaudry and DiNardo (1991), McDonald and Worswick (1999), Grant (1993) and Devereux and Hart (2005) find that the current unemployment rate affects current wages in a negative way. There are a few possible explanations for the positive estimate obtained. First, those who are still employed in deteriorating labour market conditions are not negatively influenced by the economic downturn mainly due to the insurance contracts offered by firms. Second, economic outcomes reflected in real wages lag behind unemployment variations during a recession. Third, unions play a positive role in preventing wages from varying with the employment fluctuations. The higher unionization rate in Canada in comparison to the United States may partly explain the Canada-US divergent wage responses to current labour market conditions. More particularly, the neoclassical theory relates labour demand with the marginal product of labour. If real wages reflect marginal product of labour, we would expect to see a negative correlation between the real wage and the unemployment rate. However, many theoretical and empirical studies have found a discrepancy between real wages and the marginal product of labour. For example, Bailey (1974) claims that implicit contracts

\footnotetext{
${ }^{23}$ Regressing real wages on current unemployment rates with a constant, the overall explained variation is 0.19 . The coefficient is negative but insignificant at $5 \%$ level. The overall explained variation without constant (as in the fixed effect model) is 0.96 and the coefficient is positive and significant.
} 
explain sticky wages. Real wages do not adjust in the short-run to clear the labour

market. Christiano and Eichenbaum (1992), Gomme and Greenwood (1995) and Collard and de la Croix (2000) find empirical evidence that the real wage does not follow a clear cyclical pattern in the data.

Table 4.2

Coefficient Estimates of Implicit Contracting Effects

from Fixed Effects Estimation (Native-born Group)

\begin{tabular}{|c|c|c|c|c|c|c|c|}
\hline \multirow{2}{*}{ Macroeconomic Measures } & \multicolumn{7}{|c|}{ Regression Results for the Pooled Panel 93-06 $(\mathrm{N}=74,038)$} \\
\hline & 1 & 2 & 3 & 4 & 5 & 6 & 7 \\
\hline \multirow[t]{2}{*}{ Current Unemployment Rate } & $0.0098^{*}$ & & & $0.0113^{*}$ & $0.0130^{*}$ & & $0.0129^{*}$ \\
\hline & $(0.0012)$ & & & $(0.0012)$ & $(0.0012)$ & & $(0.0012)$ \\
\hline \multirow[t]{2}{*}{ Unemployment Rate at Start of Job } & & -0.0064 & & $-0.0123^{*}$ & & 0.0095 & 0.0077 \\
\hline & & $(0.0033)$ & & $(0.0034)$ & & $(0.0051)$ & $(0.0051)$ \\
\hline \multirow[t]{2}{*}{ Minimum Rate Since Start of Job } & & & $-0.0137^{*}$ & & $-0.0214^{*}$ & $-0.0207^{*}$ & $-0.0271^{*}$ \\
\hline & & & $(0.0032)$ & & $(0.0033)$ & $(0.0050)$ & $(0.0050)$ \\
\hline
\end{tabular}

Note: 1 . Standard errors are in parentheses. The dependent variable is the log of the real composite hourly wage. The independent variables include macroeconomic measures, years of schooling, years of experience, years of experience squared, tenure, tenure squared, and controls for industry, marital status, province of residence and urban/rural status. See Appendix A for the variable definition.

2. $*=5 \%$.

3. The unemployment rate is defined out of 100 .

Figure 4.1 plots the real wages against the unemployment rate over the years 1993

to 2006. The unemployment rate hit the highest point at 11.4 percent in 1993 and

declined to the bottom at 6.3 percent in 2006 , with slight bumps during the period.

Despite the fact that real wages and the unemployment rate display opposite trends, the 
two time series move in the same direction in the years 1995-1996, 1998-1999, 20002001, 2001-2002, and 2004-2005 over the 14-year survey period. It seems to suggest that real wages may not be downwardly or upwardly rigid, although there is a relatively stagnant real wage flow implied in the series of real wages. The slight upward trend of real wages can be interpreted as an outcome of non-binding implicit contracts.

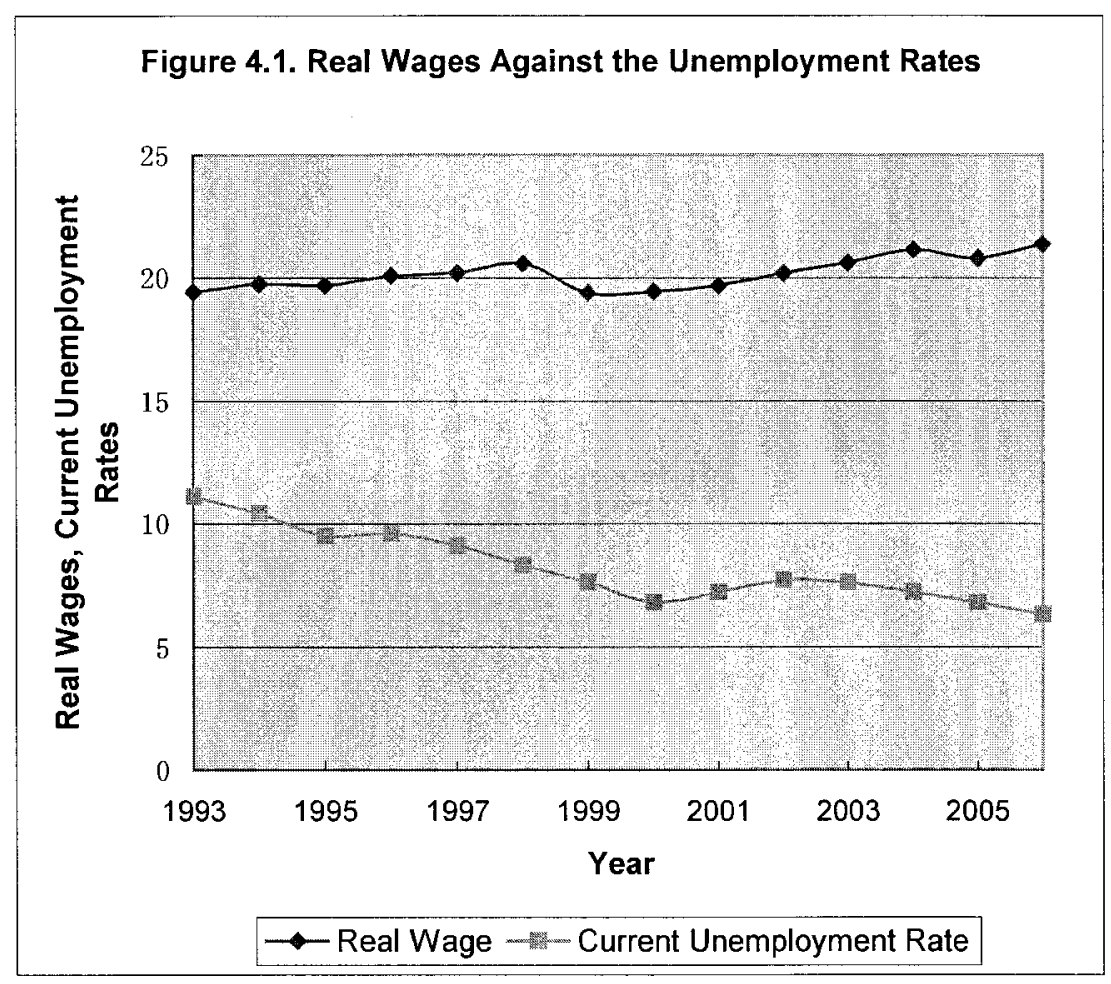

The effect of the unemployment rate at the start of the job on current wages is examined next and the result is shown in Column 2. Despite the insignificant coefficient estimate obtained, the negative estimate on the initial unemployment rate variable is consistent with wages rising during expansions and falling during contractions. This point 
estimate (although statistically insignificant) is significantly smaller in absolute magnitude than the three percentage wage drop found by Beaudry and Dinardo (1991). On the contrary, McDonald and Worswick (1999) and Devereux and Hart (2005) find a positive coefficient of the initial unemployment rate variable in both the male and female groups except that the coefficient is insignificant. Their findings seem to imply that past poor labour market conditions did not linger long so as to depress the respondents' current earnings.

In Column 3, we see how the minimum unemployment rate over an individual's job tenure influences that individual's wage earnings, or equivalently, how wage dynamics react to the best labour market conditions when workers are fully mobile between firms. The negative effect implies that the lower the minimum unemployment rate over a worker's job tenure, the better the state of the best labour market conditions since the worker was hired at the firm and the higher is the worker's wage rate at the time of the survey. The significant coefficient estimate shows that for each percentage increase in the minimum unemployment rate, there is a 1.37 percentage drop in the individual's real contract wages. The magnitude of the impact is less than the 2.9 percent estimate found by Beaudry and Dinardo (1991) using fixed effects estimation for the US, but much larger than the 0.58 percent estimate found by McDonald and Worswick (1999) who use Canadian cross-sectional data. ${ }^{24}$

Columns 4 to 7 present the regression results from models that contain different combinations of the macroeconomic variables. When letting different contract variables compete with each other, the minimum unemployment rate has the largest influence on

\footnotetext{
${ }^{24}$ We also carry out random effects estimation of the wage models as was done by McDonald and Worswick (1999). The results were qualitatively very similar and so are not reported here.
} 
wage rates. The coefficients on the current unemployment rate variable is positive and significantin each model where it appears. In Column 7, wages are shown to be positively affected by not only the current unemployment rate but also the unemployment rate at the start of job; however, the coefficient is not statistically significant in the latter case. The estimates of the minimum unemployment rate nonetheless show a negative higher impact of 2.71 percent. This empirical evidence suggests that the minimum unemployment rate has the greatest power in affecting wages when compared with the other two macroeconomic variables, and thus the implicit contract model with costless mobility does a better job of explaining the variation in wage rates than does either the spot market model or the the implicit contract model with costly mobility. This is consistent with Beaudry and Dinardo's (1991) findings and McDonald and Worswick's (1999) findings, although the magnitude of each measure of the labour market conditions is generally smaller than Beaudry and Dinardo's (1991) findings and larger than those of McDonald and Worswick (1999).

In summary, implicit contracting analysis on the native-born workers reveals that implicit contracts with costless mobility explain wage dynamics better than the other two modeling implications. In addition, the empirical evidence suggests that the current unemployment rate lags in affecting current wages, or equivalently, current wages are late in responding to current market conditions.

The aforementioned results of the contract wage model are drawn from the nativeborn Canadian sample that includes all groups of respondents. In the next sections, we will introduce group effects into the previous model by classifying the sample data sets by gender, industry and age. We investigate whether wage movements between the 
native-born men and women, across industries and different age groups react differently to altering market labour conditions. The results are presented below.

\section{Gender Differences in Implicit Contract Effect on Wages}

Both Beaudry and DiNardo (1991) and McDonald and Worswick (1999) exclude females in their implicit contract analysis and extract modeling implications solely from their analysis of the earnings of men. In contrast, we first examine the whole sample, then control for genderin the analysis and show how the female group differs from the male group in terms of wage responses to fluctuating labour market conditions. Grant (2003) found little evidence of differentials between men and women in terms of the implicit contracting effect. Devereux and Hart (2005) show weak gender effects except in responding to current labour market variations in both professional and manual jobs. For professional females, the coefficient estimate of the current unemployment rate is 1.7 percent, more than double the one found on the professional male group. For manual workers, the impact of the current labour market conditions on wage outcomes is 1.5 percent for manual females and 1.3 percent for manual males.

In Table 4.3, the estimates of macroeconomic variables for both groups of respondents are presented. The gender effect aims to derive whether the effect of implicit contracts in the Canadian labour market differ between men and women.

Similar to earlier findings regarding the impact of the current unemployment rate, we find in both male and female samples positive estimates of the coefficients on the current unemployment rate variable. The estimates of the coefficients on the initial unemployment rate are insignificant for both groups. A one percent reduction in the 
minimum unemployment rate since the individual was hired by the firm is associated with a 1.45 percent wage increase for the male group, compared with a 1.17 percent wage increase for the female group. In contrast with Grant (2003) who finds that the magnitude of the coefficient estimate of the current unemployment rate is substantially larger for young men than for young women, our finding presents larger positive impacts of the current labour market conditions on the female group than on the male group. When allowing the three macroeconomic measures to be included in the same model, the contract variables with costless mobility, or equivalently, the minimum unemployment rate over the individual's job tenure still has the largest magnitude and stands out as the dominant measure against the other two.

The positive and significant coefficient on the current unemployment rate variable in both the analysis for men and the analysis for women is surprising. The magnitude of the effect is very small for men but it is larger (at .0176) for women. It is unclear what this effect is capturing since it is hard to imagine that women's earnings rise during weak macroeconomic conditions and fall during strong macroeconomic conditions. One possibility is that this is caused by labour market participation responses where women with relatively low offered wages withdraw from the labour market in poor labour market conditions but return in stronger labour market conditions. An investigation of this possibility is left for future work. 
Table 4.3

Fixed Effects: Coefficient Estimates of Implicit Contracting Effects by Gender

\begin{tabular}{lcccc}
\hline \multirow{2}{*}{ Macroeconomic Measures } & \multicolumn{3}{c}{ Male (N=37,863) } \\
\cline { 2 - 4 } & \multicolumn{1}{c}{1} & 2 & 3 & 4 \\
\hline Current Unemployment Rate & $0.0056^{*}$ & & & $0.0034^{*}$ \\
& $(0.0016)$ & & $(0.0014)$ \\
Unemployment Rate at Start of Job & & -0.0054 & $0.0152^{*}$ \\
& & $(0.0050)$ & $(0.0026)$ \\
Minimum Rate Since Start of Job & & & $-0.0145^{*}$ & $-0.0417^{*}$ \\
& & & $(0.0046)$ & $(0.0032)$ \\
\cline { 2 - 5 } & & Female (N=36,175) \\
\hline Current Unemployment Rate & $0.0142^{*}$ & & & $0.0176^{*}$ \\
& $(0.0016)$ & & & $(0.0017)$ \\
Unemployment Rate at Start of Job & & -0.0066 & & 0.0017 \\
& & $(0.0042)$ & $(0.0064)$ \\
Minimum Rate Since Start of Job & & & $-0.0117^{*}$ & $-0.0239^{*}$ \\
& & & $(0.0045)$ & $(0.0069)$ \\
\hline
\end{tabular}

Note: 1. Standard errors are in parentheses. Variables are the same as shown in Table 4.2. $2{ }^{*}=5 \%$.

\section{Introducing into the wage model differences by industry in the contract effect}

Beaudry and DiNardo (1991) employ both aggregate and industry-specific unemployment rates to test whether the effects of past labour market conditions on wages are sensitive to the unemployment rate measure employed. They find strong evidence to support the implicit contracting view even after controlling for the contemporaneous macroeconomic variable. Unlike Beaudry and DiNardo (1991), Devereux and Hart (2005) present evidence of the importance of the spot market view for manual labour and weak evidence that implicit contracts are important in the wage determination of 
professional jobs. Devereux and Hart (2005) also explore whether there are differing results between public and private sectors and conclude that the spot market model again plays the dominant role in determining the wage outcomes compared to the implicit contracting models. Grant (2003) examines differences between union and non-union sectors in responding to business cycles and finds a stronger implicit contracting effect in union sectors.

The SLID data allows us to examine the implicit contracting effect by dividing the sample into 18 industry groups. We then estimate wage models for each specific industry group. Following Beaudry and DiNardo (1991), we mainly focus on the impact of the past macroeconomic variables on wage movements by industry. Table 4.4 reports the estimates of each coefficient on the contract variables in the wage model across 18 industries. ${ }^{25}$ In Column 1, the contract model with costly mobility (the initial unemployment rate at the time of hiring) is tested. Most of the estimates are found to be significant and negative. They also have much smaller magnitude in absolute value than those found by Beaudry and DiNardo (1991). A positive impact of the unemployment rate at the start of the job is mainly found in the manufacturing industry, transportation, finance/insurance/real estate, business service, educational service and health care services. It seems to suggest that the labour market conditions at the time of hiring in those industries either have no scarring effect or a small effect on the current wage profiles.

\footnotetext{
${ }^{25}$ Statistics Canada has released unemployment rate data by province, age and gender starting from 1976, but not by industry group. Therefore, we were unable to construct an industry-specific unemployment rate. The results are solely based on the annual aggregate national unemployment rate. Random effects approach is applied in order to make comparisons with previous findings.
} 
In Column 2, the contracting model with costless mobility (the minimum unemployment rate over an individual's job tenure) is estimated with the contract variable allowed to vary across all of the industry groupings. In each case, the effect of the minimum unemployment rate is negative and significant effects on wages. The magnitude of the impact is significantly larger in industries providing professional, scientific and technical services, as well as mining and oil industries. Unlike Beaudry and DiNardo (1991), we find a much lower implicit contracting effect in the manufacturing industry, business services, educational services and public administration.

Next, we control for all three contracting variables in the same wage model and the nested results are shown in Columns 3a to 3c. Again, current labour market conditions show no depressing impact on wage rates in most industries. In addition, the initial unemployment rate does not seem to have permanent influence on workers' current economic returns. In some cases the coefficients on the interactions of the initial unemployment rate and the industry variables are significant; however, the coefficients are typically either statistically insignificant or positive with the exception being the public administration industry. Despite the fact that all the macroeconomic indicators have differing impacts across industries, the minimum unemployment rate has, in general, the largest influence on wage rates with the effect being negative and significant varying from -.0076 in the case of the Non-durables industry category up to as high as -.0809 in the Professional, Scientific and Technical Services industry grouping. 
Table 4.4

Coefficient Estimates of Implicit Contracting Effects by Industry

\begin{tabular}{|c|c|c|c|c|c|c|}
\hline \multirow{3}{*}{ Industry } & \multirow{3}{*}{$\begin{array}{c}\text { ustr } \\
\mathbf{I}\end{array}$} & \multirow{3}{*}{$\begin{array}{c}\text { ulow } \\
2 \\
\end{array}$} & \multicolumn{3}{|c|}{ Nested Model Results } & \multirow{3}{*}{$\mathrm{N}$} \\
\hline & & & uc & ustr & ulow & \\
\hline & & & $3 \mathrm{a}$ & $3 b$ & $3 c$ & \\
\hline \multirow[t]{2}{*}{ Agriculture } & $-0.0074^{*}$ & $-0.0166^{*}$ & $0.0251^{*}$ & 0.0009 & $-0.0380^{*}$ & 945 \\
\hline & $(0.0003)$ & $(0.0005)$ & $(0.0004)$ & $(0.0005)$ & $(0.0007)$ & \\
\hline \multirow[t]{2}{*}{ Mining, oil, and gas extraction } & $-0.0164^{*}$ & $-0.0565^{*}$ & $-0.0058^{*}$ & $0.0113^{*}$ & $-0.0644^{*}$ & 1,633 \\
\hline & $(0.0003)$ & $(0.0005)$ & $(0.0002)$ & $(0.0004)$ & $(0.0006)$ & \\
\hline \multirow[t]{2}{*}{ Utilities } & $-0.0024^{*}$ & $-0.0334^{*}$ & $0.0075^{*}$ & $0.0161 *$ & $-0.0525^{*}$ & 1,081 \\
\hline & $(0.0003)$ & $(0.0006)$ & $(0.0002)$ & $(0.0004)$ & $(0.0008)$ & \\
\hline \multirow[t]{2}{*}{ Construction } & $-0.0006^{*}$ & $-0.0082^{*}$ & $-0.0006^{*}$ & $0.0089^{*}$ & $-0.0160^{*}$ & 3,533 \\
\hline & $(0.0002)$ & $(0.0002)$ & $(0.0002)$ & $(0.0003)$ & $(0.0003)$ & \\
\hline \multirow[t]{2}{*}{ Durables } & $0.0038^{*}$ & $-0.0074^{*}$ & $-0.0054^{*}$ & $0.0124^{*}$ & $-0.0162^{*}$ & 6,335 \\
\hline & $(0.0001)$ & $(0.0002)$ & $(0.0001)$ & $(0.0002)$ & $(0.0003)$ & \\
\hline \multirow[t]{2}{*}{ Non-durables } & $0.0006^{*}$ & $-0.0021^{*}$ & $0.0055^{*}$ & $0.0032 *$ & $-0.0076^{*}$ & 5,264 \\
\hline & $(0.0002)$ & $(0.0002)$ & $(0.0001)$ & $(0.0002)$ & $(0.0003)$ & \\
\hline \multirow[t]{2}{*}{ Wholesale trade } & $-0.0008^{*}$ & $-0.0301 *$ & $-0.0076^{*}$ & $0.0200^{*}$ & $-0.0414^{*}$ & 2,468 \\
\hline & $(0.0003)$ & $(0.0004)$ & $(0.0002)$ & $(0.0003)$ & $(0.0005)$ & \\
\hline \multirow[t]{2}{*}{ Retail trade } & $-0.0013^{*}$ & $-0.0287^{*}$ & $0.0143^{*}$ & $0.0204 *$ & $-0.0575^{*}$ & 7,684 \\
\hline & $(0.0001)$ & $(0.0002)$ & $(0.0001)$ & $(0.0002)$ & $(0.0003)$ & \\
\hline \multirow[t]{2}{*}{ Transportation and warehousing } & $0.0006^{*}$ & $-0.0009^{*}$ & $0.0179^{*}$ & $0.0018^{*}$ & $-0.0135^{*}$ & 3,652 \\
\hline & $(0.0002)$ & $(0.0003)$ & $(0.0002)$ & $(0.0003)$ & $(0.0004)$ & \\
\hline \multirow[t]{2}{*}{ Finance, insurance, and real estate } & $0.0007^{*}$ & $-0.0119^{*}$ & $0.0085^{*}$ & $0.0076^{*}$ & $-0.0228^{*}$ & 4,149 \\
\hline & $(0.0002)$ & $(0.0003)$ & $(0.0001)$ & $(0.0003)$ & $(0.0004)$ & \\
\hline \multirow[t]{2}{*}{ Professional, Scientific and Technical Services } & $-0.0171^{*}$ & $-0.0649^{*}$ & $-0.0048^{*}$ & $0.0218^{*}$ & $-0.0809^{*}$ & 2,589 \\
\hline & $(0.0003)$ & $(0.0004)$ & $(0.0002)$ & $(0.0004)$ & $(0.0005)$ & \\
\hline \multirow[t]{2}{*}{ Business, building, and other support services } & $0.0009^{*}$ & $-0.0130^{*}$ & $0.0374^{*}$ & $0.0021^{*}$ & $-0.0481^{*}$ & 1,523 \\
\hline & $(0.0003)$ & $(0.0005)$ & $(0.0003)$ & $(0.0005)$ & $(0.0007)$ & \\
\hline \multirow[t]{2}{*}{ Educational service } & $0.0004^{*}$ & $-0.0089^{*}$ & $0.0103^{*}$ & $0.0066^{*}$ & $-0.0202 *$ & 7,546 \\
\hline & $(0.0001)$ & $(0.0002)$ & $(0.0001)$ & $(0.0002)$ & $(0.0003)$ & \\
\hline \multirow[t]{2}{*}{ Health care and social assistance } & $0.0020^{*}$ & $-0.0136^{*}$ & $0.0165^{*}$ & $0.0096^{*}$ & $-0.0327^{*}$ & 9,834 \\
\hline & $(0.0001)$ & $(0.0002)$ & $(0.0001)$ & $(0.0002)$ & $(0.0002)$ & \\
\hline \multirow[t]{2}{*}{ Information, Culture, and Recreation } & $-0.0177^{*}$ & $-0.0345^{*}$ & $0.0123^{*}$ & $0.0007^{*}$ & $-0.0417^{*}$ & 2,661 \\
\hline & $(0.0002)$ & $(0.0003)$ & $(0.0002)$ & $(0.0003)$ & $(0.0005)$ & \\
\hline \multirow[t]{2}{*}{ Accommodation and food services } & $-0.0125^{*}$ & $-0.0282^{*}$ & $0.0122^{*}$ & $0.0069^{*}$ & $-0.0446^{*}$ & 2,744 \\
\hline & $(0.0002)$ & $(0.0002)$ & $(0.0002)$ & $(0.0003)$ & $(0.0004)$ & \\
\hline \multirow[t]{2}{*}{ Public Administration } & $-0.0126^{*}$ & $-0.0048^{*}$ & $-0.0052^{*}$ & $-0.0181 *$ & $0.0152^{*}$ & 2,322 \\
\hline & $(0.0003)$ & $(0.0004)$ & $(0.0002)$ & $(0.0004)$ & $(0.0005)$ & \\
\hline \multirow[t]{2}{*}{ Other services } & $-0.0029^{*}$ & $-0.0330^{*}$ & $=0.0118 *$ & $0.0151^{*}$ & $-0.0525^{*}$ & 7,282 \\
\hline & $(0.0001)$ & $(0.0002)$ & $(0.0001)$ & $(0.0002)$ & $(0.0003)$ & \\
\hline
\end{tabular}

Note: 1. Standard errors are in parentheses. All the estimates are obtained using the aggregate annual unemployment rate. Estimates for forestry and fishing industry are not presented due to small sample size. uc, ustr and umin stand for current, initial and minimum unemployment rate, respectively.

2. Random effects estimation is employed here for comparison purposes. 3. $*=5 \%$. 


\section{Introducing age differences in the contract effect on wages}

McDonald and Worswick (1999) re-estimate the empirical wage model by interacting five-year interval age cohort variables with the three contracting variables. Their main findings are that both younger and older male workers are affected the most by the minimum unemployment rate over their job spells. Grant (2003) applies six cohorts of US longitudinal data and finds implicit contracting differentials between young men and older men. Specifically, he finds that the coefficient estimate of the minimum unemployment rate is 2.92 percent for older workers and 2.29 percent for young workers. Additionally, a one percent decrease in the current unemployment rate leads to a 2.37 percent wage increase for young men, in comparison with a 0.41 percent of impact found on older men.

Devereux and Hart (2005) divide their sample into two sub-groups in terms of those respondents younger than the median age and those older than the median age. They re-estimate each sub-sample and their results are not sensitive to this division except in facing the effect of the minimum unemployment rate. Older males do not seem to respond to the minimum unemployment rate as do younger males. Both groups are still influenced the most by the contemporaneous labour market conditions.

To test for differences in wage responses to business cycles across age groups, we define nine indicator variables based on the age of the respondent, each having a fiveyear age interval (four-year interval for the 21-24 age group). Each of the contract variables is then included in the wage model as interactions with these age dummy variables. The coefficient estimates of the contract effects by age are reported in Table 
4.5. ${ }^{26}$ Column 1 presents the effect of the current macroeconomic conditions on wage rates. Workers age 21 to 34 years of age and workers over 60 are affected adversely by the current labour market fluctuations; however, the magnitude of these effects are small at -0.0042 and -.0043 , respectively. The wages of workers at other ages are not found to be affected significantly by fluctuations in the current macroeconomic conditions.

Next, the estimates of the implicit contracting variables with costly and costless mobility are shown respectively in Column 2 and 3 . As expected, most of the coefficient estimates are negative and significant. These estimates are larger in absolute value for the case of workers less than 35 years of age. This indicates that younger workers are more vulnerable to the impact of labour market shocks. The nested model with the three contract variables included displays a relatively consistent pattern of macroeconomic effects on wage dynamics. For all age groups, the minimum unemployment rate dominates the current and initial labour market variables in terms of affecting current wages. The one unusual finding relates to workers over the age of 55. In this case the coefficient on the minimum unemployment rate variable is positive and significant which is contrary to what the implicit contract model predicts.

Figures $4.2,4.3$ and 4.4 presents the effect of each contract variable on wage rates for each of the age groups. The effect of the current unemployment rate is mainly hillshaped as is apparent in Figure 4.2. Although those younger than 35 and those near retirement are negatively affected by the current unemployment rate, the absolute values of these adverse effects are very small. Workers between the ages of 35 and 59 years of age are also effectively unaffected by fluctuations in the current unemployment rate even

${ }^{26}$ Random effects estimation is employed in order to make the results comparable with McDonald and Worswick's (1999) findings given that they only had access to multiple cross sections of data rather than panel data. 
though the coefficients are positive and significant in most cases. Figures 4.3 and 4.4 capture the effect of past labour market conditions on wage variations for the nine age groups. The two series of the effects illustrate similar patterns, each characterized by a random shape. It is worth noting that these patterns differ from what was found by McDonald and Worswick (1999). According to them, past best labour market conditions over male workers' job tenure present a hill-shaped impact on the wage movement of a series of age cohorts, with both younger workers and older workers at the bottom of the curve and the middle-aged at the top. Contrary to McDonald and Worswick's (1999) findings, our work suggests that individuals near the usual age of retirement are no longer adversely affected by the minimum unemployment rate in terms of their current wages. This is somewhat consistent with the empirical results suggested by Fang and Gunderson (2009) in that the minimum wage does not negatively affect older workers as it does young workers. Additionally, workers in their early thirties are the most sensitive to past macroeconomic fluctuations. The negative effect is fully captured by lower wage returns, and is shown hitting the lowest point of the curve. More specifically, a one percent increase in the minimum unemployment rate leads to a 3.33 percent drop in the wage profile for individuals aged 30 to 34. 
Table 4.5

Coefficient Estimates of Implicit Contracting Effects by Age (Men and Women)

\begin{tabular}{|c|c|c|c|c|c|c|c|}
\hline \multirow[b]{3}{*}{ Age } & \multirow[b]{2}{*}{ uc } & \multirow[b]{2}{*}{ ustr } & \multirow[b]{2}{*}{ ulow } & \multicolumn{3}{|c|}{ Nested Results } & \multirow{3}{*}{$\begin{array}{l}\text { Number of } \\
\text { Observations }\end{array}$} \\
\hline & & & & uc & ustr & ulow & \\
\hline & 1 & 2 & 3 & $4 a$ & $4 b$ & $4 c$ & \\
\hline \multirow[t]{2}{*}{$21-24$} & $-0.0042^{*}$ & $-0.0091^{*}$ & $-0.0225^{*}$ & $0.0214^{*}$ & $0.0095^{*}$ & $-0.0539^{*}$ & 3,876 \\
\hline & $(0.0001)$ & $(0.0001)$ & $(0.0002)$ & $(0.0002)$ & $(0.0003)$ & $(0.0003)$ & \\
\hline \multirow[t]{2}{*}{$25-29$} & $-0.0009^{*}$ & $-0.0120^{*}$ & $-0.0243^{*}$ & $0.0140^{*}$ & $-0.0021^{*}$ & $-0.0365^{*}$ & 6,888 \\
\hline & $(0.0001)$ & $(0.0001)$ & $(0.0002)$ & $(0.0001)$ & $(0.0002)$ & $(0.0003)$ & \\
\hline \multirow[t]{2}{*}{$30-34$} & $-0.0032^{*}$ & $-0.0150^{*}$ & $-0.0333^{*}$ & $0.0094^{*}$ & $-0.0033^{*}$ & $-0.0401^{*}$ & 10,160 \\
\hline & $(0.0001)$ & $(0.0001)$ & $(0.0002)$ & $(0.0001)$ & $(0.0001)$ & $(0.0002)$ & \\
\hline \multirow[t]{2}{*}{$35-39$} & $0.0027^{*}$ & $0.0003^{*}$ & $-0.0099^{*}$ & $0.0064^{*}$ & $0.0055^{*}$ & $-0.0202^{*}$ & 12,576 \\
\hline & $(0.0001)$ & $(0.0001)$ & $(0.0002)$ & $(0.0001)$ & $(0.0001)$ & $(0.0002)$ & \\
\hline \multirow[t]{2}{*}{$40-44$} & $0.0065^{*}$ & $-0.0002^{*}$ & $-0.0115^{*}$ & $0.0099^{*}$ & $0.0067^{*}$ & $-0.0240^{*}$ & 13,180 \\
\hline & $(0.0001)$ & $(0.0001)$ & $(0.0002)$ & $(0.0001)$ & $(0.0001)$ & $(0.0002)$ & \\
\hline \multirow[t]{2}{*}{$45-49$} & $0.0075^{*}$ & $-0.0052^{*}$ & $-0.0124^{*}$ & $0.0087^{*}$ & $0.0013^{*}$ & $-0.0159^{*}$ & 11,882 \\
\hline & $(0.0001)$ & $(0.0001)$ & $(0.0002)$ & $(0.0001)$ & $(0.0001)$ & $(0.0002)$ & \\
\hline \multirow[t]{2}{*}{$50-54$} & $0.0086^{*}$ & $-0.0068^{*}$ & $-0.0142 *$ & $0.0095^{*}$ & $-0.0005^{*}$ & $-0.0155^{*}$ & 8,977 \\
\hline & $(0.0001)$ & $(0.0001)$ & $(0.0002)$ & $(0.0001)$ & $(0.0002)$ & $(0.0002)$ & \\
\hline \multirow[t]{2}{*}{$55-59$} & $0.0074^{*}$ & $0.0044^{*}$ & $0.0125^{*}$ & $0.0066^{*}$ & $0.0005^{*}$ & $0.0103^{*}$ & 5,043 \\
\hline & $(0.0002)$ & $(0.0002)$ & $(0.0003)$ & $(0.0002)$ & $(0.0002)$ & $(0.0004)$ & \\
\hline \multirow[t]{2}{*}{$60+$} & $-0.0043^{*}$ & $-0.0108^{*}$ & $0.0098^{*}$ & $-0.0055^{*}$ & $-0.0202^{*}$ & $0.0333^{*}$ & 1,456 \\
\hline & $(0.0003)$ & $(0.0003)$ & $(0.0006)$ & $(0.0003)$ & $(0.0004)$ & $(0.0007)$ & \\
\hline \multirow[t]{2}{*}{ Pooled } & $0.0098^{*}$ & -0.0064 & $-0.0137^{*}$ & $0.0129 *$ & 0.0077 & $-0.0271^{*}$ & 74,038 \\
\hline & $(0.0012)$ & $(0.0033)$ & $(0.0032)$ & $(0.0012)$ & $(0.0051)$ & $(0.0050)$ & \\
\hline
\end{tabular}

Note: 1. Standard errors are in parentheses. All the estimates are obtained using the aggregate annual unemployment rate. uc, ustr and umin stand for current, initial and minimum unemployment rate, respectively.

2. Random effects estimation is employed.

$3 . *=5 \%$. 


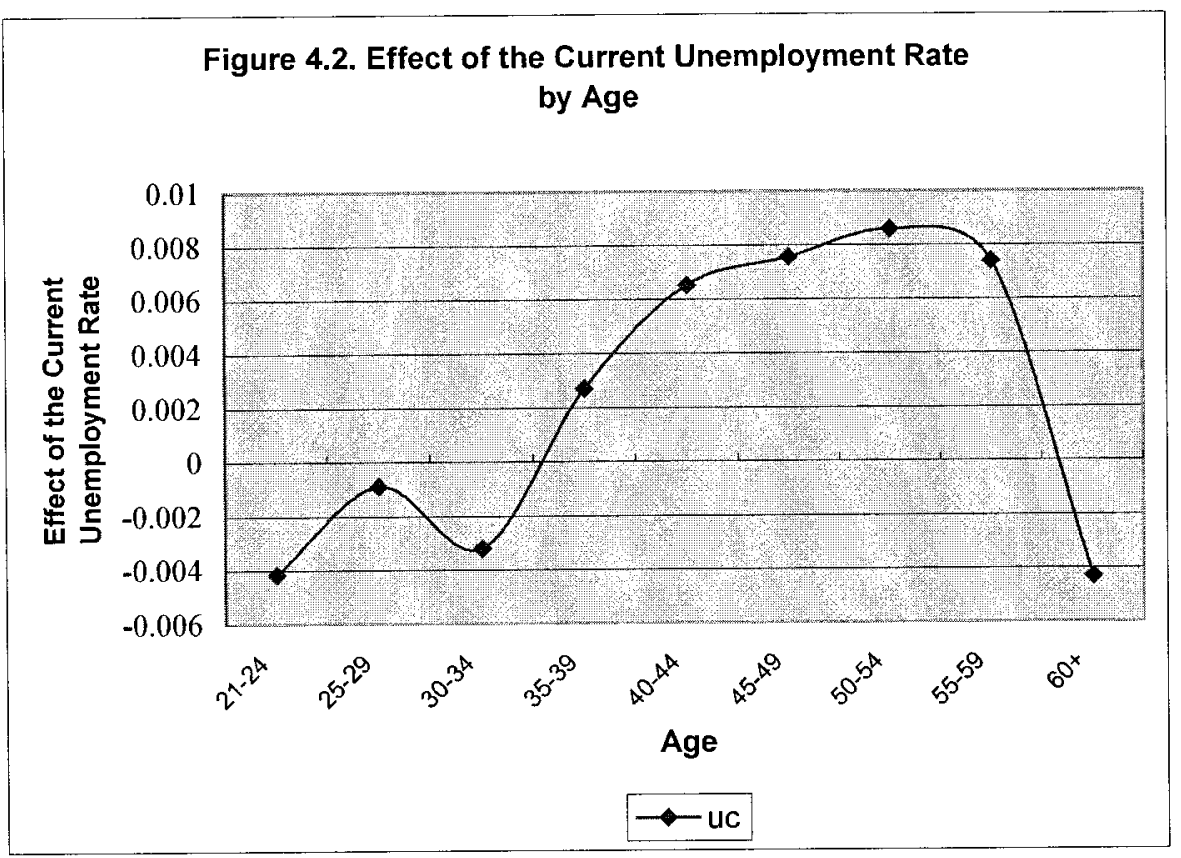

Note: uc stands for the current unemployment rate.

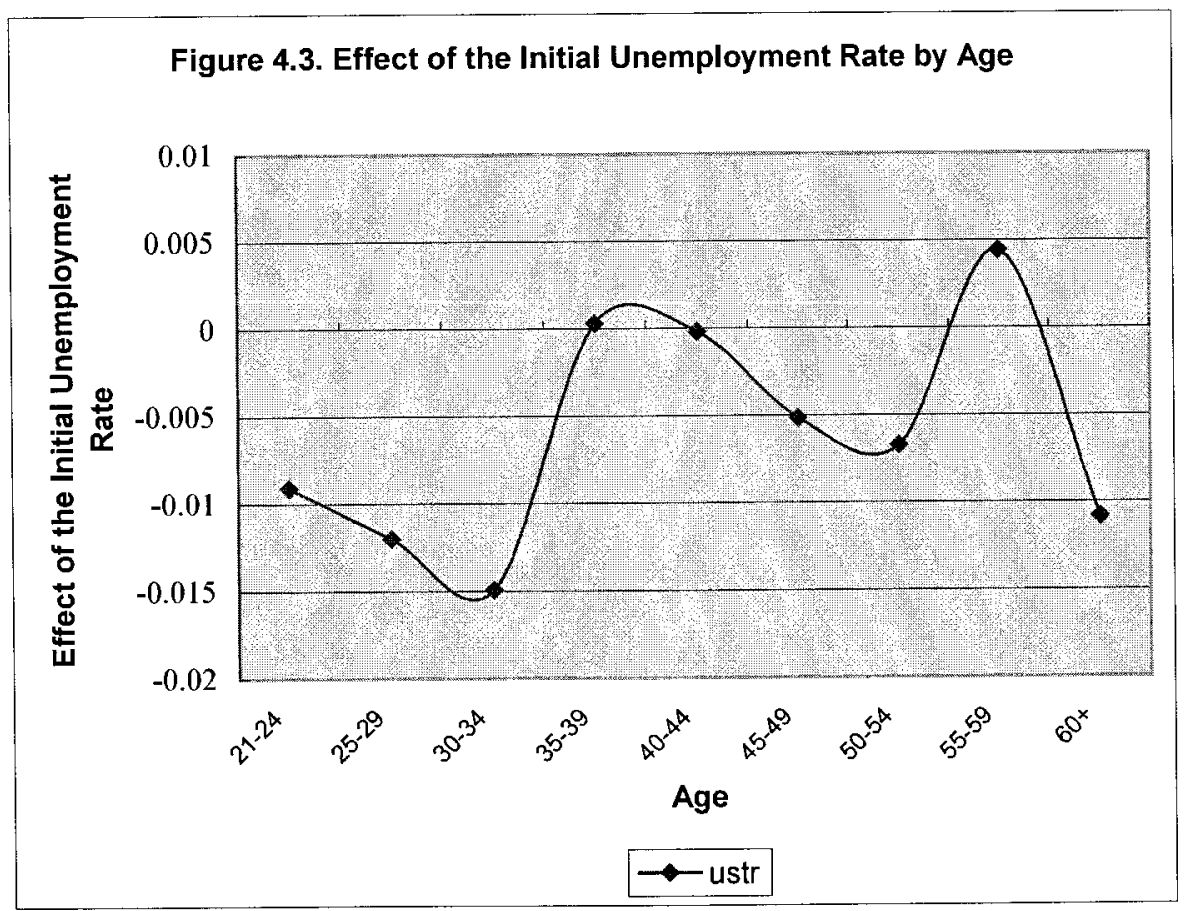

Note: ustr stands for the unemployment rate at the time the worker was first hired by the current firm. 


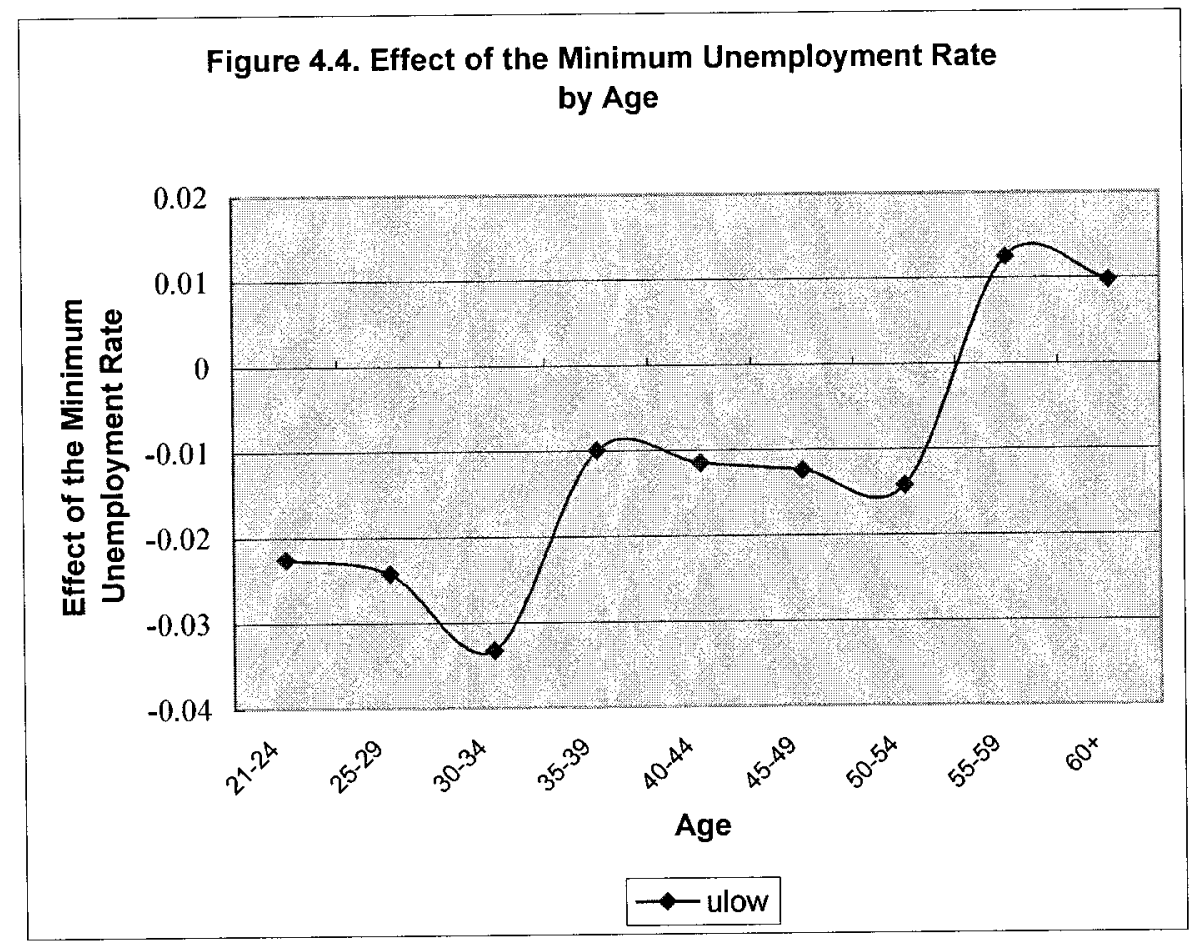

Note: ulow stands for the minimum unemployment rate since the worker was first hired at the firm.

\section{Controlling for union status in explaining wage contract effects}

McDonald and Worswick (1999) find a much lower magnitude of contract effects on Canadian wages than those found on American wages (Beaudry and DiNardo, 1991). They attribute this discrepancy partly to the higher rate of union coverage in the Canadian labour market than in the United States. Due to a lack of information on union status in their data, they are unable to examine this hypothesis about the union impact. Beaudry and DiNardo (1991) test the union/non-union differentials and find that the negative impact of the labour market conditions at the time of hiring on wages of non-union workers is almost double that on union workers' wages. The minimum unemployment rate has a nearly 55 percent higher adverse effect on wages of the non-union group than 
on the union group. However, using data from the UK, Devereux and Hart (2005) find little impact of collective coverage status on implicit contract effects for either men or women.

We first test the sensitivity of implicit contracting effects with the inclusion of the union status information. All non-union members are placed in the default group. ${ }^{27}$ Later we divide the sample into two subgroups by gender to examine whether the impact of the union/collective agreement coverage on contract wage outcomes differs by gender. Approximately 44 percent of the respondents are union members.

Table 4.6 presents wage regression estimates from a model with the three contract variables as well as a union variable estimates over the entire sample and separately for each gender. Evidence suggests that being covered by a union agreement leads to a five to six percent higher wage rate than otherwise, with female workers having one percent higher returns to union status in comparison to male workers. Compared to Table 4.2 and Table 4.3 in which estimates are obtained from modeling specifications without the union control, the estimates of the initial and the minimum unemployment rates from Table 4.6 display slightly declining magnitudes in absolute values. The change in estimates of the current measure is barely noticeable. Similar to previous findings, the minimum unemployment rate is the determinant factor among the three macroeconomic measures in affecting wage outcomes.

\footnotetext{
${ }^{27}$ Hereinafter, non-union members refer to those who are neither a union member nor covered by a collective agreement while all other workers are referred to as union members.
} 
Table 4.6

Fixed Effects: Coefficient Estimates of Implicit Contracting Effects After Controlling for Union Status

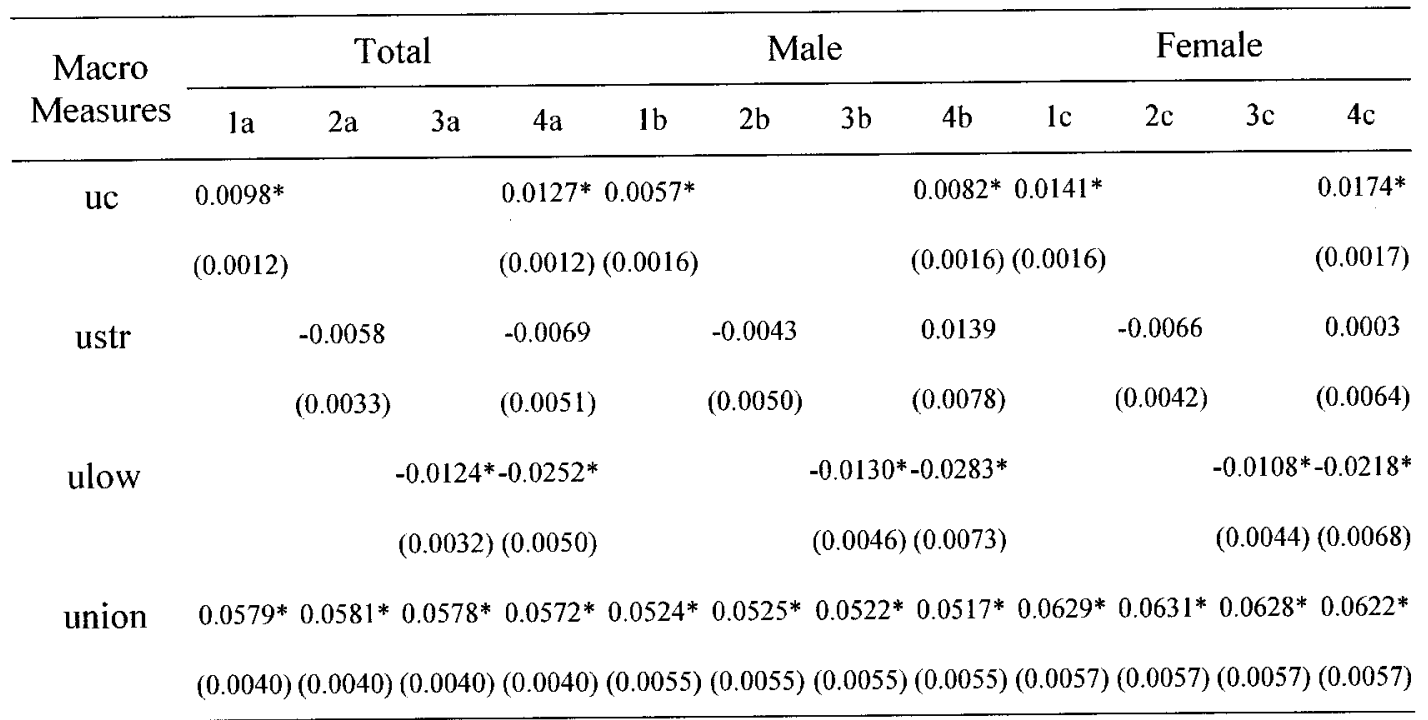

Note: 1. Standard errors are in parentheses. uc, ustr and umin stand for current, initial and minimum unemployment rate, respectively. Union is the flag to indicate whether or not a respondent is either: 1) a union member or 2 ) covered by a collective agreement.

$2{ }^{*}=5 \%$.

Next, we divide the sample by union status and run separate regressions for each group. Two sets of estimates are listed in Table 4.7 representing implicit contracting effects for both the union group and the non-union group. For the union group, despite the statistical insignificance and the small magnitude of most contract variables, all three estimates of the macroeconomic indicators turn out to have positive signs except the estimate of the initial unemployment rate in the nested model. However, only the current unemployment rate variable is statistically significant. For respondents who are in the non-union sub-sample, their wage profiles in response to the macro controls present quite different outcomes. Although current macro conditions have a positive influence in the wage outcomes of uncovered workers (similar to what was found in the union sample 
analysis), past business cycle patterns especially the minimum unemployment rate show stronger contract effects. Approximately a one percent decrease in the minimum unemployment rate since the start of the job is associated with 1.07 percent wage increase. Differing from Beaudry and DiNardo (1991) who find both union and non-union members are adversely impacted by past macro conditions with the magnitude of implicit contracting effects larger for the non-union group, our empirical evidence gives rise to the conclusion that the wages of union covered workers are not negatively affected by either current o past macro conditions.

Table 4.7

Implicit Contracting Effects by Union Status from Fixed Effects Estimation

\begin{tabular}{|c|c|c|c|c|c|c|c|c|}
\hline \multirow{2}{*}{$\begin{array}{c}\text { Macro } \\
\text { Measures }\end{array}$} & \multicolumn{4}{|c|}{ Union } & \multicolumn{4}{|c|}{ Non-Union } \\
\hline & $1 \mathrm{a}$ & $2 a$ & $3 a$ & $4 a$ & $\mathrm{lb}$ & $2 b$ & $3 b$ & $4 b$ \\
\hline \multirow[t]{2}{*}{ uc } & $0.0091^{*}$ & & & $0.0092^{*}$ & $0.0091^{*}$ & & & $0.0125^{*}$ \\
\hline & $(0.0015)$ & & & $(0.0015)$ & $(0.0017)$ & & & $(0.0017)$ \\
\hline \multirow[t]{2}{*}{ ustr } & & 0.0009 & & -0.0065 & & -0.0025 & & $0.0124^{*}$ \\
\hline & & $(0.0063)$ & & $(0.0098)$ & & $(0.0040)$ & & $(0.0063)$ \\
\hline \multirow[t]{2}{*}{ ulow } & & & 0.0045 & 0.0046 & & & $-0.0107^{*}$ & $-0.0276^{*}$ \\
\hline & & & $(0.0062)$ & $(0.0096)$ & & & $(0.0040)$ & $(0.0064)$ \\
\hline
\end{tabular}

Note: 1. Standard errors are in parentheses. uc, ustr and umin stand for current, initial and minimum unemployment rate, respectively. Union is the flag to indicate whether a respondent is a union member or 2) covered by a collective agreement.

2. ${ }^{*}=5 \%$.

Next, we e investigate whether gender differences are present in terms of the implicit contracting effects for the case of both unionized and non-unionized workers. The upper panel of Table 4.8 reports the macroeconomic estimates by gender for the 
union group. Differing from union male workers who seem to be fully insured against current and past labour market fluctuations, female workers in the union group are still influenced adversely in their wage returns to past macroeconomic variations. In particular, it is the unemployment rate at the start of the worker's job which has the most explanatory power for the case of women in union jobs. For the non-union group, both male and female workers display a larger magnitude of wage reaction to the minimum unemployment rate implying the importance of implicit contracts with costless mobility.

Table 4.8

Implicit Contracting Effects by Union Status and Gender from Fixed Effects Estimation

\begin{tabular}{|c|c|c|c|c|c|c|c|c|}
\hline \multirow{3}{*}{$\begin{array}{c}\text { Macro } \\
\text { Measures }\end{array}$} & \multicolumn{8}{|c|}{ Union } \\
\hline & \multicolumn{4}{|c|}{ Male } & \multicolumn{4}{|c|}{ Female } \\
\hline & $1 \mathrm{a}$ & $2 a$ & $3 a$ & $4 a$ & $1 \mathrm{~b}$ & $2 b$ & $3 b$ & $4 \mathrm{~b}$ \\
\hline \multirow[t]{2}{*}{$\mathrm{Uc}$} & 0.0030 & & & 0.0020 & $0.0160^{*}$ & & & $0.0170^{*}$ \\
\hline & $(0.0021)$ & & & $(0.0021)$ & $(0.0022)$ & & & $(0.0023)$ \\
\hline \multirow[t]{2}{*}{ Ustr } & & $0.0188^{*}$ & & 0.0134 & & $-0.0191 *$ & & $-0.0272^{*}$ \\
\hline & & $(0.0082)$ & & $(0.0133)$ & & $(0.0096)$ & & $(0.0137)$ \\
\hline \multirow[t]{3}{*}{ Ulow } & & & $0.0173^{*}$ & 0.0057 & & & -0.0096 & 0.0023 \\
\hline & & & $(0.0077)$ & $(0.0126)$ & & & $(0.0098)$ & $(0.0143)$ \\
\hline & \multicolumn{8}{|c|}{ Non-Union } \\
\hline \multirow[t]{2}{*}{ Uc } & $0.0067^{*}$ & & & $0.0101^{*}$ & $0.0116^{*}$ & & & $0.0149 *$ \\
\hline & $(0.0024)$ & & & $(0.0025)$ & $(0.0023)$ & & & $(0.0024)$ \\
\hline \multirow[t]{2}{*}{ Ustr } & & -0.0028 & & 0.0176 & & -0.0012 & & 0.0086 \\
\hline & & $(0.0063)$ & & $(0.0098)$ & & $(0.0050)$ & & $(0.0080)$ \\
\hline \multirow[t]{2}{*}{ Ulow } & & & $-0.0126^{*}$ & $-0.0321^{*}$ & & & -0.0081 & $-0.0237^{*}$ \\
\hline & & & $(0.0058)$ & $(0.0092)$ & & & $(0.0054)$ & $(0.0087)$ \\
\hline
\end{tabular}

Note: 1. Standard errors are in parentheses. uc, ustr and umin stand for current, initial and minimum unemployment rate, respectively. Union is the flag to indicate whether a respondent is either: 1) a union member or 2) covered by a collective agreement. $2{ }^{*}=5 \%$. 


\section{Conclusions}

Mainly replicating the previous work by Beaudry and DiNardo (1991), we employ the pooled panel data sets from the Survey of Labour and income Dynamics to test whether Canadian wages of Canadian born workers are better explained by a spot market view or by an implicit contracting view. Using current and past unemployment rates as measures for labour market conditions, we found evidence that wage dynamics are best explained by an implicit contract model with costless mobility rather than the spot market view or an implicit contract with costly mobility over the survey period 1993 to 2006. In terms of the empirical findings, these contract differences are captured by the fact that it is the minimum unemployment rate since the start of the worker's employment with the firm that has the most influence on current wages as opposed to either the current unemployment rate or the unemployment rate at the start of employment with the current firm.

The extension of adding contracting effects differences by gender, industry and age into the wage model also supports the importance of the implicit contracting view rather than the spot market view. In addition, labour market conditions have differing impacts on wage variations between men and women. Female workers are more sensitive to current labour market conditions and less affected by the best labour market conditions since the start of the working with the firm compared to male workers. The effect of macroeconomic variables also differs across industries. Unlike a hill-shaped implicit contracting effect found in earlier literature, past labour market conditions are found to affect the current wage rate of different age groups without a clear pattern. Finally, implicit contracting effects differ between union members and non-union 
members. Non-union members seem to be unable to avoid the scarring effect of past economic recessions. While union covered workers seem to be less affected by past macroeconomic conditions and in the cases where past macro effects are present, they are not consistent with an implicit contract model with costless mobility, unlike the case of non-union workers. 


\section{Chapter 5 \\ Implicit Contracts and Immigrant Wage Determination}

The purpose of this chapter is to examine the implicit contract model and its importance in terms of explaining the wage dynamics of immigrants. We adopt the same empirical implicit contract framework as in Chapter 4 and investigate the labour market performance of immigrants in Canada taking into account both current and past macroeconomic conditions. This is the first study in which the implicit contract model is integrated into an immigrant earnings analysis. Not only the implicit contracting effect for immigrants is examined, but also extensions are made to test for differences in the wage effects of business cycles fluctuations between immigrants and the native born.

The chapter is organized as follows. Section 1 contains the discussion of the sample statistics. Section 2 draws modeling inferences for implicit contracting effects facing immigrants. The key empirical findings are presented. In Sections 3, 4 and 5, we discuss gender differences and immigrant-native earnings differences in terms of the sensitivity of wages to current and past macroeconomic variations. The major findings and policy implications are presented in Section 6.

\section{Sample statistics}

Table 5.1 contains sample means of selected variables from the pooled SLID full sample (column 1), the native born sub-sample (column 2), the immigrant sub-sample (column 3), the male immigrant sub-sample (column 4) and the female immigrant subsample (column 5). Male immigrants earn roughly 35 percent higher hourly wages than female immigrants. They have approximately four more years of work experience, one 
more year of job tenure and slightly higher education compared to female immigrants.

There is also evidence of differences in the individual characteristics between immigrants and native-born Canadians. In general, immigrants seem to have relatively higher hourly wage rates than the native born. Immigrants are more than three years older, more likely to be married, and more likely to live in an urban area. They also have slightly higher education and labour market experience but fewer years of job tenure relative to the native born.

Table 5.1

Implicit Contracts: Sample Means for Selected Variables (Full Sample and Immigrant Sub-sample)

\begin{tabular}{|c|c|c|c|c|c|}
\hline Variable & $\begin{array}{c}\text { Total } \\
\mathrm{N}=80,925\end{array}$ & $\begin{array}{c}\text { Native } \\
\mathrm{N}=74,038\end{array}$ & $\begin{array}{l}\text { Immigrants } \\
\mathrm{N}=6,887\end{array}$ & $\begin{array}{c}\text { Male } \\
\text { Immigrant } \\
N=3,691\end{array}$ & $\begin{array}{c}\text { Female } \\
\text { Immigrant } \\
N=3,196\end{array}$ \\
\hline Composite Hourly Wage & 20.29 & 20.18 & 21.52 & 24.44 & 18.14 \\
\hline Log Composite Hourly Wage & 2.90 & 2.90 & 2.96 & 3.10 & 2.79 \\
\hline Age & 41.09 & 40.77 & 44.50 & 44.58 & 44.41 \\
\hline Male & 0.51 & 0.51 & 0.54 & & - \\
\hline Years Since Immigration & - & - & 25.29 & 24.83 & 25.84 \\
\hline Married & 0.67 & 0.66 & 0.76 & 0.79 & 0.72 \\
\hline Urban & 0.74 & 0.73 & 0.87 & 0.89 & 0.85 \\
\hline Years of Schooling & 13.83 & 13.80 & 14.23 & 14.39 & 14.04 \\
\hline Years of Work Experience & 17.75 & 17.61 & 19.20 & 21.21 & 16.89 \\
\hline Years of Job Tenure & 10.47 & 10.48 & 10.39 & 10.97 & 9.72 \\
\hline Total number of weeks employed & 50.61 & 50.56 & 51.12 & 51.17 & 51.06 \\
\hline
\end{tabular}

Note: $1 . \mathrm{N}$ stands for the number of observations.

2. All monetary amounts were converted into 2004 Canadian dollars using the Consumer Price Index. 


\section{Testing the spot market view vs. the implicit contract view}

In this section, our analysis of the impact of implicit contracts on wages is extended to the case of immigrants. Regression results based on model 2.1.2 are displayed in Table 5.2 which contains the fixed effect coefficient estimates of different combinations of the contract variables: the current unemployment rate, the unemployment rate at the time of hiring and the minimum unemployment rate over an individual's job tenure. The minimum unemployment rate has the greatest influence on immigrant wages relative to the other two labour market measures as shown in the table, which is consistent with the findings for native-born persons or a combined sample with both immigrant and the native born in previous studies (Beaudry and DiNardo, 1991, and McDonald and Worswick, 1999). This evidence found on immigrants gives further support to the view that the implicit contract model with costless mobility does a better job of explaining the variation in wages in the SLID data than does either the spot market model of the implicit contract model with costly mobility,

Columns 1 to 3 contain the estimates where only one of the three macroeconomic variables is included in the model, and Columns 4 to 7 contain the estimates from models using four combinations of the three macroeconomic variables. In Column 1, the current unemployment rate is examined separately. The coefficient estimate is not only of small negative magnitude but it is statistically insignificant at the five percent level. This finding is similar to that of McDonald and Worswick (1999) in their analysis of the earnings of Canadian-born men. ${ }^{28}$ It differs from our previous findings on the native

\footnotetext{
${ }^{28}$ It differs from previous findings on non-immigrant data or mixed-data in which Beaudry and DiNardo (1991), Grant (1993) and Devereux and Hart (2005) have presented a statistically significant coefficient of current unemployment rate with higher negative magnitude.
} 
born in which the current unemployment rate has a positive impact on wages despite the small magnitude.

The coefficient estimates of the unemployment rate at the start of the job are shown in Column 2. The negative and significant coefficient of -0.0410 suggests that past labour market conditions have a permanent impact on immigrant current wages so long as the immigrant remains with that employer. Workers benefit in their future wage profiles from good labour market conditions at the time of hiring, or otherwise suffer unfavorable earnings resulting from the poor labour market consequences when they were hired. The magnitude of the effect indicates that a one percent increase in the initial unemployment rate tends to shrink immigrant wages by 4.10 percent, as compared to a 2.1 percent found in the analysis of pooled immigrant and native born data in the analysis by Beaudry and Dinardo (1991) and a much smaller magnitude found in the analysis of native-born men by McDonald and Worswick (1999) and Devereux and Hart (2005). It is also significantly higher than the coefficient estimate we find on the native-born sample $(-0.0064)$.

Next, we examine the effect of the minimum unemployment rate over the individual's job tenure on each individual's current wage and present these results in Column 3. The analysis in effect tests how wage dynamics react to the best labour market conditions under the assumption that workers are fully mobile between firms. The negative and significant coefficient implies that the lower the minimum unemployment rate over an individual's job tenure, the better the state of the best labour market and the higher the worker's wage. In comparison with McDonald and Worswick's (1999) finding that a one percent decrease in the minimum unemployment rate leads to 
0.58 percent increase in native-born men's earnings, a 5.35 percent increase in the hourly wage rate is found in response to a one percent decrease in the minimum unemployment rate variable. This magnitude of effect found in Canadian immigrant wages is also much higher than the equivalent coefficient estimate of -0.0137 that we find on the native-born workers and all previous findings on non-immigrants and all-inclusive data.

Columns 4 to 7 present the regression estimates from different combinations of the unemployment rate variables that are nested in the same contract wage model. When letting different measures compete with each other, the minimum unemployment rate variable stands out as having the coefficient with the largest absolute value. In addition, it is the only one of the coefficients on the macro variables in Columns 5 through 7 that is statistically significant. For example, as shown in Column 7 when all three macroeconomic measures compete in the same wage model, estimates for both current and initial unemployment rates are not statistically significant. 


\section{Table 5.2}

Implicit Contracting Effects from Fixed Effects Estimation: Immigrant Men and Women

\begin{tabular}{|c|c|c|c|c|c|c|c|}
\hline & \multicolumn{7}{|c|}{$\begin{array}{l}\text { Regression Results for the Pooled Panel 93-06 } \\
\qquad(\mathrm{N}=6,887)\end{array}$} \\
\hline & 1 & 2 & 3 & 4 & 5 & 6 & 7 \\
\hline \multirow[t]{2}{*}{ Current Unemployment Rate } & -0.0048 & & & -0.0014 & 0.0013 & & 0.0013 \\
\hline & $(0.0035)$ & & & $(0.0034)$ & $(0.0035)$ & & $(0.0035)$ \\
\hline \multirow[t]{2}{*}{ Unemployment Rate at Start of Job } & & $-0.0410^{*}$ & & $-0.0404^{*}$ & & -0.0055 & -0.0055 \\
\hline & & $(0.0113)$ & & $(0.0113)$ & & $(0.0148)$ & $(0.0148)$ \\
\hline \multirow[t]{2}{*}{ Minimum Rate Since Start of Job } & & & $-0.0535^{*}$ & & $-0.0543^{*}$ & $-0.0496^{*}$ & $-0.0504^{*}$ \\
\hline & & & $(0.0113)$ & & $(0.0114)$ & $(0.0148)$ & $(0.0150)$ \\
\hline
\end{tabular}

Note: 1. Standard errors are in parentheses. The dependent variable is the log of the real composite hourly wage. The independent variables include macroeconomic measures, years since migration and years since migration squared, years of schooling, years of experience, years of experience squared, tenure, tenure squared, and controls for industry, marital status, province of residence and urban/rural status. See Appendix A for the variable definitions.

2. ${ }^{*}=5 \%$.

\section{Gender differences in the contract effect}

Most of the previous analyses of implicit contract effects on wages have focused exclusively on men. Devereux and Hart (2005) analyze gender differences in the impact of implicit contracts on wages using data from the UK and found little evidence of gender differentials in contracting wage variations. Grant (2003) examines the National Longitudinal Surveys including six cohorts categorized by gender and age. He also finds support for a similar impact of implicit contracts on the wage movement of men and women.

This research chapter, for the first time, selects immigrants as a target group to examine the contracting effect, then extends the model to allow for gender differences in 
an effort to determine whether immigrant men and women are affected equally in terms of the impact of implicit contracts on wages when facing fluctuating macroeconomic conditions.

In Table 5.3, the estimates from models with different controls for past macroeconomic variables are presented for both men and women separately. Splitting the sample by gender, Columns 1 to 3 and Columns 5 to 7 contain estimates of each macroeconomic variable; Column 4 through 8 contain estimates of models where different combinations of the macroeconomic variables are nested in the wage model.

The main results regarding gender differentials in immigrant implicit contract wage studies are as follows. First, estimates of the coefficient on the current unemployment rate variable for both genders are insignificant and have the coefficient estimates (in terms of absolute value) when either entering the model as a single macroeconomic measure or when nested with the other two measures. . Second, as shown in Columns 2 and 3, both the unemployment rate at the start of the job and the minimum unemployment rate since the start of the job turn out to be statistically significant for male immigrants and the coefficients imply at least a five percent wage increase in response to a one unit decline in the relevant unemployment rate variable. For female immigrants, both estimates of the coefficients on the past macroeconomic variables indicate that the impact on the current wage rate of an improvement in past macroeconomic conditions is smaller than is case for men. Third, when the three macroeconomic variables work against each other in the same wage model, most coefficient estimates of the macroeconomic variables are insignificant with the exception of the minimum unemployment rate variable for men. A one percent decrease in the 
lowest unemployment rate over a male immigrant's job tenure is associated with a 5.04 percent increase $(6.25$ percent in the wage model with only the minimum unemployment rate variable present) in wage rates. In the analysis for women, The minimum unemployment measure still has the largest coefficient (in terms of absolute value) in comparison with the other two measures suggesting that the implicit contract model with costless mobility better fits the data than either the spot market model or the implicit contract model with costly mobility. However, we cannot say definitively that the implicit contract model with costless mobility does a better job of explaining the data than either the spot market model or the implicit contract model with costly mobility for the case of immigrant women.

In addition, the effect of labour market conditions in terms of current and past unemployment rates differs across genders. The impact of macroeconomic fluctuations on immigrant wages does not affect male immigrants and female immigrants in the same way. The wage pattern of male immigrants displays a larger magnitude of variation in response to macroeconomic cycles. Female immigrants differ from male immigrants in bearing the labour market outcomes. They are found to be less sensitive to labour market conditions than male immigrants. 
TABLE 5.3 Contracting Wage Effect for Immigrants by Gender: Results from the Pooled Panel 93-06

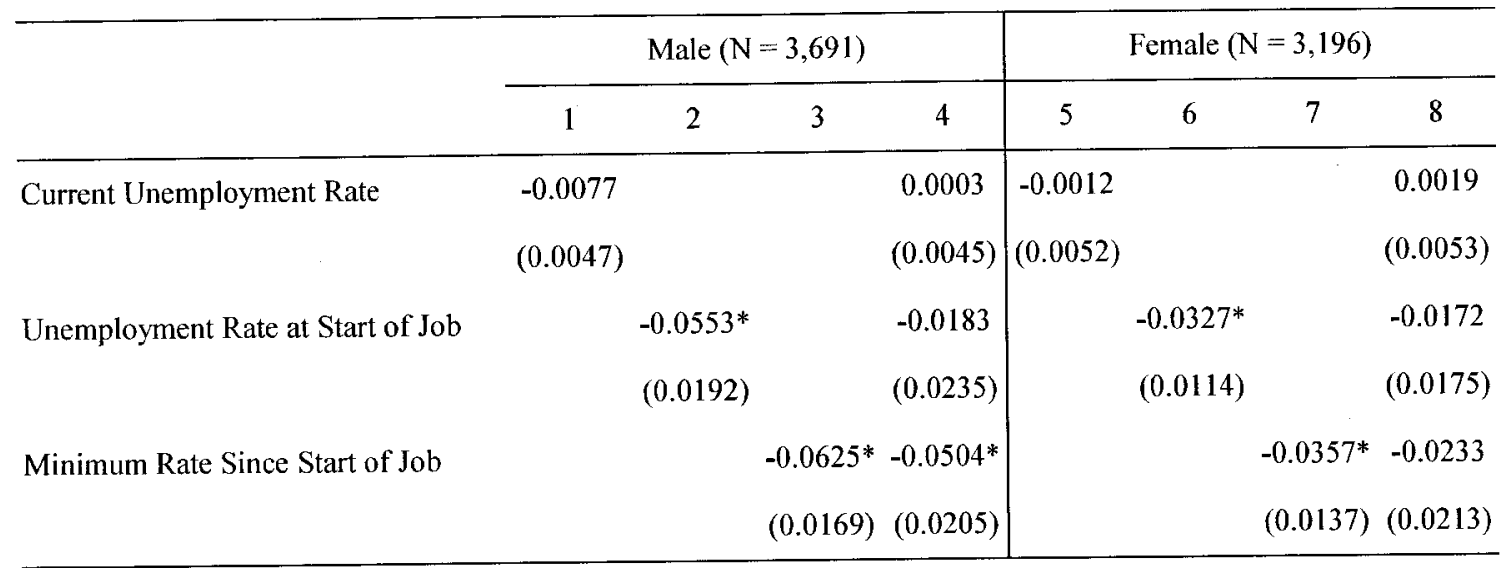

Note: $1 . \mathrm{N}$ stands for the number of observations.

2. Standard errors are in parentheses. Variables are the same as shown in Table 5.2.

3. $*=5 \%$.

\section{Immigrant-Native born differences in wage response to macroeconomic conditions}

Immigrants are usually assumed to be more vulnerable to macroeconomic shocks than are their native born counterparts. For example, Chiswick, Cohen and Zach (1997) find an adverse effect of poor labour market conditions on immigrants' employment probabilities (see also, McDonald and Worswick, 1997). McDonald and Worswick (1998) find that earnings differences between immigrants and the native born can be explained in part by worsening labour market conditions due to economic recessions. Aydemir (2003) presents evidence of a negative impact of initial labour market conditions on the economic performance of immigrants.

Using the three contract variables, as well as the interaction of immigrant status with these three macroeconomic indicators in a series of contract wage models, we investigate the differences between immigrants and native-born workers in their wage 
response to labour market fluctuations. Model 2.1.3 is estimated with the additional controls for interactions of immigrant status with the macroeconomic measures. The data set is expanded to include both immigrants and native-born workers for the contractual wage model regressions. The underlying theory behind the specification simply states that the impact of macroeconomic conditions may differ between immigrants and the native born. The coefficients of the interaction terms capture the amount of differences reflected in wage impacts to macroeconomic conditions. Table 5.4 presents the regression results of to the impact of the different macroeconomic measures, as well as immigrant-native wage differentials when facing macroeconomic variation. Results based on the entire sample are reported in Columns 1 to 4 . Estimates in Columns 5 to 8 are obtained from the model that includes additional controls for immigrant-native differences in the contracting effect.

The coefficient estimate of the current unemployment rate has experienced a noticeable change compared to earlier results from Table 5.2. The coefficient is positive and significant similar to what was found in the analysis of native-born workers in the previous chapter. The estimate in Column 1 shows a 0.85 percent wage increase linking to a one percent rise in the current unemployment rate. The implication that real wage earnings grow when labour current labour market conditions deteriorate differs from previous findings of Beaudry and DiNardo (1991), McDonald and Worswick (1999), Grant (1993) and Devereux and Hart (2005) who all find a negative impact of current macroeconomic conditions on current wages. ${ }^{29}$

\footnotetext{
${ }^{29}$ The positive impact of current macroeconomic conditions on the native-born earnings is discussed in Section 2 of Chapter 4.
} 
With native-born workers included in the sample, the estimates of past labour market conditions display a marked drop in the magnitude in both the single-variable specifications and in the nested models. Despite the decline in the estimates, regression results still suggest that the minimum unemployment rate, or equivalently, the best labour market conditions over an individual's job tenure is the most important macroeconomic measure in terms of determining wage rates.

In Columns 5 through 8 of Table 5.4, each macroeconomic variable is interacted with an immigrant status indicator variable and these additional controls are included in the model to capture immigrant-native born differentials in the wage reaction to variation in current and past labour market conditions. The estimates of the macroeconomic variables do not vary much in magnitude from those estimated without interaction terms. Further evidence found on estimates of the interaction terms demonstrates a clear picture of an increased sensitivity on the part of immigrants to fluctuations in current and past macroeconomic conditions. Immigrants are found to be more adversely affected by each of the three macroeconomic measures compared to native-born workers when the relevant variable is included on its own. The positive coefficient on the current unemployment rate variable, 0.0097 , is more than compensated by the coefficient on the variable's interaction with the immigrant variable, -0.0147 . The coefficient on the interaction of the unemployment rate at the start of the job and the immigrant indicator variable is -0.0266 indicating that immigrants are significantly more sensitive to the macro conditions at the start of the job than are native-born workers. Similarly, the coefficient on the interaction between the immigrant variable and the minimum unemployment rate variable is also negative and significant at -0.0308 indicating that 
immigrants are more sensitive to the best labour market conditions over the job tenure than are native-born workers. Furthermore, when all three macroeconomic variables and their immigrant interaction terms are nested in the same wage model, empirical evidence suggests that the implicit contract model with costless mobility is preferred to either the spot market model or the implicit contract model with costly mobility despite the fact that the interaction terms with past labour market measures turn out to be insignificant.

Table 5.4

Estimates Representing Immigrant-Native Differentials in Contracting Wages: Men and Women

\begin{tabular}{|c|c|c|c|c|c|c|c|c|}
\hline & \multicolumn{8}{|c|}{ Regression Results with Full Sample $(\mathrm{N}=80,925)$} \\
\hline & 1 & 2 & 3 & 4 & 5 & 6 & 7 & 8 \\
\hline \multirow[t]{2}{*}{ Current Unemployment Rate } & $0.0085^{*}$ & & & $0.0118^{*}$ & $0.0097^{*}$ & & & $0.0128^{*}$ \\
\hline & $(0.0011)$ & & & $(0.0011)$ & $(0.0012)$ & & & $(0.0012)$ \\
\hline \multirow[t]{2}{*}{ Unemployment Rate at Start of Job } & & $-0.0083^{*}$ & & 0.0073 & & -0.0064 & & 0.0083 \\
\hline & & $(0.0032)$ & & $(0.0048)$ & & $(0.0033)$ & & $(0.0050)$ \\
\hline \multirow[t]{2}{*}{ Minimum Rate Since Start of Job } & & & $-0.0159^{*}$ & $-0.0283 *$ & & & $-0.0137^{*}$ & $-0.0276^{*}$ \\
\hline & & & $(0.0031)$ & $(0.0048)$ & & & $(0.0032)$ & $(0.0050)$ \\
\hline \multirow[t]{2}{*}{ immst* uc } & & & & & $-0.0147^{*}$ & & & $-0.0127^{*}$ \\
\hline & & & & & $(0.0037)$ & & & $(0.0036)$ \\
\hline \multirow[t]{2}{*}{ immst * ustr } & & & & & & $-0.0266^{*}$ & & -0.0155 \\
\hline & & & & & & $(0.0107)$ & & $(0.0147)$ \\
\hline \multirow[t]{2}{*}{ immst * ulow } & & & & & & & $-0.0308^{*}$ & -0.0120 \\
\hline & & & & & & & $(0.0114)$ & $(0.0157)$ \\
\hline
\end{tabular}

Note: $1 . \mathrm{N}$ stands for the number of observations. uc, ustr and ulow represent respectively the current unemployment rate, unemployment rate at start of job and the minimum unemployment rate since start of each job. immst is an indicator for immigrant status.

2. Standard errors are in parentheses. The dependent variable is the log of the real composite hourly wage. In addition to the regressors defined in Table 5.2, interactions of immigrant status with macroeconomic measures are included to capture immigrant-native differences in wage returns to macroeconomic conditions.

3. $*=5 \%$. 
In the previous Sections 4.3 and 5.3, we show that both native-born Canadians and immigrants experience differentials between men and women in their wage returns to the macroeconomic measures. Next, we test for immigrant-native differences in implicit contracting effects separately by gender. We divide the full sample into male and female subgroups and re-estimate Model 2.1.3 both with and without interaction controls for each subgroup. Table 5.5 presents estimates representing the impact of different contract variables on wages across genders, as well as contracting wage differentials between native-born men and male immigrants, and between native-born women and female immigrants.

The estimates shown in Columns 1 to 4 represent the individual and joint effect of the three macroeconomic indicators. Regression results are displayed separately for men and women. When the samples of native-born Canadians and immigrants are pooled together by gender, we find similar results as presented earlier regarding the positive impact of the current unemployment rate in both male and female samples. The coefficient estimates of the initial unemployment rate are negative, though statistically insignificant, for both groups. Compared to the results found in the female sample in the lower panel of Table 5.5, male workers are more vulnerable to the impact of past labour market shocks. For example, a 1.77 percent increase in wages stems from a one percent decrease in the minimum unemployment rate (or an improvement in the best labour market conditions since the start of the job), compared with a 1.28 percent wage increase for female workers. When we include all three macroeconomic indicators in the same wage model, the minimum unemployment rate over the individual's job tenure has the largest magnitude of impact on wage returns for both men and women, implying the 
greatest importance of implicit contract with costless mobility. Next, we add interaction terms of each macroeconomic variable with an immigrant status indicator variable as additional controls to test for immigrant/native born differences in the wage effects of variation in current and past macroeconomic conditions and this is carried out separately for each gender. The regression results are reported in Columns 5 to 8. Empirical evidence suggests that the wages of both immigrant men and women are more sensitive to economic downturns than are the wages of their native-born counterparts. It is notable that immigrant men are relatively more adversely affected by the past labour market conditions compared to native-born male workers, than are female immigrants in comparison to native-born women. The coefficient estimates on the interaction terms between the initial/minimum unemployment rate with immigrant status variable are both negative and significant at approximately four percent for male immigrants, while those found on female immigrants are not only insignificant but are much smaller in absolute value at 1.45-1.90 percent. Moreover, evidence found in the nested model with all three macroeconomic variables and the immigrant interaction terms further supports the impact of past labour market conditions on immigrant-native born wage differentials for both genders, despite the fact that some estimates of the interaction terms are insignificant. However, this negative coefficient on the immigrant interaction with the current unemployment rate merely offsets the positive coefficient on the unemployment rate variable indicating that the wages of immigrant men and women are not sensitive to the current unemployment rate. 
Table 5.5

Immigrant-Native Differentials in Contracting Wage Effects by Gender

\begin{tabular}{|c|c|c|c|c|c|c|c|c|}
\hline & \multicolumn{8}{|c|}{ Regression Results with Male Sample $(\mathrm{N}=41,554)$} \\
\hline & 1 & 2 & 3 & 4 & 5 & 6 & 7 & 8 \\
\hline \multirow[t]{2}{*}{ Current Unemployment Rate } & $0.0042 *$ & & & $0.0073 *$ & $0.0056^{*}$ & & & $0.0084^{*}$ \\
\hline & $(0.0015)$ & & & $(0.0016)$ & $(0.0016)$ & & & $(0.0016)$ \\
\hline \multirow[t]{2}{*}{ Unemployment Rate at Start of Job } & & -0.0087 & & $0.0118^{*}$ & & -0.0058 & & 0.0138 \\
\hline & & $(0.0048)$ & & $(0.0074)$ & & $(0.0050)$ & & $(0.0077)$ \\
\hline \multirow[t]{2}{*}{ Minimum Rate Since Start of Job } & & & $-0.0177^{*}$ & $-0.0309 *$ & & & $-0.0146^{*}$ & $-0.0300^{*}$ \\
\hline & & & $(0.0044)$ & $(0.0068)$ & & & $(0.0046)$ & $(0.0072)$ \\
\hline \multirow[t]{2}{*}{ immst* uc } & & & & & $-0.0149^{*}$ & & & $-0.0105^{*}$ \\
\hline & & & & & $(0.0050)$ & & & $(0.0048)$ \\
\hline \multirow[t]{2}{*}{ immst * ustr } & & & & & & $-0.0410^{*}$ & & -0.0297 \\
\hline & & & & & & $(0.0171)$ & & $(0.0225)$ \\
\hline \multirow[t]{4}{*}{ immst * ulow } & & & & & & & $-0.0406^{*}$ & -0.0129 \\
\hline & & & & & & & $(0.0159)$ & $(0.0209)$ \\
\hline & & Regres & ssion Resul & Its with $\mathrm{Fe}$ & emale Sam & nple $(\mathrm{N}=3$ & $39,371)$ & \\
\hline & 1 & 2 & 3 & 4 & 5 & 6 & 7 & 8 \\
\hline \multirow[t]{2}{*}{ Current Unemployment Rate } & $0.0131 *$ & & & $0.0163 *$ & $0.0141^{*}$ & & & $0.0175^{*}$ \\
\hline & $(0.0016)$ & & & $(0.0016)$ & $(0.0016)$ & & & $(0.0017)$ \\
\hline \multirow[t]{2}{*}{ Unemployment Rate at Start of Job } & & -0.0074 & & 0.0022 & & -0.0064 & & 0.0025 \\
\hline & & $(0.0040)$ & & $(0.0061)$ & & $(0.0042)$ & & $(0.0064)$ \\
\hline \multirow[t]{2}{*}{ Minimum Rate Since Start of Job } & & & $-0.0128^{*}$ & $-0.0245^{*}$ & & & $-0.0116^{*}$ & $-0.0244^{*}$ \\
\hline & & & $(0.0043)$ & $(0.0066)$ & & & $(0.0045)$ & $(0.0069)$ \\
\hline \multirow[t]{2}{*}{ immst* uc } & & & & & $-0.0140^{*}$ & & & $-0.0144^{*}$ \\
\hline & & & & & $(0.0054)$ & & & $(0.0055)$ \\
\hline \multirow[t]{2}{*}{ immst * ustr } & & & & & & -0.0145 & & $-0.0068^{*}$ \\
\hline & & & & & & $(0.0115)$ & & $(0.0175)$ \\
\hline \multirow[t]{2}{*}{ immst * ulow } & & & & & & & -0.0190 & -0.0048 \\
\hline & & & & & & & $(0.0154)$ & $(0.0233)$ \\
\hline
\end{tabular}

Note: $1 . \mathrm{N}$ stands for the number of observations. uc, ustr and ulow represent respectively the current unemployment rate, unemployment rate at start of job and the minimum unemployment rate since start of each job. immst is an indicator for immigrant status.

2. Standard errors are in parentheses. Variables are the same as shown in Table 5.4.

$3 . *=5 \%$. 


\section{Tests for immigrant-native differentials in the wage response to job tenure}

Job tenure has been found to be an important factor in analyzing wage dynamics. Many empirical studies have shown a positive impact of tenure (interpreted as a proxy for firm-specific capital) on workers' wage outcomes. For example, Topel (1991) presents positive wage returns to job tenure. Altonji and Williams (2005) find 11 percent net wage return associated with 10 years of tenure. McDonald and Worswick (1998) allow for job tenure controls in their immigrant wage study, and present evidence of an important tenure effect in contributing to entry wage differences and the speed of assimilation.

The regression results of the selected coefficient estimates are reported in Table 5.6. Columns 1 to 4 contain estimates of each macroeconomic measure in modeling specifications with both job tenure and immigrant-tenure interaction terms. In comparison with earlier results that are obtained from models with tenure variables but without tenure interaction terms as shown in Columns 5 to 8 of Table 5.4, the implicit contracting results show largely unaffected estimates of the macroeconomic control terms, as well as the immigrant-macro interaction terms. Immigrants still face a less favourable economic outcome than native-born persons in front of labour market fluctuations. The lowest unemployment rate still takes the dominant position in affecting wage variations against the current and initial unemployment rate either competing individually or in the nested model as shown in Column 4.

The negative estimates of the tenure interaction term indicate that there is a wage gap between immigrants and native-born workers for the same amount of tenure accumulation. Non-immigrants gain approximately a nine percent net return to 10 years 
of job tenure. While immigrants earn 0.58-0.77 percent less wages to an additional year of tenure compared to their native-born counterparts.

\section{Table 5.6}

Estimates Representing Immigrant-Native Wage Differentials to Job Tenure: Men and Women

\begin{tabular}{|c|c|c|c|c|}
\hline & 1 & 2 & 3 & 4 \\
\hline \multirow[t]{2}{*}{ Current Unemployment Rate } & $0.0098^{*}$ & & & $0.0129^{*}$ \\
\hline & $(0.0012)$ & & & $(0.0012)$ \\
\hline \multirow[t]{2}{*}{ Unemployment Rate at Start of Job } & & -0.0064 & & 0.0076 \\
\hline & & $(0.0033)$ & & $(0.0050)$ \\
\hline \multirow[t]{2}{*}{ Minimum Rate Since Start of Job } & & & $-0.0137^{*}$ & $-0.0271^{*}$ \\
\hline & & & $(0.0032)$ & $(0.0050)$ \\
\hline \multirow[t]{2}{*}{ immst* uc } & $-0.0144^{*}$ & & & $-0.0121^{*}$ \\
\hline & $(0.0037)$ & & & $(0.0036)$ \\
\hline \multirow[t]{2}{*}{ immst $*$ ustr } & & $-0.0261^{*}$ & & -0.0072 \\
\hline & & $(0.0115)$ & & $(0.0158)$ \\
\hline \multirow[t]{2}{*}{ immst * ulow } & & & $-0.0317^{*}$ & -0.0194 \\
\hline & & & $(0.0115)$ & $(0.0159)$ \\
\hline \multirow[t]{2}{*}{ jobyr } & $0.0088^{*}$ & $0.0091^{*}$ & $0.0088^{*}$ & $0.0087^{*}$ \\
\hline & -0.0007 & -0.0008 & -0.0007 & $(0.0008)$ \\
\hline \multirow[t]{2}{*}{ jobyr^2 } & $-0.0001^{*}$ & $-0.0001^{*}$ & $-0.0001^{*}$ & $-0.0001^{*}$ \\
\hline & $(0.0000)$ & $(0.0000)$ & $(0.0000)$ & $(0.0000)$ \\
\hline \multirow[t]{2}{*}{ immst * jobyr } & $-0.0077^{*}$ & $-0.0058^{*}$ & $-0.0074^{*}$ & $-0.0074 *$ \\
\hline & $(0.0023)$ & $(0.0024)$ & $(0.0023)$ & $(0.0024)$ \\
\hline \multirow[t]{2}{*}{ immst $*$ jobyr ${ }^{\wedge} 2$} & $0.0003^{*}$ & $0.0003^{*}$ & $0.0003 *$ & $0.0003^{*}$ \\
\hline & $(0.0001)$ & $(0.0001)$ & $(0.0001)$ & $(0.0001)$ \\
\hline
\end{tabular}

Note: $1 . \mathrm{N}$ stands for the number of observations. uc, ustr and ulow represent respectively the current unemployment rate, unemployment rate at start of the job and the minimum unemployment rate since start of each job. immst is an indicator for immigrant status.

2. Standard errors are in parentheses. The dependent variable is the log of the real composite hourly wage. In addition to the regressors defined in Table 5.4, interactions of immigrant status with job tenure (jobyr) are included to capture immigrant-native differences in wage returns to tenure variables. $3 . *=5 \%$. 
Again, we go further in our analysis of finding the gender sensitivity of immigrant-native wage differentials to job tenure within an implicit contract setting. In Columns 1 to 4 of Table 5.7, we present estimates of the contract variables and immigrant interaction terms derived from models inclusive of tenure and interaction controls for the male sample. Again, immigrant men are found to be more negatively impacted by the past labour market conditions compared to native-born men. For example, the coefficient on the interaction of the initial unemployment rate and the immigrant indicator for the male sample is -0.0471 indicating that the immigrant-native wage gap is as large as 4.71 percent in responding to a one percent increase in the initial labour market measure. Labour market conditions at the time of hiring have a significant scarring effect on immigrants' current wages. In contrast, the immigrant-native wage inequality to past macroeconomic conditions for the female sample is not as severe as for the male sample. It is also notable that immigrant men earn lower wage returns to job tenure than native-born men, while the immigrant-native wage gap is barely noticeable for female samples. Evidence suggests that the wage gap stemmed from ten years of job tenure is approximately 10 percent between immigrant men and native-born workers. 


\section{Table 5.7}

Immigrant-Native Wage Differentials to Job Tenure by Gender

\begin{tabular}{|c|c|c|c|c|c|c|c|c|}
\hline & \multicolumn{4}{|c|}{ Male Sample $(\mathrm{N}=41,554)$} & \multicolumn{4}{|c|}{ Female Sample $(\mathrm{N}=39,371)$} \\
\hline & 1 & 2 & 3 & 4 & 5 & 6 & 7 & 8 \\
\hline \multirow[t]{2}{*}{ Current Unemployment Rate } & $0.0056^{*}$ & & & $0.0083^{*}$ & $0.0142 *$ & & & $0.0176^{*}$ \\
\hline & $(0.0016)$ & & & $(0.0016)$ & $(0.0016)$ & & & $(0.0017)$ \\
\hline \multirow[t]{2}{*}{ Unemployment Rate at Start of Job } & & -0.0055 & & 0.0136 & & -0.0067 & & 0.0017 \\
\hline & & $(0.0050)$ & & $(0.0078)$ & & $(0.0042)$ & & $(0.0064)$ \\
\hline \multirow[t]{2}{*}{ Minimum Rate Since Start of Job } & & & $-0.0145^{*}$ & $-0.0295 *$ & & & $-0.0118^{*}$ & $-0.0239 *$ \\
\hline & & & $(0.0046)$ & $(0.0072)$ & & & $(0.0045)$ & $(0.0069)$ \\
\hline \multirow[t]{2}{*}{ immst* uc } & $-0.0137^{*}$ & & & -0.0083 & $-0.0153 *$ & & & $-0.0157^{*}$ \\
\hline & $(0.0050)$ & & & $(0.0048)$ & $(0.0055)$ & & & $(0.0055)$ \\
\hline \multirow[t]{2}{*}{ immst * ustr } & & $-0.0471^{*}$ & & -0.0302 & & -0.0105 & & -0.0047 \\
\hline & & $(0.0186)$ & & $(0.0248)$ & & $(0.0123)$ & & $(0.0192)$ \\
\hline \multirow[t]{2}{*}{ immst * ulow } & & & $-0.0438^{*}$ & -0.0179 & & & -0.0178 & -0.0116 \\
\hline & & & $(0.0159)$ & $(0.0210)$ & & & $(0.0155)$ & $(0.0239)$ \\
\hline \multirow[t]{2}{*}{ jobyr } & $0.0084^{*}$ & $0.0088^{*}$ & $0.0086^{*}$ & $0.0079 *$ & $0.0096^{*}$ & $0.0097^{*}$ & $0.0093^{*}$ & $0.0100^{*}$ \\
\hline & $(0.0010)$ & $(0.0011)$ & $(0.0010)$ & $(0.0011)$ & $(0.0010)$ & $(0.0011)$ & $(0.0010)$ & $(0.0011)$ \\
\hline \multirow[t]{2}{*}{ jobyr ${ }^{\wedge} 2$} & -0.0001 & $-0.0001^{*}$ & $-0.0001^{*}$ & -0.0001 & -0.0002 & $-0.0002^{*}$ & $-0.0002^{*}$ & -0.0002 \\
\hline & $(0.0000)$ & $(0.0000)$ & $(0.0000)$ & $(0.0000)$ & $(0.0000)$ & $(0.0000)$ & $(0.0000)$ & $(0.0000)$ \\
\hline \multirow[t]{2}{*}{ immst * jobyr } & $-0.0120^{*}$ & $-0.0091^{*}$ & $-0.0120^{*}$ & $-0.0103 *$ & -0.0019 & -0.0006 & -0.0013 & -0.0025 \\
\hline & $(0.0031)$ & $(0.0032)$ & $(0.0031)$ & $(0.0032)$ & $(0.0034)$ & $(0.0035)$ & $(0.0034)$ & $(0.0036)$ \\
\hline \multirow[t]{2}{*}{ immst * jobyr^2 } & $0.0005^{*}$ & $0.0005^{*}$ & $0.0006^{*}$ & $0.0005^{*}$ & 0.0001 & 0.0001 & 0.0001 & 0.0000 \\
\hline & $(0.0001)$ & $(0.0001)$ & $(0.0001)$ & $(0.0001)$ & $(0.0001)$ & $(0.0001)$ & $(0.0001)$ & $(0.0001)$ \\
\hline
\end{tabular}

Note: 1. $\mathrm{N}$ stands for the number of observations. uc, ustr and ulow represent respectively the current unemployment rate, unemployment rate at start of the job and the minimum unemployment rate since start of each job. immst is an indicator for immigrant status.

2. Standard errors are in parentheses. Variables are the same as shown in Table 5.6. 


\section{Conclusions}

Using the pooled panel of the Survey of Labour and Income Dynamics (SLID), we integrate the approach of Beaudry and DiNardo (1991) into the immigrant earnings literature by incorporating the three macroeconomic contract variables into the immigrant wage model and test whether immigrants' wage dynamics are more consistent with an implicit contract model or a spot market model. The wage gap between genders and between immigrants and native-born workers in responding to economic fluctuations is also examined.

The main contribution of this chapter is that it fills the void of implicit contract wage studies for the case of immigrants, as well as how the economic productivity of immigrants would differ from their native-born counterparts in facing labour market fluctuations. Consistent with most previous findings which favour implicit contract models with costless mobility, immigrant wages respond relatively more to the minimum unemployment rates than to contemporaneous and initial labour market conditions, indicating the implicit contracting view with costless mobility dominates the spot market view and the implicit contracting view with costly mobility. Tests for gender differences reveal that the labour market effects due to macroeconomic fluctuations do differ across genders. Female immigrants are found to be less sensitive to labour market conditions than male immigrants. Further extensions have been made to test differences in the immigrant wage response to macroeconomic cycles compared to native-born persons. Evidence suggests a wage discrepancy between immigrants and native-born workers in response to labour market fluctuations. For male immigrants, a strong effect is found in terms of past labour market conditions. However, it is unclear whether it is the 
macroeconomic conditions at the start of the job or the best macroeconomic conditions since the start of the job that are most important. Consequently, while there is overall support for an implicit contract view of the labour market, for immigrant men, it is unclear whether it is a model with costless mobility or a model with costly mobility that best fits the movements in the data.

The negative coefficient estimates of job tenure interaction terms indicate that male immigrants earn a lower return to tenure than native-born men. These findings lead to important policy implications in that immigration policy involves identifying problems facing immigrants, and making adjustment according to immigrant performance during business cycles. 


\section{Chapter 6 \\ Immigrant Wages: Macroeconomic Conditions \\ and Job Tenure}

In this chapter, we go further to examine how immigrants differ from the native born in terms of wage performance both at the time of immigration and after immigration. We mainly focus on three immigrant wage hypotheses concerning whether immigrants encounter an entry wage disadvantage in comparison to the native born, whether immigrant cohort quality declines, and whether immigrants experience wage assimilation over time since immigration. Controls for job tenure and macroeconomic conditions are included to test whether tenure and the business cyclical pattern account for any wage gap between immigrants and their native-born counterparts. Most importantly, we integrate macroeconomic contract variables into the immigrant wage assimilation literature. The novel approach enables us to examine the wage performance of immigrants within the context of the implicit contracts literature.

This chapter is organized as follows. Section 1 summarizes the sample statistics. In Section 2, the empirical results are interpreted and key findings are presented regarding three immigrant wage hypotheses. Issues examined in Sections 3, 4 and 5 include the role of tenure controls, age proxy versus actual work experience, an extension with gender differences and the introduction of macroeconomic controls. Section 6 focuses on results obtained from fixed effects estimation and the discussion of unobserved heterogeneity bias. In Section 7, the major findings in this chapter are summarized. 


\section{Sample statistics}

The SLID data provide detailed information on immigrant demographic characteristics. For this thesis chapter on immigrant wage hypotheses, we classify immigrants into nine cohorts based on year of arrival in Canada. They are defined in terms of the following arrival cohorts: $1960-64,1965-69,1970-74,1975-79,1980-84$, $1985-89,1990-94,1995-99$ and $2000-04 .^{30}$.Our sample conditions on individual respondents who are working.

Table 6.1 reports the sample means of selected variables. The sample size is balanced across genders. The summary statistics present evidence of differences in individual characteristics between immigrants and native-born persons, as well as between male and female respondents. In general, immigrants have relatively higher hourly wage rates than their native-born counterparts. They are approximately two to three years older, more likely to be married, much more likely to live in an urban area, have slightly higher education and labour market experience but lower job tenure in comparison to the native-born persons. There are notable gender differences as shown in the statistics. Compared to the male group, female workers have about four years less work experience, 1.7 years less job tenure and 25.41 percent lower composite hourly wage rates. Females are more likely to live in an urban area and have slightly higher education.

The average number of years of residence in Canada for immigrants in the SLID sample is above 21.1 years as illustrated in Table 6.1. The mean age of immigrants at arrival is reported in Table 6.2. Immigrants who arrived before the mid 1970 s are mainly youths in the SLID sample as opposed to the adult immigrants arriving afterwards. The

\footnotetext{
${ }^{30}$ We drop sample immigrants who arrived before 1960 because of the small sample size of this group.
} 
increasing average immigration age is mainly due to the age upper limit set in our research sample (64 of age). For an immigrant to be included in our sample, he/she must be young if he/she immigrated to Canada in the $1960 \mathrm{~s}$. Due to the relatively small number of observations of immigrants in our pooled SLID sample, we include all immigrants (whether they arrive as adults or arrive as children). Dropping from our sample immigrants who arrived at the age of 15 or younger does not affect results significantly. 





TABLE 6.2

Mean Age at Immigration

\begin{tabular}{cc}
\hline Cohort & Mean Age at Immigration \\
\hline Year 1960-64 & 11 \\
Year 1965-69 & 15 \\
Year 1970-74 & 18 \\
Year 1975-79 & 21 \\
Year 1980-84 & 24 \\
Year 1985-89 & 28 \\
Year 1990-94 & 30 \\
Year 1995-99 & 33 \\
Year 2000-04 & 34
\end{tabular}

Note: Nine cohorts in total are defined according to time of arrival.

\section{Immigrant wage disadvantage upon entry and the wage integration process}

Using the SLID data, we first estimated model 2.2.1 to generate estimates of the cohort effects and the assimilation effect. ${ }^{31}$ Regression results with and without tenure controls are presented separately below. Table 6.3 presents the coefficient estimates (and standard errors) for the nine cohort dummy variables and for the linear and quadratic years-since-immigration variables in the wage specifications without tenure controls. It is common for the age of the respondent to be used as a proxy for actual work experience in the estimation of the human capital wage model. However, one of the strengths of the SLID data is the fact that actual work experience is included so that we are able to investigate whether the results are sensitive to the use of actual work experience as

\footnotetext{
${ }^{31}$ Unless otherwise indicated, all the empirical results hereinafter are obtained from random effects estimations.
} 
opposed to using age as a proxy for work experience. ${ }^{32}$ In light of different specifications of labour market experience, the analysis of Column 1 uses actual work experience and the analysis of Column 2 employs the more conventional age proxy approach.

The following models estimate over the sample of immigrants and the native born. Recall that the default group in the model are native born individuals; therefore, the coefficient on each cohort dummy variable can be interpreted as the difference between the log wage of that cohort of immigrants immediately after arrival in Canada and the log wage of otherwise similar native-born individuals. With actual years of work experience included in the wage equation, regression results yield negative coefficient estimates for all nine cohort dummy variables. It is notable that the magnitude of the initial wage disadvantage faced by immigrants is much lower than those found in the earlier literature (Borjas, 1985, Baker and Benjamin, 1994, and McDonald and Worswick, 1998). The initial wage gap ranges from 6 percent to 12 percent for Canadian immigrants arriving between 1965 and 1979, as compared to 30 to 31 percent found in cohorts across 1966 to 1980 by McDonald and Worswick (1998) who use Canadian cross-sectional data and log of weekly earnings as the dependent variable rather the log hourly wage rate. Moreover, a picture of a declining tendency of cohort quality and a low speed of wage convergence is displayed despite a slight increase in the economic performance of the most recent cohort. For example, the entry wage of the 1960-64 cohort of immigrants is only 2.21 percent lower than that of native-born workers, while the wage disadvantage of the 199599 cohort of immigrants is 13.23 percent lower. Equivalently, the early $1960-64$ cohort

\footnotetext{
${ }^{32}$ We do not control for the dummy variable of the full/part time status. Therefore the sample includes both full-time and part-time workers.
} 
of immigrants has entry wages that are 11 percent higher than those of the 1995-99 cohort.

The coefficient estimates of "Years Since Immigration" variable and its squared form allow the wage difference between a particular immigrant arrival cohort and the native-born comparison group to change with the number of years of residence in Canada of the immigrants, ceteris paribus. The positive coefficient on the years-sinceimmigration variable and the negative coefficient on its square indicate a positive and concave relationship between the immigrant log wage and the time in Canada. The assimilation process captures a gradually decreasing wage gap between immigrants and native-born workers, as immigrants accumulate specific human capital with time in Canada. The results indicate a slow rate of convergence. For example, immigrants who arrived between 1970 and 1974 will eventually close the initial 6.35 percent wage gap relative to their native-born counterparts after approximately 15 years of residence in Canada. For immigrants who landed after 1974, the estimates present less evidence that the initial wage disadvantage will be eliminated quickly. 
TABLE 6.3

Coefficient Estimates of Immigrant Variables (without Tenure Controls): Men and Women

\begin{tabular}{lcc}
\hline & Actual Work & Age Proxy \\
Variable & 1 & 2 \\
\hline Year 1960-64 & $-0.0221^{*}$ & $-0.1580^{*}$ \\
Year 1965-69 & $(0.0018)$ & $(0.0019)$ \\
Year 1970-74 & $-0.0611^{*}$ & $-0.1782^{*}$ \\
Year 1975-79 & $(0.0016)$ & $(0.0016)$ \\
& $-0.0635^{*}$ & $-0.1720^{*}$ \\
Year 1980-84 & $(0.0015)$ & $(0.0015)$ \\
Year 1985-89 & $-0.1247^{*}$ & $-0.2371^{*}$ \\
Year 1990-94 & $(0.0015)$ & $(0.0015)$ \\
Year 1995-99 & $-0.1298^{*}$ & $-0.2423^{*}$ \\
Year 2000-04 & $(0.0014)$ & $(0.0014)$ \\
Years Since Immigration & $-0.1282^{*}$ & $-0.2395^{*}$ \\
Years Since Immigration ${ }^{2} / 100$ & $(0.0011)$ & $(0.0012)$ \\
No. of Observations & $-0.1374^{*}$ & $-0.2604^{*}$ \\
\hline & $(0.0011)$ & $(0.0011)$ \\
& $-0.1323^{*}$ & $-0.2675^{*}$ \\
& $(0.0011)$ & $(0.0011)$ \\
& $-0.0806^{*}$ & $-0.2293^{*}$ \\
& $(0.0019)$ & $(0.0019)$ \\
& $0.0062^{*}$ & $0.0100^{*}$ \\
& $(0.0001)$ & $(0.0001)$ \\
& $-0.0125^{*}$ & $\left(0.00119^{*}\right.$ \\
& $(0.0002)$ & 96,927 \\
\hline
\end{tabular}

Note: $1 . \mathrm{N}$ stands for the number of observations.

2. Standard errors are in parentheses. The dependent variable is the log of the real composite hourly wage. The independent variables include nine cohorts, years since immigration and years since immigration squared, years of schooling, years of experience / age proxy, years of experience squared / age squared, and controls for industry, marital status, province of residence and urban/rural status. See Appendix A for the variable definitions.

3. $*=5 \%$. 
Next, the model is re-estimated with an age and age-squared term included in place of the linear/quadratic specification in actual work experience. The new estimates of cohort and assimilation variables are reported in Column 2. Many wage studies select age or potential work experience as a proxy for actual work experience to capture the wage return to labour market experience, in situations where data on actual work experience is not available (for example, Chiswick, 1978, and McDonald and Worswick, 1998). It is argued that applying proxies for human capital in immigrant wage studies may bias the true entry effect and the catching-up speed (Hum and Simpson, 2004). In addition, it is worth noting the problems may arise from using the age proxy. Immigrants who arrive at a more mature age will mostly likely need to go through a foreign credential recognition process. They encounter difficulty finding jobs. Some of them drop out of the labour market and go back to school. Therefore, labour market inactivity and disruption may result from an adjustment to the new labour environment. Age may not be as appropriate of a variable as actual work experience to capture the true economic return when labour market interruptions exist. Logically, biases may arise from using age proxy to explain immigrants' entry and post-immigration performance. For example, if immigrants are more likely to experience spells out of employment than are the native born then the age variable will tend to overstate the true number of years of work experience for immigrants.

After replacing the work experience variables with the linear and quadratic form of the age proxy, the empirical evidence suggests that employing the age proxy increase both the wage gap at entry for each arrival cohort and also the magnitude of the assimilation effect. 
The initial wage gap is still estimated to be the smallest for the earliest cohort and exhibits deterioration through the second last cohort. However, the wage gap narrows slightly for the most recent cohort. While the cohort coefficients are larger in absolute value in column 2 relative to column 1, the cross cohort decline is similar. In the model of column1, the 2000-04 cohort has a predicted $\log$ wage that is 5.8 percent lower than the predicted log wage of the 1960-64 cohort, while the equivalent difference in column 2 is 7.1 percent. In comparison to estimates obtained with actual work experience, a higher rate of assimilation is evident in the estimates of column 2. The point estimates of the two sets of cohort dummy variables representing immigrants' initial wage disadvantage are depicted in Figure 6.1. As shown in the figure, the two cohort lines exhibit a closely synchronized pattern. Earlier cohorts in both series display better wage outcomes than do recent ones. The entry wage disparity is generally 11 to 14 percent larger in the wageage specification than in the wage-experience specification. 


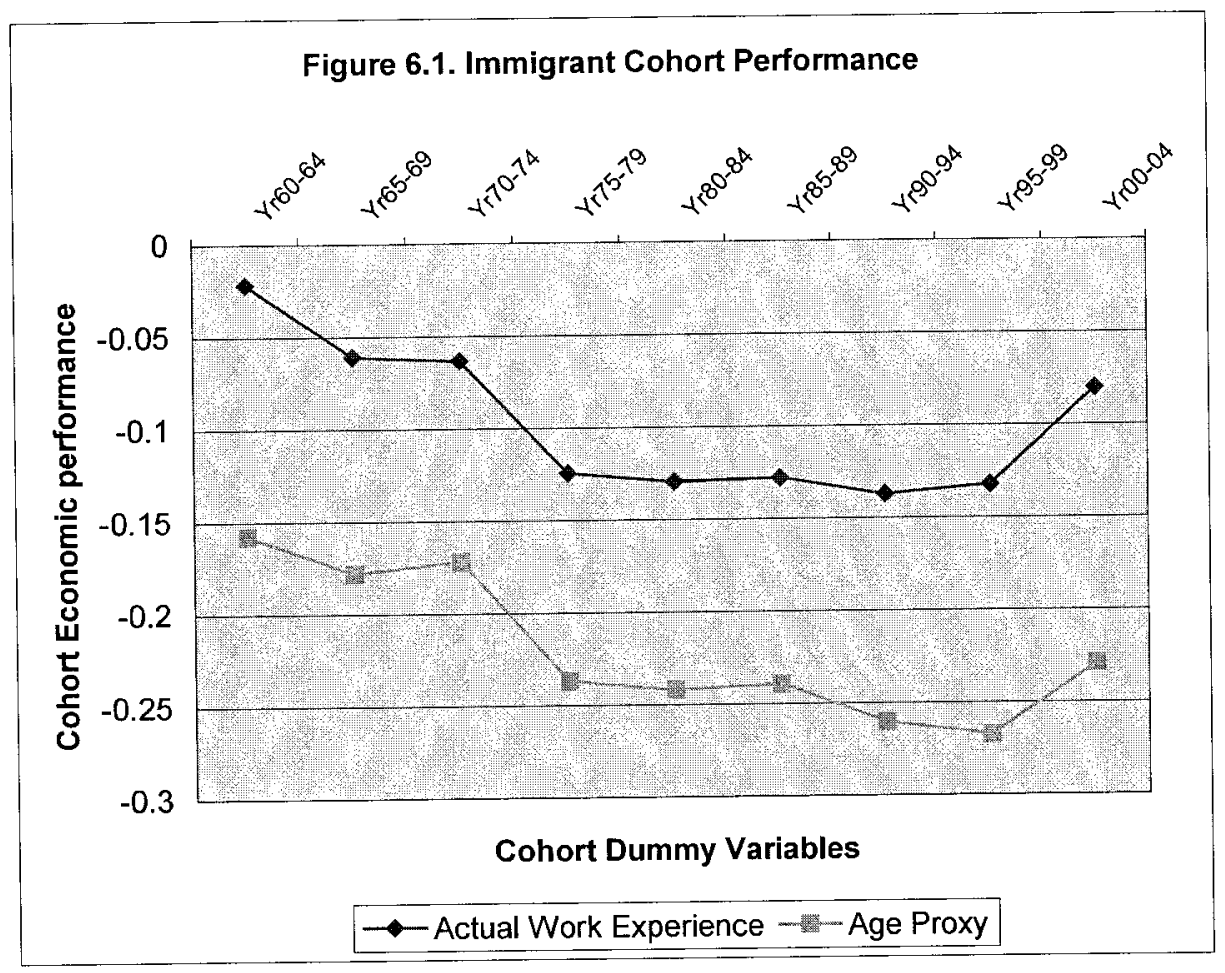

The coefficient estimate of the "Years Since Immigration" variable is larger at 0.01 in column 2 compared with 0.0062 in column 1 . Cohorts of immigrants who arrived before 1975 would spend 22 to 26 years to gradually catch up to the log wage of otherwise similar native-born workers, and even surpass the economic performance of the native-born. Those who immigrated after the mid-70s could gradually reduce the wage differences but never completely close the gap.

Under different measures of labour market experience, Figures 6.2 and 6.3 plot the immigrant/native-born wage differences for each arrival cohort according to how many years the immigrants have been in Canada. The two figures display divergent patterns in terms of the wage profiles of the cohort immigrants. With actual work 
experience included, the curves that capture the wage differentials between each cohort of immigrants and the comparable native born present hill-shaped tendencies, in contrast to the upward trend of the wage growth paths resulting from the age-wage estimations. For each cohort in both graphs, the series starts below zero indicating the initial wage gap between immigrants and native-born workers, followed by an increasing tendency along the growth paths to the peak, then a gradual decline happening at the middle stage of employment with the actual experience approach and at later years of employment with the age proxy. The 1960-64, 1965-69 and 1970-74 cohorts start and remain at higher points than the rest of the cohorts, representing better wage outcomes than those of earlier immigrants. The three cohorts show convergence tendency at around four to 15 years after immigration with actual work experience ( 21 to 25 years after immigration with the age proxy), and then continue to exceed the wage earnings of the native born until later years of employment or in the remaining years. For immigrants who arrived after the mid-70s, no catch-up is suggested despite the wage assimilation of the cohorts. For example, the 2000-04 cohort starts with a 22.93 percent initial wage gap in Figure 6.3, followed by an increasing tendency until reaching a 1.92 percent wage gap, and then the gap grows larger again in absolute value at higher YSM. Predicted wage differentials display no evidence of wage equality between the most recent immigrant cohorts and their comparables at the end, despite the fact that immigrants do improve their economic performance with time in the Canadian labour market. In summary, estimated models using age as a proxy for actual years of work experience overestimate the cohort effect as well as the assimilation effect. 


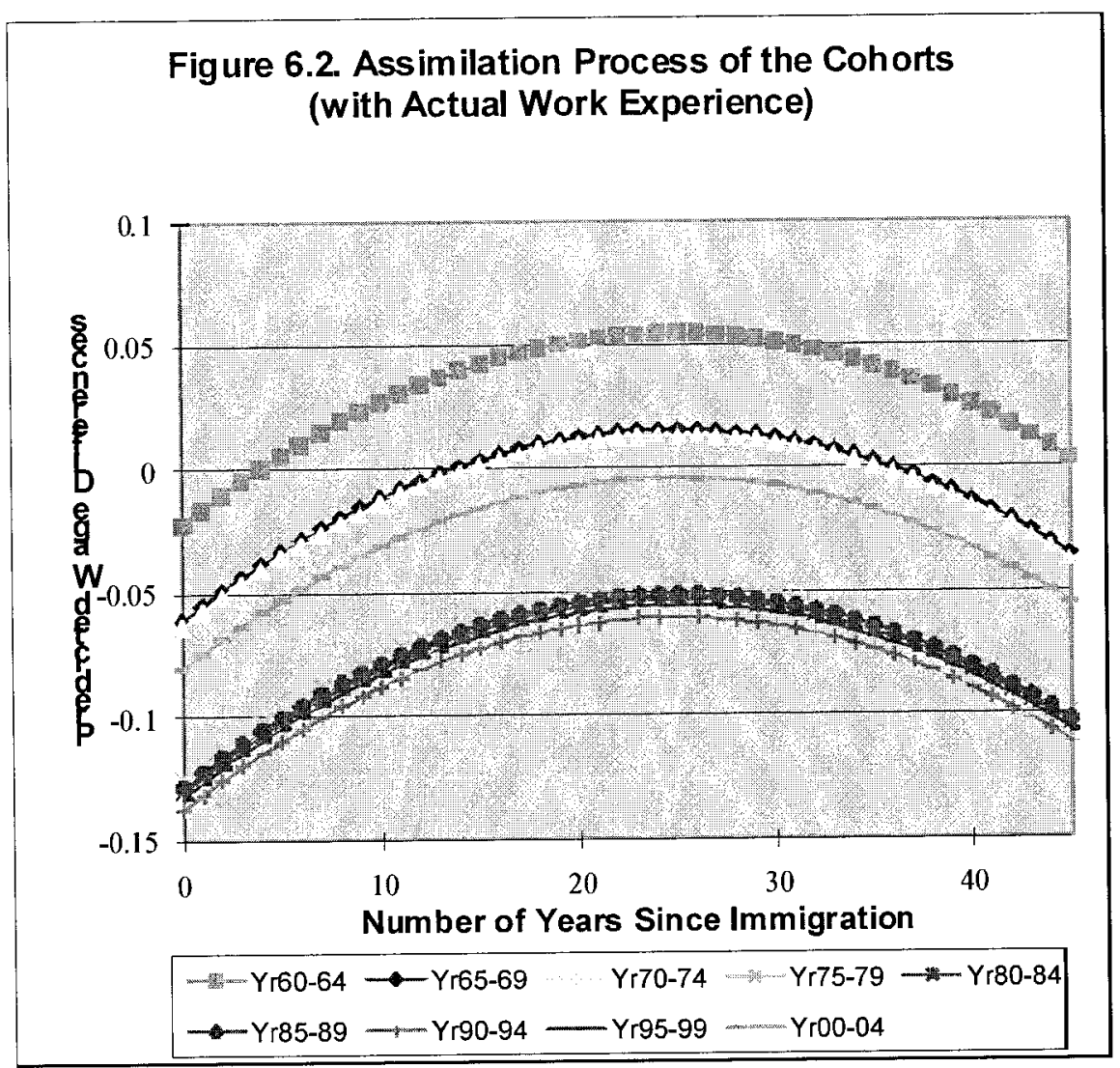

Note: Author's calculations based on estimates from Column 1 of Table 6.3. 


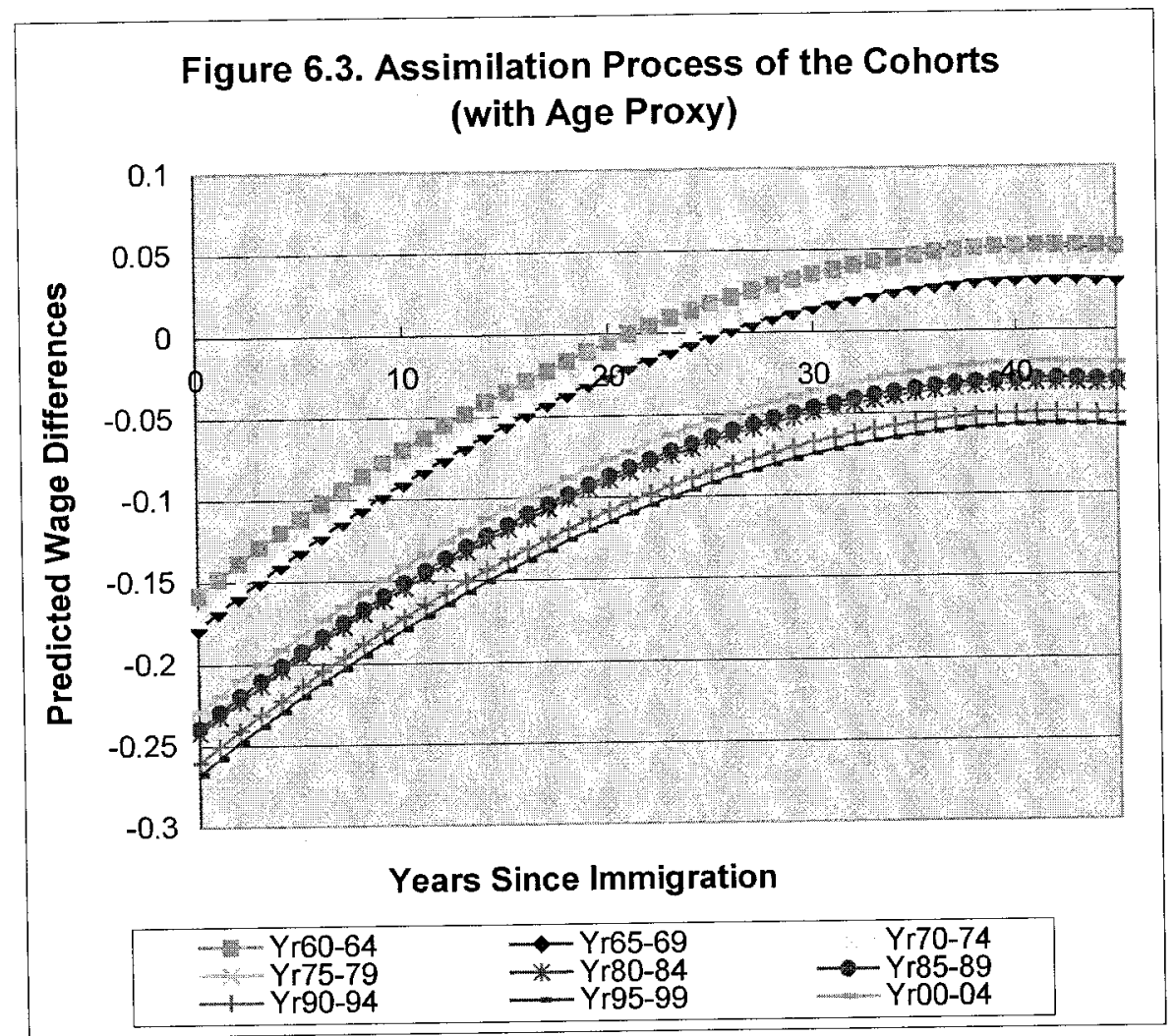

Note: Author's calculations based on estimates from Column 2 of Table 6.3.

\section{Tests for the sensitivity of cohort differences and wage growth to the inclusion of}

\section{tenure controls}

Next, the wage model is extended to include job tenure controls and the results are presented in Table 6.4. The linear and quadratic tenure variables are added as additional regressors to investigate whether cohort effects and the assimilation effect are sensitive to the inclusion of job tenure. Moreover, tenure variables are interacted with a foreign born indicator to allow for a differential impact of job tenure on wage dynamics. This could be caused by different rates of investment in firm specific human capital on the part of immigrant workers relative to native-born workers. 
Topel (1991) analyzes longitudinal data on wage-tenure profiles for men and found a substantial impact of job seniority on wages. According to his study, 10 years of job tenure leads to a 25 percent increase in wages. Juhn, Murphy and Pierce (1993) examine wage inequality for males between the years of 1963 and 1983. They find large wage rises for skilled workers and a moderate wage decline for unskilled workers with additional job tenure. Their study suggests that the rise in wage differentials is due to an increase in return to firm-specific skills rather than education and general labour market experience. Abraham and Farber (1987) consider implicit contracts with deferral of wage payment as incentives and argue that the wage-tenure profile would be upward sloping under the deferred wage contract. They find a small return to job seniority for both white collar and blue-collar workers.

One of the major issues in wage-tenure studies is in regards to the overestimation of the tenure effect on wages due to individual heterogeneity and job match heterogeneity. Jovanovic (1979) explains that heterogeneous job match quality would be detected with the passage of time. He derives the probability density function of turnover conditional on the length of job tenure. The equilibrium wage contract suggests that individuals with a better job match and higher productivity have a smaller turnover rate implying longer tenure and higher wages on average.

To correct for heterogeneity bias, Altonji and Shakotko (1987) adopt an instrumental variable approach in which deviation of tenure from its job match mean is used as an instrument for tenure. They find that individual heterogeneity and job match heterogeneity accounts for a significant part of wage growth through job duration. It is general labour market experience other than job tenure that contributes to most wage 
growth. Altonji and Williams (2005) reassess the wage-tenure relationship with more recent data and find that the net return to 10 years of tenure is 11 percent.

So far, economists have treated job tenure as firm specific in wage-tenure studies. All of the conclusions and empirical results are based on this double classification of labour market experience, i.e., the firm tenure and the general labour market experience. Parent (2000) casts doubts on this decomposition and argues whether it is appropriate to ignore the industry tenure accumulation and only focus on a worker's job tenure with the current employer and the general work experience in the wage-tenure profile. Apart from previous studies, he suggests that industry tenure should also be controlled for to analyze the partial effect of job tenure on wages. After introducing industry specific capital into the wage model, the job tenure effect on wages dropped dramatically. Hence, Parent (2000) concludes that it is industry-specific capital rather than firm specific capital that affects wages. ${ }^{33}$

A novel approach is adopted by McDonald and Worswick (1998) in that they allow for job tenure effects within an immigrant wage framework. They find that 10 years of job tenure leads to a 23.1 percent wage increase. They also present evidence of a reduction in the magnitude of entry wage differences and a reduction in the speed of the assimilation effect once tenure controls are included. Without tenure controls, the coefficients of the arrival cohorts range from -0.4468 to -0.2963 in the full sample. After controlling for the tenure variables, the cohort coefficients drop to between -0.3952 and -0.2345 . The YSM coefficient also falls from 0.0117 to 0.0084 . Therefore, ignoring

\footnotetext{
${ }^{33}$ We explored the possibility of employing Parent's approach to test the wage variations to different classifications of human capital. The short panel nature of the SLID data did not allow for enough detail on the industry-work history of the respondents to enable us to estimate the Parent specification with confidence.
} 
controls for tenure variables in the wage specification leads to biased estimates of those effects.

TABLE 6.4

Coefficient Estimates of Immigrant Variables (with Tenure Controls): Men and Women

\begin{tabular}{lcc|cc}
\hline Variable & \multicolumn{2}{c|}{ Actual Work Exnerience } & \multicolumn{2}{c}{ Age Proxv } \\
\cline { 2 - 5 } Year 1960-64 & 1 & 2 & 3 & 4 \\
\cline { 2 - 5 } & $-0.0040^{*}$ & -0.0001 & $-0.1342^{*}$ & $-0.1308^{*}$ \\
Year 1965-69 & $(0.0018)$ & $(0.0018)$ & $(0.0018)$ & $(0.0018)$ \\
& $-0.0357^{*}$ & $-0.0348^{*}$ & $-0.1459^{*}$ & $-0.1451^{*}$ \\
Year 1970-74 & $(0.0015)$ & $(0.0015)$ & $(0.0015)$ & $(0.0015)$ \\
& $-0.0395^{*}$ & $-0.0386^{*}$ & $-0.1388^{*}$ & $-0.1380^{*}$ \\
Year 1975-79 & $(0.0015)$ & $(0.0015)$ & $(0.0015)$ & $(0.0015)$ \\
& $-0.0932^{*}$ & $-0.0935^{*}$ & $-0.1883^{*}$ & $-0.1888^{*}$ \\
Year 1980-84 & $(0.0014)$ & $(0.0014)$ & $(0.0014)$ & $(0.0014)$ \\
& $-0.1088^{*}$ & $-0.1009^{*}$ & $-0.2055^{*}$ & $-0.1980^{*}$ \\
Year 1985-89 & $(0.0014)$ & $(0.0014)$ & $(0.0014)$ & $(0.0014)$ \\
& $-0.1021^{*}$ & $-0.0932^{*}$ & $-0.1899^{*}$ & $-0.1814^{*}$ \\
Year 1990-94 & $(0.0011)$ & $(0.0011)$ & $(0.0011)$ & $(0.0011)$ \\
& $-0.1125^{*}$ & $-0.1027^{*}$ & $-0.2071^{*}$ & $-0.1977^{*}$ \\
Year 1995-99 & $(0.0010)$ & $(0.0010)$ & $(0.0011)$ & $(0.0011)$ \\
& $-0.0961^{*}$ & $-0.0883^{*}$ & $-0.1962^{*}$ & $-0.1885^{*}$ \\
Year 2000-04 & $(0.0011)$ & $(0.0011)$ & $(0.0011)$ & $(0.0011)$ \\
& $-0.0488^{*}$ & $-0.0382^{*}$ & $-0.1592^{*}$ & $-0.1489^{*}$ \\
Years Since Immigration & $(0.0018)$ & $(0.0018)$ & $(0.0018)$ & $(0.0018)$ \\
& $0.0044^{*}$ & $0.0073^{*}$ & $0.0082^{*}$ & $0.0110^{*}$ \\
Years Since Immigration ${ }^{2} / 100$ & $(0.0001)$ & $(0.0001)$ & $(0.0001)$ & $(0.0001)$ \\
& $-0.0098^{*}$ & $-0.0139^{*}$ & $-0.0095^{*}$ & $-0.0133^{*}$ \\
Job Tenure & $(0.0002)$ & $(0.0002)$ & $(0.0002)$ & $(0.0002)$ \\
& $0.0135^{*}$ & $0.0142^{*}$ & $0.0139^{*}$ & $0.0145^{*}$ \\
Job Tenure & $(0.0000)$ & $(0.0000)$ & $(0.0000)$ & $(0.0000)$ \\
Tenure * immst & $-0.0002^{*}$ & $-0.0002^{*}$ & $-0.0001^{*}$ & $-0.0001^{*}$ \\
Tenure ${ }^{2}$ immst & $(0.0000)$ & $(0.0000)$ & $(0.0000)$ & $(0.0000)$ \\
No. of Observations & & $-0.0080^{*}$ & & $-0.0076^{*}$ \\
& & $(0.0001)$ & & $(0.0001)$ \\
& & $0.0002^{*}$ & & $0.0002^{*}$ \\
& & $(0.0000)$ & & $(0.0000)$ \\
& & 96.927 & 96.927 \\
\hline
\end{tabular}

Note: 1 . $\mathrm{N}$ stands for the number of observations. immst is the foreign born indicator.

2. Standard errors are in parentheses. In addition to the regressors defined in Table 6.3, tenure, tenure

squared and interactions of a foreign-born indicator with tenure variables are included to capture tenure effect on wage returns.

$3{ }^{*}=5 \%$. 
To test for the sensitivity of the wage-tenure relationship, we estimated the extended model 2.2.2 and the results are reported in Table 6.4. Again, different specifications of labour market experience are employed and estimates of the coefficients on the cohort variables and the years-since-migration variables are presented. All groups of estimates display downward trends of cohort quality from early 60 s to mid 90 s with a slight bumping-up in the mid and late $80 \mathrm{~s}$, followed by an improving movement of the wages of immigrants across arrival cohorts until 2004. Similarly, the estimates under the wage-age equation specification have 9 to 13 percent larger magnitude in absolute values than in the wage-experience equation, implying an exaggerating impact on the estimated wage differentials faced by immigrants by replacing actual work experience with the age variables.

After including the tenure variables, the magnitude of the coefficient estimates of the cohort variation differs from what was found when the tenure controls were not included. In Figure 6.4 and Figure 6.5, we depict the comparison of the cohort coefficients between the wage specifications with and without job tenure controls, and under both the wage-experience specification and the wage-age specification. Both graphs reveal a declining cohort quality when tenure variables are excluded. Including additional controls for tenure leads to a reduction of 2.65 percent in the initial wage gap between immigrants and non-immigrants for the wage-experience model and 4.66 percent of the wage gap for the wage-age specification. Also, the differences are larger in magnitude for the recent 95-99 and 00-04 cohorts than for earlier cohorts.

The inclusion of tenure variables has led to a drop in the impact of the "Years Since Immigration" variable, in comparison with what was found in the wage specifications without tenure controls. The magnitude of the coefficient on the YSM squared estimate (in absolute value) has also decreased, indicating a slower decline in the rate of assimilation with more years in Canada. Altogether, a lower wage growth rate is seen in the wage-tenure model. Again, little evidence of integration is suggested for most cohorts except for earlier cohorts arriving before 1975 and the most recent cohort. In Figure 6.6, we plot the wage growth paths of the 1980-84 cohort from wage specifications with and without tenure controls. It is shown that the coefficient of the 1980-84 arrival cohort is reduced in magnitude when tenure variables are included. The rate of assimilation before controlling for tenure grows at a faster rate and surpasses the growth path of that obtained from the tenure-wage model. The crossover point happens after 16 years of residence since immigration, and the wage differences between 1980-84 
cohort of immigrants and their comparable native born continue to be larger in the wagetenure specification in the remaining years.



Note: Author's calculations based on estimates of the 1980-84 cohort from Column 1 of Table 6.3 and Table 6.4.

In addition, significant estimates of tenure variables and the tenure interaction terms are presented. ${ }^{34}$ The wage return to an additional year of staying at the current job is around 1.35 percent ( 1.39 percent under the wage-age specification), which is close to Altonji and Williams' (2005) finding and significantly lower than that of Topel (1991). The interaction of the tenure variable with an immigrant indicator variable allows for a

\footnotetext{
${ }^{34}$ Following McDonald and Worswick (1998), we also interact tenure with the cohort dummy variables. All cohorts of immigrants have shown lower returns to job tenure than the native-born. The magnitude of the coefficients ranges from -0.0545 to -0.0009 .
} 
test of whether there is a differential between immigrants and native-born workers in their wage returns to job tenure. The negative estimate of the linear interaction term represents approximately 0.8 percent lower wage return to job tenure for immigrants in comparison to their native-born counterparts ( 0.76 percent under the wage-age specification). Figure 6.7 displays the tenure-wage profiles for both the native-born workers and immigrant workers. The concave pattern of the tenure profile for the native born goes on top of the slightly convex tenure curve of immigrants most of the times. The net wage returns to tenure for immigrants will only be possible to exceed that of the native born after 41 years of tenure accumulation. The lower return to years of tenure faced by immigrants may, in part, explain the slow rate of assimilation found in this chapter.

In summary, the results suggest that tenure differences may be an important factor in explaining immigrant initial wage disadvantage relative to native-born persons.

Failing to control for tenure variables results in biased estimates of both cohort differences and the rate of assimilation. 


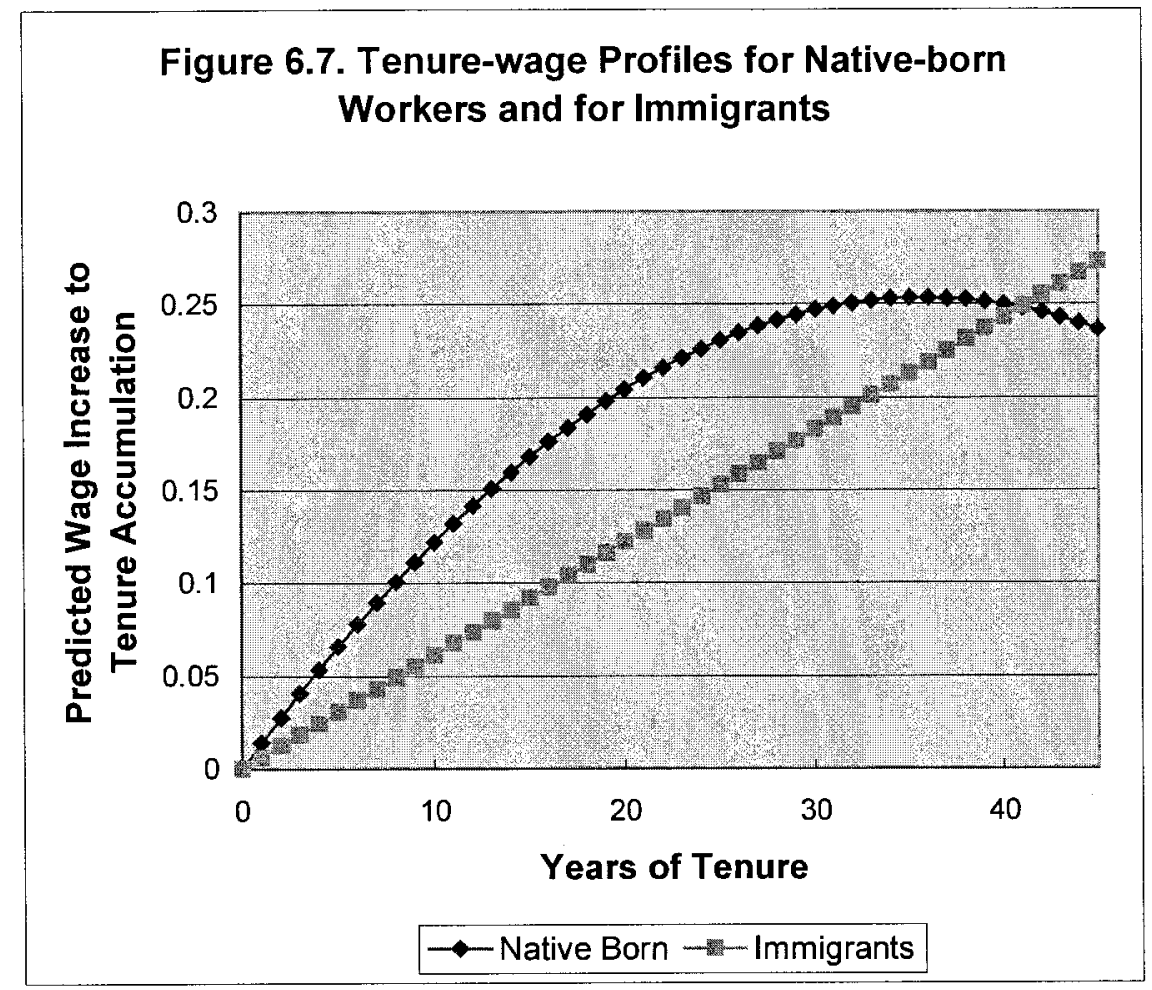

Note: Author's calculations based on estimates of the tenure variables from Columns 2 of Table 6.4 .

\section{Tests for differences by gender in entry wage differentials and wage assimilation}

Unlike most previous wage studies that have excluded women and extract modeling inferences solely from data on men, we next extend the model to include gender differences in terms of initial wage differences, cohort differences and rates of wage assimilation. In Table 6.5 , results are presented from separate wage regression estimation by gender. The major findings are as follows. First, the negative wage gap is smaller for female immigrants who arrived in the 1960s. Under wage models without tenure controls, the entry wage gap is 0.72 percent for the $1960-64$ cohort of female immigrants, and 2.65 percent for the 1965-69 female cohort. No evidence of wage disadvantage is found in the 1960s' cohorts of female immigrants under the wage-tenure 
specification in column 4. Second, female immigrants differ from male immigrants in their initial wages. The immigrant-native initial wage gap is much larger in absolute value for the male group than for the female group. The initial wage gap for all male immigrant cohorts is between 11.08 percent and 21.45 percent $(10.55-19.20$ percent under wage-tenure models), as opposed to $0.72-11.64$ percent for all female immigrants (-1.22-9.03 percent under wage-tenure models). Thus the wage differential at time of immigration is above 10 percent on average between male and female immigrants. Third, the rate of wage assimilation displays different tendencies across genders. Drawn from the wage models with and without tenure controls, Figures 6.8-6.11 plot the earnings convergence paths by gender. Although male immigrants are found to have lower cohort quality at the time of arrival than the female immigrants, they catch up along a much steeper curve in their wage profiles. Unlike a concave convergence curve shown by male immigrants along their wage growth paths, female immigrants have a relatively flat convex wage growth curve under the wage-tenure specification. As shown in Figure 6.8 and Figure 6.10 regarding the assimilation process, male immigrants who arrived between mid 1980s and late 1990s do not show catch-up effect of wages, while those earlier male cohorts seem to gradually integrate to the local market in about 12 to 25 years after immigration. For female immigrants, the only two cohorts that show tendencies of wage assimilation are the 1960-64 cohort and the 1965-69 cohort as shown in Figure 6.9 and Figure 6.11. Those who arrived after 1970 will never catch up to their native-born counterparts. 
TABLE 6.5

Coefficient Estimates of Immigrant Variables by Gender Using Actual Work Experience (with and without Tenure Controls)

\begin{tabular}{|c|c|c|c|c|}
\hline \multirow[b]{2}{*}{ Variable } & \multicolumn{2}{|c|}{ without Tenure } & \multicolumn{2}{|c|}{ with Tenure } \\
\hline & $\begin{array}{c}\text { Male } \\
1\end{array}$ & $\begin{array}{c}\text { Female } \\
2 \\
\end{array}$ & $\begin{array}{c}\text { Male } \\
3 \\
\end{array}$ & $\begin{array}{c}\text { Female } \\
4 \\
\end{array}$ \\
\hline Year 1960-64 & $\begin{array}{c}-0.1240^{*} \\
(0.0025)\end{array}$ & $\begin{array}{c}-0.0072^{*} \\
(0.0026)\end{array}$ & $\begin{array}{l}-0.1055^{*} \\
(0.0024)\end{array}$ & $\begin{array}{c}0.01220^{*} \\
(0.0026)\end{array}$ \\
\hline Year 1965-69 & $\begin{array}{c}-0.1767^{*} \\
(0.0021)\end{array}$ & $\begin{array}{c}-0.0265^{*} \\
(0.0023)\end{array}$ & $\begin{array}{c}-0.1551^{*} \\
(0.0020)\end{array}$ & $\begin{array}{c}0.0065^{*} \\
(0.0022)\end{array}$ \\
\hline Year 1970-74 & $\begin{array}{c}-0.1108^{*} \\
(0.0020)\end{array}$ & $\begin{array}{c}-0.0586^{*} \\
(0.0022)\end{array}$ & $\begin{array}{c}-0.0919^{*} \\
(0.0020)\end{array}$ & $\begin{array}{c}-0.0263^{*} \\
(0.0021)\end{array}$ \\
\hline Year 1975-79 & $\begin{array}{c}-0.1916^{*} \\
(0.0019)\end{array}$ & $\begin{array}{c}-0.0816^{*} \\
(0.0021)\end{array}$ & $\begin{array}{c}-0.1563^{*} \\
(0.0019)\end{array}$ & $\begin{array}{c}-0.0502^{*} \\
(0.0021)\end{array}$ \\
\hline Year 1980-84 & $\begin{array}{c}-0.2080^{*} \\
(0.0019)\end{array}$ & $\begin{array}{c}-0.0647^{*} \\
(0.0020)\end{array}$ & $\begin{array}{c}-0.1920^{*} \\
(0.0018)\end{array}$ & $\begin{array}{c}-0.0361^{*} \\
(0.0020)\end{array}$ \\
\hline Year 1985-89 & $\begin{array}{c}-0.2009^{*} \\
(0.0015)\end{array}$ & $\begin{array}{c}-0.0776^{*} \\
(0.0016)\end{array}$ & $\begin{array}{c}-0.1755^{*} \\
(0.0015)\end{array}$ & $\begin{array}{c}-0.0482 * \\
(0.0016)\end{array}$ \\
\hline Year 1990-94 & $\begin{array}{c}-0.1784^{*} \\
(0.0014)\end{array}$ & $\begin{array}{c}-0.1164^{*} \\
(0.0016)\end{array}$ & $\begin{array}{c}-0.1536^{*} \\
(0.0014)\end{array}$ & $\begin{array}{c}-0.0903^{*} \\
(0.0015)\end{array}$ \\
\hline Year 1995-99 & $\begin{array}{c}-0.2145^{*} \\
(0.0014)\end{array}$ & $\begin{array}{c}-0.0733^{*} \\
(0.0016)\end{array}$ & $\begin{array}{c}-0.1757^{*} \\
(0.0014)\end{array}$ & $\begin{array}{c}-0.0373^{*} \\
(0.0016)\end{array}$ \\
\hline Year 2000-04 & $\begin{array}{c}-0.1471 \\
(0.0023)\end{array}$ & $\begin{array}{c}-0.0694^{*} \\
(0.0030)\end{array}$ & $\begin{array}{c}-0.1085^{*} \\
(0.0022)\end{array}$ & $\begin{array}{c}-0.0493^{*} \\
(0.0029)\end{array}$ \\
\hline Years Since Immigration & $\begin{array}{c}0.0114^{*} \\
(0.0001)\end{array}$ & $\begin{array}{c}0.0011^{*} \\
(0.0001)\end{array}$ & $\begin{array}{c}0.0100^{*} \\
(0.0001)\end{array}$ & $\begin{array}{c}-0.0012 * \\
(0.0001)\end{array}$ \\
\hline Years Since Immigration $^{2} / 100$ & $\begin{array}{c}-0.0173^{*} \\
(0.0003)\end{array}$ & $\begin{array}{c}-0.0008 \\
(0.0003)\end{array}$ & $\begin{array}{c}-0.0153^{*} \\
(0.0003)\end{array}$ & $\begin{array}{c}0.0031^{*} \\
(0.0003)\end{array}$ \\
\hline Job Tenure & & & $\begin{array}{c}0.0120^{*} \\
(0.0000)\end{array}$ & $\begin{array}{c}0.0160^{*} \\
(0.0000)\end{array}$ \\
\hline Job Tenure ${ }^{2}$ & & & $\begin{array}{c}-0.0001 * \\
(0.0000)\end{array}$ & $\begin{array}{c}-0.0003^{*} \\
(0.0000)\end{array}$ \\
\hline
\end{tabular}

Note: 1. Standard errors are in parentheses. In addition to the regressors defined in Table 6.3 , tenure and tenure squared are included to deliver results shown in Columns 3 and 4.

2. $*=5 \%$. 

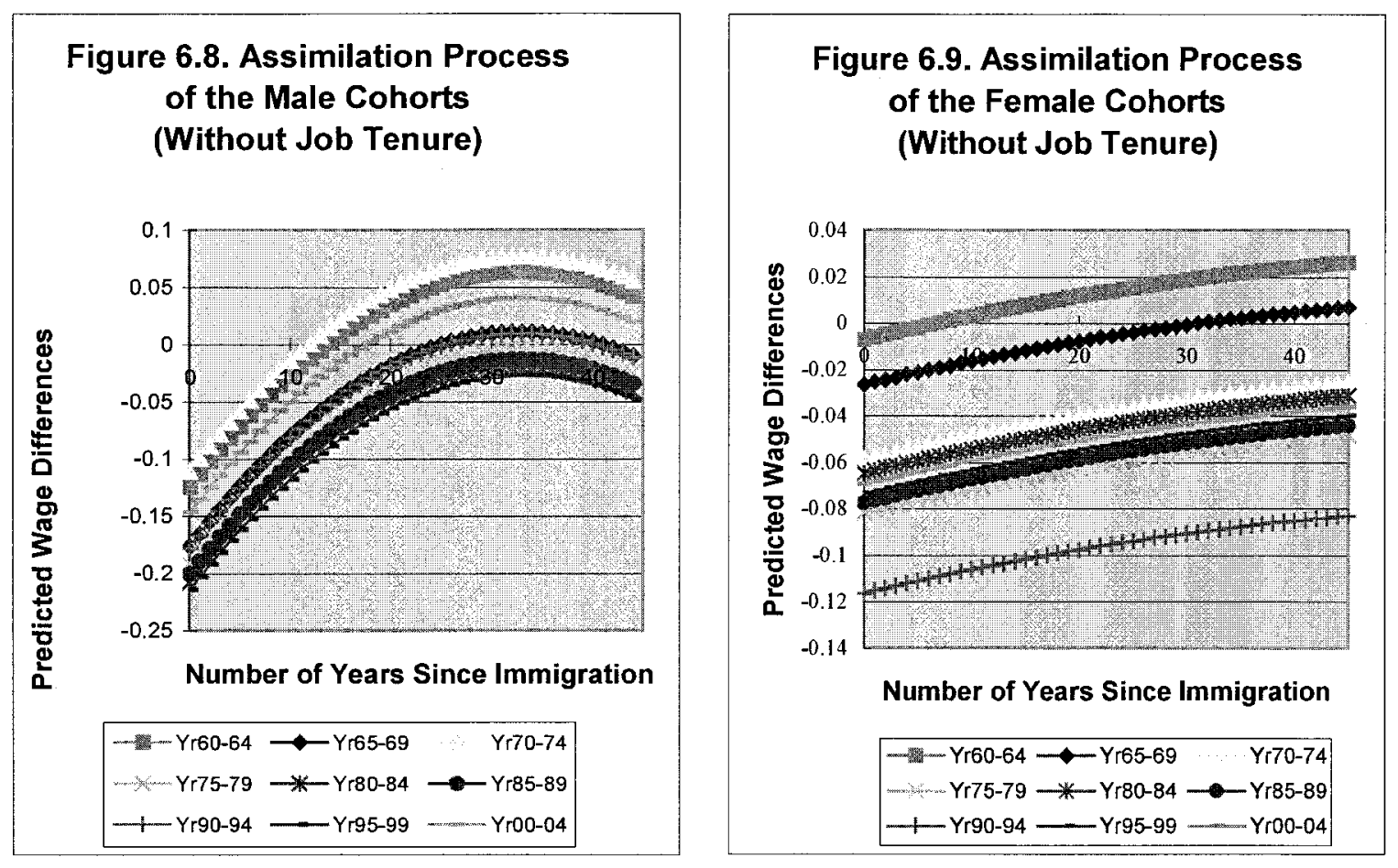

Note: Author's calculations based on estimates from Columns 1 and 2 of Table 6.5. 


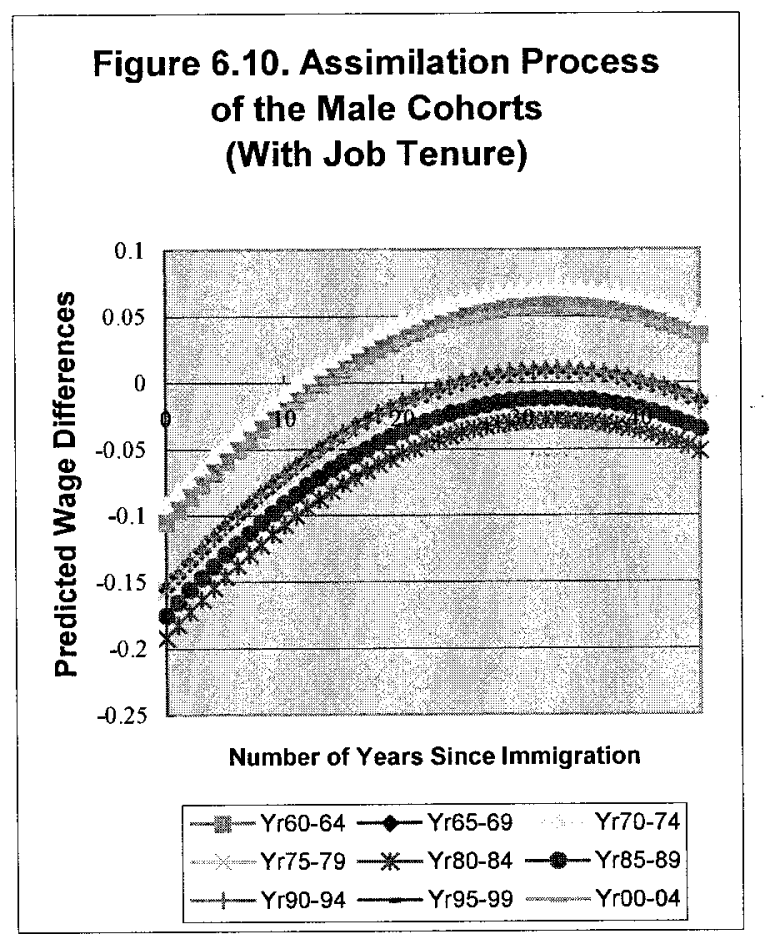

\section{Figure 6.11. Assimilation Process of the FemaleCohorts (With Job Tenure)}

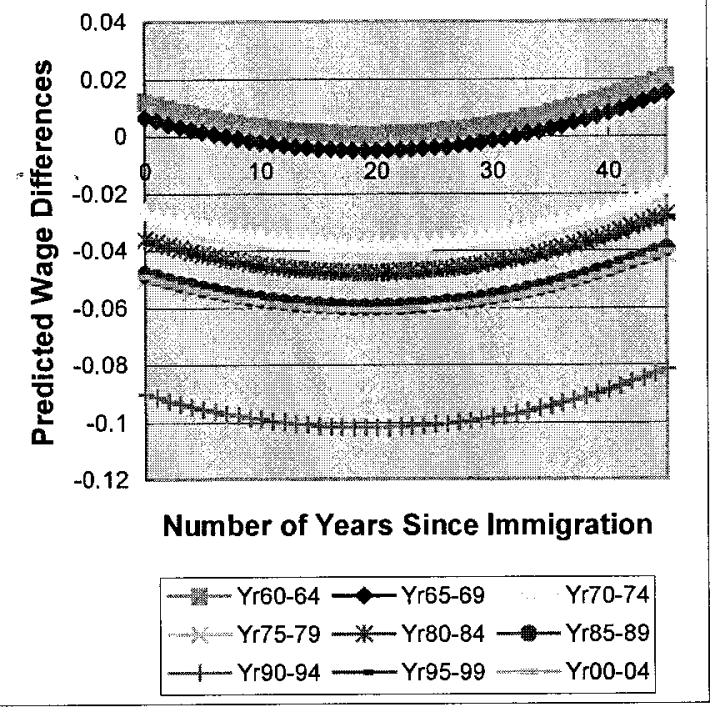

Note: Author's calculations based on estimates from Columns 3 and 4 of Table 6.5 .

Figure 6.12 and Figure 6.13 depict the cohort-specific immigrant/native-born wage differentials by gender based on regression models with and without tenure controls. The wage gap between female immigrants and their native-born counterparts is much smaller in magnitude than between male immigrants and their counterparts. With tenure variables in the model, female immigrants who arrived after 1969 earn a 2.63-9.03 percent lower wage rate than do non-immigrants at the time of immigration, as opposed to a $9.19-19.20$ percent wage gap faced by male immigrants. Moreover, cohort quality displays diversifying patterns by gender as shown in these two Figures. Male and female immigrants show distinct peak and trough of initial wage differentials. For female 
immigrants, the entry wage gap is the largest for the 1990-94 cohort and the smallest for the earliest 1960-64 cohort. Male immigrants who arrived in the early 1980s have experienced the worst wage outcomes in comparison to earlier and successive immigrants. The early 1970s' cohort of male immigrants had relatively better wage outcomes than the rest of the groups. The 1965-69 and the 1980-84 cohorts of immigrants faced the largest magnitude of gender differences.
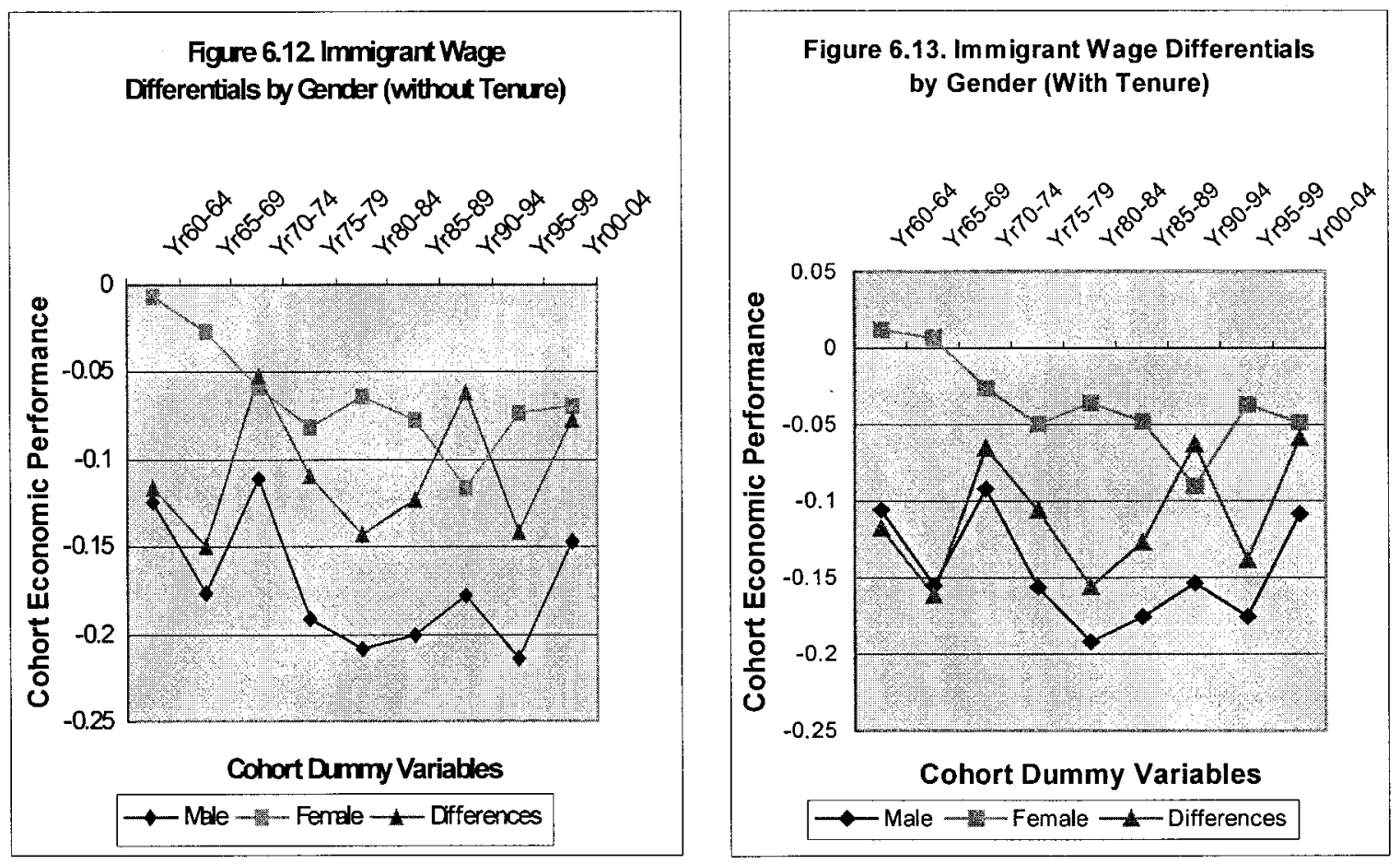

Note: Author's calculations based on estimates from Table 6.5 . 
One explanation for the time-varying characteristics of immigrant wage differentials between men and women may relate to business cycles. Canada suffered severe economic downturns during the 1980s and 1990s recessions. The declining labour market conditions may be reflected in poorer immigrant economic performance, indicating that immigrants are more vulnerable when facing business downturns than are native-born workers. More importantly, female immigrants may be less sensitive to labour market variations than male immigrants at the time of immigration. The sensitivity of labour market outcomes for immigrants to business cycle fluctuations will be discussed in the next section. Lastly, exclusion of tenure variables biases upwards the estimates representing immigrants' entry wage disparity and the speed of wage growth. It is also found that the net return to a single year of job tenure is 1.2 percent for male workers and is 0.4 percent lower than for female workers.

\section{Introducing initial and contemporaneous macroeconomic conditions into wage equations}

One of the main goals of this chapter is to gain an understanding of how macroeconomic conditions affect immigrant cohort performance and the speed of wage assimilation. Following McDonald and Worswick (1998) and Aydemir (2003), we introduce into model 2.2.3 an additional control for the aggregate annual unemployment rate at the time of immigration and also the contemporaneous unemployment rate so as to capture the macroeconomic impact on immigrants' wage growth paths. The history of Canadian unemployment rates between 1960 and 2006 is illustrated in Figure 6.14. Early years represent the after-war boom period. The Canadian economy expanded immensely 
during that period of time and unemployment remained low. Recessions in the early $1980 \mathrm{~s}$ and 1990s are reflected in higher unemployment rates with two peaks associated with the economic crises. Since the mid 1990s, the Canadian economy has steadily recovered despite occasional falls.

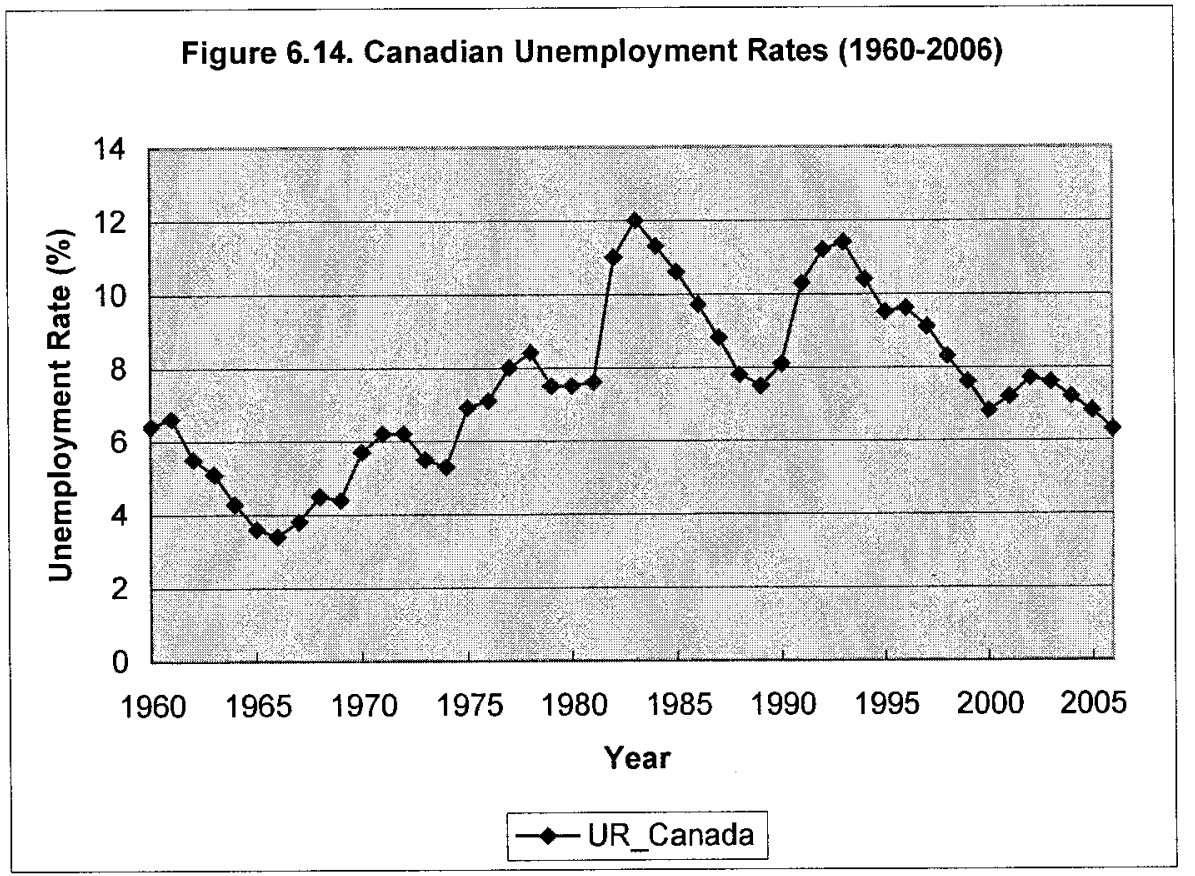

Note: The Canadian aggregate annual unemployment rate of Statistics Canada is employed.

The wage regressions are estimated with and without job tenure controls in both wage-experience and wage-age settings separately in order to make corresponding comparisons with earlier estimations that have excluded macroeconomic variables. Table 6.6 reports the regression results from model 2.2.3 reflecting the impact of business cycles on wage differentials between immigrants and non-immigrants. First, results from 
all models indicate a declining wage performance across immigrant arrival cohort quality for immigrants arriving before 2000 . Those who came afterwards exhibit a slightly improved performance compared to the 1980 s and 1990 s cohorts. The absolute magnitude of the cohort estimates is the greatest for the early 1990 s cohort in most estimations. After controlling for both labour market conditions and tenure variables, the magnitude of the coefficients drops. It is noticeable that both coefficient estimates of the macroeconomic variables turn out to be positive albeit with a very small magnitude, which seems to indicate little evidence of a scarring effect of past labour market conditions nor any adverse impact of the current macroeconomic conditions on current wages. Compared to our earlier findings from models without macroeconomic controls as shown in Table 6.3 and Table 6.4 , the cohort quality worsens after including controls for the current unemployment rate and the unemployment rate at the time of arrival. Therefore, excluding macroeconomic measures results in their impact falling into the cohort effects.

Moreover, although the trend that captures immigrant's entry economic performance has not been changed, the average entry effect is amplified by 5.33 percent after adding macroeconomic measures under the wage-experience-tenure specification. Immigrant rate of assimilation profile is unchanged compared with earlier estimates. No evidence suggests that immigrants arriving since the late 1970 s will eventually close the wage gap and assimilate to the local labour market.

Again, the sensitivity of the immigrant entry effect and the rate of assimilation to the additional controls for job tenure is witnessed. Comparing the two sets of estimates under the experience model as well as the age model, it is evident that the magnitude of 
both the initial immigrant-native wage differential and the rate of convergence is smaller in the wage-tenure specifications. Adding tenure variables results in an average reduction of 2.08 percent in the entry wage gap between immigrants and the native born for the experience model (3.56 percent for the wage-age specification). The decline in the YSM coefficient suggests that immigrant wages grow at a lower speed when allowing for the tenure effect. The role of job tenure played in the wage-tenure relationship reveals a 13.5 percent wage return to 10 years of tenure. 
TABLE 6.6

Coefficients from Immigrant Variables when Macroeconomic Controls Are Included in the Model (with and without Tenure Controls): Men and Women

\begin{tabular}{|c|c|c|c|c|}
\hline \multirow[b]{2}{*}{ Variable } & \multicolumn{2}{|c|}{ without Tenure Controls } & \multicolumn{2}{|c|}{ with Tenure Controls } \\
\hline & $\begin{array}{c}\text { Actual Work } \\
\text { Experience } \\
1 \\
\end{array}$ & $\begin{array}{c}\text { Age Proxy } \\
2 \\
\end{array}$ & $\begin{array}{c}\text { Actual Work } \\
\text { Experience } \\
3 \\
\end{array}$ & $\begin{array}{c}\text { Age Proxy } \\
4 \\
\end{array}$ \\
\hline Year 1960-64 & $\begin{array}{l}-0.0725^{*} \\
(0.0024)\end{array}$ & $\begin{array}{c}-0.1793^{*} \\
(0.0024)\end{array}$ & $\begin{array}{c}-0.0628^{*} \\
(0.0023)\end{array}$ & $\begin{array}{l}-0.1666^{*} \\
(0.0023)\end{array}$ \\
\hline Year 1965-69 & $\begin{array}{c}-0.1016^{*} \\
(0.0019)\end{array}$ & $\begin{array}{c}-0.1958^{*} \\
(0.0019)\end{array}$ & $\begin{array}{c}-0.0832 * \\
(0.0019)\end{array}$ & $\begin{array}{l}-0.1723^{*} \\
(0.0019)\end{array}$ \\
\hline Year 1970-74 & $\begin{array}{c}-0.1095^{*} \\
(0.0021)\end{array}$ & $\begin{array}{c}-0.1905^{*} \\
(0.0022)\end{array}$ & $\begin{array}{c}-0.0923 * \\
(0.0021)\end{array}$ & $\begin{array}{l}-0.1676^{*} \\
(0.0021)\end{array}$ \\
\hline Year 1975-79 & $\begin{array}{c}-0.1764^{*} \\
(0.0025)\end{array}$ & $\begin{array}{c}-0.2567^{*} \\
(0.0025)\end{array}$ & $\begin{array}{c}-0.1516^{*} \\
(0.0024)\end{array}$ & $\begin{array}{l}-0.2197^{*} \\
(0.0024)\end{array}$ \\
\hline Year 1980-84 & $\begin{array}{c}-0.1871^{*} \\
(0.0028)\end{array}$ & $\begin{array}{c}-0.2627^{*} \\
(0.0029)\end{array}$ & $\begin{array}{c}-0.1726^{*} \\
(0.0028)\end{array}$ & $\begin{array}{c}-0.2392^{*} \\
(0.0028)\end{array}$ \\
\hline Year 1985-89 & $\begin{array}{c}-0.1779^{*} \\
(0.0026)\end{array}$ & $\begin{array}{c}-0.2568^{*} \\
(0.0026)\end{array}$ & $\begin{array}{c}-0.1570^{*} \\
(0.0025)\end{array}$ & $\begin{array}{l}-0.2187^{*} \\
(0.0025)\end{array}$ \\
\hline Year 1990-94 & $\begin{array}{c}-0.1913^{*} \\
(0.0029)\end{array}$ & $\begin{array}{c}-0.2783^{*} \\
(0.0030)\end{array}$ & $\begin{array}{c}-0.1714^{*} \\
(0.0028)\end{array}$ & $\begin{array}{c}-0.2377^{*} \\
(0.0028)\end{array}$ \\
\hline Year 1995-99 & $\begin{array}{c}-0.1777^{*} \\
(0.0027)\end{array}$ & $\begin{array}{l}-0.2818^{*} \\
(0.0028)\end{array}$ & $\begin{array}{c}-0.1453^{*} \\
(0.0026)\end{array}$ & $\begin{array}{c}-0.2216^{*} \\
(0.0026)\end{array}$ \\
\hline Year 2000-04 & $\begin{array}{c}-0.1139^{*} \\
(0.0027)\end{array}$ & $\begin{array}{c}-0.2396^{*} \\
(0.0027)\end{array}$ & $\begin{array}{c}-0.0845^{*} \\
(0.0026)\end{array}$ & $\begin{array}{c}-0.1777^{*} \\
(0.0026)\end{array}$ \\
\hline Years Since Immigration & $\begin{array}{c}0.0067^{*} \\
(0.0001)\end{array}$ & $\begin{array}{c}0.0103^{*} \\
(0.0001)\end{array}$ & $\begin{array}{l}0.0052^{*} \\
(0.0001)\end{array}$ & $\begin{array}{c}0.0087^{*} \\
(0.0001)\end{array}$ \\
\hline Years Since Immigration ${ }^{2} / 100$ & $\begin{array}{l}-0.0126^{*} \\
(0.0002)\end{array}$ & $\begin{array}{l}-0.0120^{*} \\
(0.0002)\end{array}$ & $\begin{array}{l}-0.0099 * \\
(0.0002)\end{array}$ & $\begin{array}{c}-0.0095^{*} \\
(0.0002)\end{array}$ \\
\hline uc & $\begin{array}{l}0.0032 * \\
(0.0000)\end{array}$ & $\begin{array}{c}0.0019^{*} \\
(0.0000)\end{array}$ & $\begin{array}{c}0.0039^{*} \\
(0.0000)\end{array}$ & $\begin{array}{c}0.0025^{*} \\
(0.0000)\end{array}$ \\
\hline ue & $\begin{array}{l}0.0051^{*} \\
(0.0003)\end{array}$ & $\begin{array}{l}0.0016^{*} \\
(0.0003)\end{array}$ & $\begin{array}{c}0.0055^{*} \\
(0.0003)\end{array}$ & $\begin{array}{l}0.0028^{*} \\
(0.0003)\end{array}$ \\
\hline Job Tenure & & & $\begin{array}{l}0.0135^{*} \\
(0.0000)\end{array}$ & \\
\hline Job Tenure ${ }^{2}$ & & & $\begin{array}{l}-0.0002 * \\
(0.0000)\end{array}$ & \\
\hline
\end{tabular}

Note: 1. uc and ue stand for the current unemployment rate and the unemployment rate at the time of immigration, respectively.

2. Standard errors are in parentheses. In addition to the regressors defined in Table 6.3 , tenure, tenure squared, labour market conditions are included. (Tenure variables are not included in Columns 1 and 2 ). 3. $*=5 \%$. 
An average 2.08 percent of the immigrant initial wage disadvantage to nativeborn persons can be explained by job tenure. Employing the wage-age profile again biases up immigrants' initial wage differentials relative to non-immigrants relative to the case of controlling for actual work experience.

Surprisingly, in contrast with previous findings where macroeconomic conditions have a negative impact on immigrant current wage performance (Chiswick, Cohen and Zach, 1997, McDonald and Worswick, 1998, and Aydemir, 2003), we find positive coefficient estimates on both the current unemployment rate and the unemployment rate in the year of arrival although the magnitudes of the coefficients are small. It suggests that immigrants who arrived in periods of recessions may not suffer from permanent damaging effects in their wage earnings. The positive impact of current labour market conditions is also witnessed in the previous implicit contract wage chapters. Again, one interpretation for the positive estimate of the coefficient on the current unemployment rate could be that those who are still employed in recessions are insured by implicit contracts and thus are guarded against the economic downturn. It is also possible that economic outcome lags behind unemployment variations during a recession. Third, a gap between real wages and marginal product of labour has been found in many theoretical and empirical studies (see, Bailey, 1974, and Christiano and Eichenbaum, 1992).

The impact of current and past macroeconomic conditions may differ between men and women. Most previous findings on the effects of macroeconomic conditions on immigrant wages are based on data for men. Since our above results are extracted from data sets including both men and women, we next extend the analysis to see whether it is the case that male immigrants differ from female immigrants in terms of their wage 
response to business cycle variation. More importantly, we integrate the implicit contracts literature into the immigrant earnings assimilation literature. By introducing the contract effects into the cohort-assimilation wage model, we investigate which macroeconomic variable wins out when all controls are included.

In Columns $1 \mathrm{a}-4 \mathrm{~b}$ of Table 6.7 , the estimates representing entry cohort effects and assimilation effects, as well as macroeconomic and tenure effects, are presented from models estimated separately by gender. After controlling for the macroeconomic variables, there is still a wage gap between male and female immigrants along their wage growth paths. Male immigrants, in general, experience higher initial wage disadvantage relative to native-born workers than do female immigrants. However, the comparison of the YSM and YSM-squared coefficients indicates that male immigrants tend to catch up more quickly to their native-born counterparts, in comparison with female immigrants' wage growth patterns. It is worth noting that the initial wage performance of female immigrants varies dramatically after adding macroeconomic controls. Their average entry wage gap goes up to 12.52 percent, enlarged by 8.97 percent than before. ${ }^{35}$ Male immigrants, on the contrary, present less evidence of wage sensitivity to the inclusion of labour market indicators. Also differing from the wage response to business cycles for female immigrants, male immigrants are adversely affected by both current macroeconomic variation and variation and time of arrival. A one percent increase in the current unemployment rate leads to a 0.2 percent wage drop for male immigrants. The coefficient on the initial unemployment rate is small and insignificant suggesting that weak macroeconomic conditions at arrival have little scarring effect on the current wage

\footnotetext{
${ }^{35}$ The two sets of cohort estimates in comparison are Column $1 \mathrm{~b}$ from Table 6.7 and Column 4 from Table 6.5 .
} 
of male immigrants. Also immigrants earn lower wages than the native born when facing fluctuating macroeconomic conditions. The wage gap is smaller for male immigrants than for female immigrants. In terms of wage returns to tenure, the female group earns four percent higher returns to 10 -year tenure than the male group. Besides, the evidence suggests a discrepancy in the wage returns to job tenure between immigrants and nonimmigrants. The gap is larger for the male group than for the female group.

Next, we extend the model to allow for the controls for implicit contract effects. In addition to the current unemployment rate, we introduce into the model two past labour market indicators, the unemployment rate at the time when an individual starts his job and the minimum unemployment rate over this individual's entire job tenure, to compare which macroeconomic variable has the largest impact in determining an individual's current wages. Estimates of the contract variables and immigrant-contract interaction variables are reported by gender in Columns $3 \mathrm{a}-4 \mathrm{~b}$ of Table 6.7 . Similar to the results shown earlier in Table 5.7, the estimates of the current unemployment rate turn out to be positive and significant for both male and female samples, the magnitude of which is much smaller for male than for female. Despite the significant nature of the estimates, the coefficients of the initial unemployment rate are also positive and have similar magnitude as found in Table 5.7. Empirical evidence also suggests that the minimum unemployment rate for both genders has the larger coefficients in absolute values than both the current and the initial labour market variables, which further implies a more important role of the implicit contracts model with costless mobility in terms of explaining wage dynamics. Specifically, a one percent drop in the lowest unemployment rate over a male/female worker's job tenure is associated with a 2.71 to 2.89 percent 
increase in wage rates. Moreover, interactions of macroeconomic measures with immigrant status are controlled for to examine differences between immigrant earnings and native-born earnings to business cycle fluctuations operating through contract effects. Male immigrants are found to be more affected economically than native-born workers by the best labour market conditions over an individual's job spell. Surprisingly, they do not seem to perform poorer than their native-born counterparts in their wage response to the initial labour market conditions, which is in contrast with our earlier findings. For female immigrants, the depressing impact of business cycle variations on their wage rates in relative to native-born earnings is not obvious. 
TABLE 6.7

Coefficients from Immigrant Variables by Gender when Macroeconomic Controls Are Included in the Model

\begin{tabular}{|c|c|c|c|c|c|c|c|c|}
\hline Variable & $\begin{array}{c}\text { Male } \\
1 \mathrm{a}\end{array}$ & $\begin{array}{c}\text { Female } \\
\text { lb }\end{array}$ & $\begin{array}{c}\text { Male } \\
2 a\end{array}$ & $\begin{array}{c}\text { Female } \\
2 b\end{array}$ & $\begin{array}{c}\text { Male } \\
3 a\end{array}$ & $\begin{array}{c}\text { Female } \\
3 \mathbf{b}\end{array}$ & $\begin{array}{c}\text { Male } \\
4 a\end{array}$ & $\begin{array}{c}\text { Female } \\
4 b \\
\end{array}$ \\
\hline \multirow[t]{2}{*}{ Year 1960-64 } & $-0.0873^{*}$ & $-0.0803^{*}$ & $-0.0564^{*}$ & 0.0056 & $0.0741^{*}$ & $-0.1419^{*}$ & $0.1093^{*}$ & $-0.1300^{*}$ \\
\hline & $(0.003 I)$ & $(0.0032)$ & $(0.0043)$ & $(0.0046)$ & $(0.0029)$ & $(0.0030)$ & $(0.0030)$ & $(0.0031)$ \\
\hline \multirow[t]{2}{*}{ Year 1965-69 } & $-0.1390^{*}$ & $-0.0662 *$ & $-0.1134^{*}$ & $0.0111^{*}$ & -0.0039 & $-0.0750^{*}$ & $0.0321^{*}$ & $-0.0618^{*}$ \\
\hline & $(0.0025)$ & $(0.0026)$ & $(0.0038)$ & $(0.0040)$ & $(0.0022)$ & $(0.0023)$ & $(0.0023)$ & $(0.0024)$ \\
\hline \multirow[t]{2}{*}{ Year 1970-74 } & $-0.0781^{*}$ & $-0.1109^{*}$ & $-0.0528^{*}$ & $-0.0365^{*}$ & $0.0351^{*}$ & $-0.1483^{*}$ & $0.0801^{*}$ & $-0.1310^{*}$ \\
\hline & $(0.0028)$ & $(0.0029)$ & $(0.0039)$ & $(0.0041)$ & $(0.0028)$ & $(0.0029)$ & $(0.0029)$ & $(0.0029)$ \\
\hline \multirow[t]{2}{*}{ Year 1975-79 } & $-0.1442^{*}$ & $-0.1463^{*}$ & $-0.1220^{*}$ & $-0.0737^{*}$ & $0.0176^{*}$ & $-0.1989^{*}$ & $0.0774^{*}$ & $-0.1793^{*}$ \\
\hline & $(0.0033)$ & $(0.0033)$ & $(0.0041)$ & $(0.0043)$ & $(0.0035)$ & $(0.0035)$ & $(0.0036)$ & $(0.0036)$ \\
\hline \multirow[t]{2}{*}{ Year $1980-84$} & $-0.1823^{*}$ & $-0.1450^{*}$ & $-0.1490^{*}$ & $-0.0718^{*}$ & $-0.0534^{*}$ & $-0.1594^{*}$ & $0.0246^{*}$ & $-0.1251^{*}$ \\
\hline & $(0.0037)$ & $(0.0038)$ & $(0.0044)$ & $(0.0045)$ & $(0.0041)$ & $(0.0042)$ & $(0.0043)$ & $(0.0044)$ \\
\hline \multirow[t]{2}{*}{ Year 1985-89 } & $-0.1692^{*}$ & $-0.1431^{*}$ & $-0.1386^{*}$ & $-0.0736^{*}$ & $-0.0382^{*}$ & $-0.2150^{*}$ & $0.0533^{*}$ & $-0.1702^{*}$ \\
\hline & $(0.0034)$ & $(0.0033)$ & $(0.0040)$ & $(0.0040)$ & $(0.0038)$ & $(0.0039)$ & $(0.0040)$ & $(0.0041)$ \\
\hline \multirow[t]{2}{*}{ Year 1990-94 } & $-0.1492 *$ & $-0.1938^{*}$ & $-0.1204^{*}$ & $-0.1259^{*}$ & -0.0015 & $-0.2059^{*}$ & $0.0975^{*}$ & $-0.1561^{*}$ \\
\hline & $(0.0038)$ & $(0.0037)$ & $(0.0042)$ & $(0.0043)$ & $(0.0043)$ & $(0.0044)$ & $(0.0045)$ & $(0.0046)$ \\
\hline \multirow[t]{2}{*}{ Year 1995-99 } & $-0.1746^{*}$ & $-0.1269^{*}$ & $-0.1496^{*}$ & $-0.0686^{*}$ & $-0.0810^{*}$ & $-0.2260^{*}$ & $0.0228 *$ & $-0.1743^{*}$ \\
\hline & $(0.0035)$ & $(0.0035)$ & $(0.0038)$ & $(0.0040)$ & $(0.0040)$ & $(0.0042)$ & $(0.0042)$ & $(0.0044)$ \\
\hline \multirow[t]{2}{*}{ Year 2000-04 } & $-0.1090^{*}$ & $-0.1139^{*}$ & $-0.0846^{*}$ & $-0.0582 *$ & $-0.0466^{*}$ & $-0.2717^{*}$ & $0.0539^{*}$ & $-0.2107^{*}$ \\
\hline & $(0.0033)$ & $(0.0038)$ & $(0.0036)$ & $(0.0041)$ & $(0.0037)$ & $(0.0047)$ & $(0.0039)$ & $(0.0049)$ \\
\hline \multirow[t]{2}{*}{ Years Since Immigration } & $0.0095^{*}$ & $-0.0003^{*}$ & $0.0120^{*}$ & $0.0013^{*}$ & $0.0046^{*}$ & $0.0028^{*}$ & $0.0101^{*}$ & $0.0081^{*}$ \\
\hline & $(0.0001)$ & $(0.0001)$ & $(0.0001)$ & $(0.0001)$ & $(0.0001)$ & $(0.0001)$ & $(0.0001)$ & $(0.0001)$ \\
\hline \multirow[t]{2}{*}{ Years Since Immigration $^{2} / 100$} & $-0.0151^{*}$ & $0.0033^{*}$ & $-0.0199^{*}$ & $0.0012^{*}$ & $-0.0074^{*}$ & $-0.0053^{*}$ & $-0.0142^{*}$ & $-0.0113^{*}$ \\
\hline & $(0.0003)$ & $(0.0003)$ & $(0.0003)$ & $(0.0003)$ & $(0.0002)$ & $(0.0002)$ & $(0.0002)$ & $(0.0002)$ \\
\hline \multirow[t]{2}{*}{ ue } & -0.0001 & $0.0100^{*}$ & -0.0008 & $0.0091^{*}$ & $-0.0089^{*}$ & $0.0111^{*}$ & $-0.0104^{*}$ & $0.0106^{*}$ \\
\hline & $(0.0004)$ & $(0.0004)$ & $(0.0004)$ & $(0.0004)$ & $(0.0004)$ & $(0.0004)$ & $(0.0004)$ & $(0.0004)$ \\
\hline \multirow[t]{2}{*}{ uc } & $-0.0023^{*}$ & $0.0052^{*}$ & $-0.0022^{*}$ & $0.0055^{*}$ & $0.0022^{*}$ & $0.0117^{*}$ & $0.0027^{*}$ & $0.0126^{*}$ \\
\hline & $(0.0000)$ & $(0.0000)$ & $(0.0000)$ & $(0.0000)$ & $(0.0000)$ & $(0.0000)$ & $(0.0000)$ & $(0.0000)$ \\
\hline \multirow[t]{2}{*}{ ustr } & & & & & $0.0103^{*}$ & $0.0043^{*}$ & $0.0102 *$ & $0.0044^{*}$ \\
\hline & & & & & $(0.0001)$ & $(0.0001)$ & $(0.0001)$ & $(0.0001)$ \\
\hline \multirow[t]{2}{*}{ ulow } & & & & & $-0.0289^{*}$ & $-0.0271^{*}$ & $-0.0279^{*}$ & $-0.0275^{*}$ \\
\hline & & & & & $(0.0001)$ & $(0.0001)$ & $(0.0001)$ & $(0.0001)$ \\
\hline \multirow[t]{2}{*}{ uc $*$ immst } & & & $-0.0009^{*}$ & $-0.0055^{*}$ & & & $-0.0023^{*}$ & $-0.0081^{*}$ \\
\hline & & & $(0.0002)$ & $(0.0002)$ & & & $(0.0001)$ & $(0.0002)$ \\
\hline
\end{tabular}




\begin{tabular}{|c|c|c|c|c|c|c|c|c|}
\hline \multirow[t]{2}{*}{ ustr * immst } & & & & & & & $0.0016^{*}$ & -0.0005 \\
\hline & & & & & & & $(0.0003)$ & $(0.0003)$ \\
\hline \multirow[t]{2}{*}{ ulow * immst } & & & & & & & $-0.0133 *$ & $0.0010^{*}$ \\
\hline & & & & & & & $(0.0004)$ & $(0.0004)$ \\
\hline \multirow[t]{2}{*}{ Job Tenure } & $0.0120^{*}$ & $0.0161^{*}$ & $0.0126^{*}$ & $0.0167^{*}$ & $0.0105^{*}$ & $0.0144^{*}$ & $0.0113^{*}$ & $0.0150^{*}$ \\
\hline & $(0.0000)$ & $(0.0000)$ & $(0.0000)$ & $(0.0000)$ & $(0.0000)$ & $(0.0000)$ & $(0.0000)$ & $(0.0000)$ \\
\hline \multirow[t]{2}{*}{ Job Tenure ${ }^{2}$} & $-0.0001^{*}$ & $-0.0003^{*}$ & $-0.0001^{*}$ & $-0.0003^{*}$ & $-0.0001^{*}$ & $-0.0002^{*}$ & $-0.0001^{*}$ & $-0.0003^{*}$ \\
\hline & $(0.0000)$ & $(0.0000)$ & $(0.0000)$ & $(0.0000)$ & $(0.0000)$ & $(0.0000)$ & $(0.0000)$ & $(0.0000)$ \\
\hline \multirow[t]{2}{*}{ Job Tenure * immst } & & & $-0.0085^{*}$ & $-0.0066^{*}$ & & & $-0.0088^{*}$ & $-0.0083^{*}$ \\
\hline & & & $(0.0001)$ & $(0.0001)$ & & & $(0.0001)$ & $(0.0001)$ \\
\hline \multirow[t]{2}{*}{ Job Tenure ${ }^{2} *$ immst } & & & $0.0002 *$ & $0.0001^{*}$ & & & $0.0003^{*}$ & $0.0002^{*}$ \\
\hline & & & $(0.0000)$ & $(0.0000)$ & & & $(0.0000)$ & $(0.0000)$ \\
\hline
\end{tabular}

Note: 1. ue, uc, ustr and ulow stand for the unemployment rate at the time of immigration, the current unemployment rate, the initial unemployment rate and the minimum unemployment rate, respectively. immst represents a foreign-born indicator.

2. Standard errors are in parentheses. In addition to the regressors defined in Table 6.6, interactions of a foreign-born indicator with tenure variables and macroeconomic measures are included to capture immigrant-native differences in wage returns to tenure and macroeconomic conditions.

$3 . *=5 \%$.

\section{Fixed Effects Estimation}

Previous studies on immigrant wages have primarily relied on cross-sectional analysis, which can be subject to biases due to unobserved heterogeneity. For example, workers' wage rates may be associated with unobserved ability, morale, turnover decision, etc. Firms tend to offer higher wages to attract high-ability workers. Thus the unmeasured ability reflected in wages may bias the true returns to job tenure. In addition, higher ability individuals may have fewer spells of long term unemployment and therefore have greater years of actual work experience, ceteris paribus. The concern of unobserved heterogeneity may, in the same sense, be a major issue for studies on immigrant wage assimilation. In this section, we control for individual fixed effects using the SLID panel to overcome the limitation of the cross-sectional nature of data sets 
and mitigate the risk of unobserved heterogeneity bias. Table 6.8 reports the main results obtained from the fixed effects estimation. ${ }^{36}$

The coefficient estimates of assimilation indicators "Years Since Immigration" and YSM squared in all wage specifications fit the hypothesis of decreasing rate of convergence of wages, despite the insignificant nature of the estimates. Without controlling for job tenure variables, immigrant wages grow at a speed $(0.0041-$ $0.000118 Y$ YM) as shown in Column 1 , in comparison to the wage growth rate (0.0062$0.000125 \mathrm{YSM}$ ) under random effects estimation. It seems to suggest a slower rate of wage convergence when individual specific mean is removed. ${ }^{37}$ Next, we repeat the analysis by including tenure controls and the results are presented in Column 2 . The magnitude of the YSM and YSM squared coefficients in absolute values has slightly decreased, which is similar to the results we discussed in the random effects models. The job tenure estimate indicates an 8.4 percent wage rise associated with 10 years of tenure, a 5.1 percent reduction in comparison to the random effects estimate. It also suggests that immigrants earn a 0.65 percent less wage to an additional year of tenure than nativeborn workers after controlling for the interaction of tenure variables with a foreign-born indicator. In brief, lack of control for individual heterogeneity may lead to biased estimates of true returns to tenure.

Next, we test the sensitivity of immigrant assimilation effect to the inclusion of macroeconomic controls. Again, the magnitude of rate of assimilation has dropped when facing labour market fluctuations as shown in Columns 4 and 5. Similar to the random

\footnotetext{
${ }^{36}$ All of the estimation in this section is based on wage-experience specifications. Fixed effects estimations by using wage-age specifications again biased up the YSM estimators.

${ }^{37}$ The YSM needs to be larger than 300 to make the wage growth rate obtained from fixed effects estimation exceed the rate under random effects estimation, which is unrealistic.
} 
effects results on the macroeconomic indicator, a positive coefficient of the current unemployment rate is presented. Including the interaction of the current unemployment rate with a foreign born indicator aims to test differences between immigrants and the native born in their wage response to labour market variations. It is not surprising that immigrants are more adversely affected economically than native-born workers when facing business shocks. For immigrants, the predicted less wage returns to a one percent increase in the current unemployment rate is 0.98 percent.

A key innovation of this chapter is that the impact of the implicit contract macroeconomic variables is integrated into the immigrant wage convergence model. We go one step further to add two more past macro indicators to examine what role the labour market conditions at different stages of an individual's job tenure play on the wage movements. Though insignificant, the positive coefficient of the initial unemployment rate seems to indicate that the macroeconomic conditions at the time of hiring has no permanent scarring effect in workers' wage outcomes. Among the three labour market measures, the lowest unemployment rate representing the best labour market conditions over worker's job tenure stand out to be the determinant factor in influencing the earnings variations of workers. The amount of differences reflected in wage responses to macroeconomic conditions that is captured by the negative coefficients of the interaction terms is shown in Column 6 . The interaction term of the minimum unemployment rate displays the largest magnitude than the other two. The wage returns of immigrants in relative to the native born are 2.5 percent lower when the minimum unemployment rate increases one percent. 


\section{TABLE 6.8}

Coefficients of Immigrant Variables after Controlling for Fixed Effects: Men and Women

\begin{tabular}{|c|c|c|c|c|c|c|}
\hline Variable & 1 & 2 & 3 & 4 & 5 & 6 \\
\hline \multirow[t]{2}{*}{ Years Since Immigration } & 0.0041 & .0 .0040 & 0.0064 & 0.0039 & 0.0039 & 0.0045 \\
\hline & $(0.0034)$ & $(0.0035)$ & $(0.0037)$ & $(0.0035)$ & $(0.0037)$ & $(0.0040)$ \\
\hline \multirow[t]{2}{*}{ Years Since Immigration ${ }^{2} / 100$} & -0.0118 & -0.0107 & -0.0147 & -0.0112 & -0.0143 & -0.0163 \\
\hline & $(0.0074)$ & $(0.0074)$ & $(0.0082)$ & $(0.0074)$ & $(0.0082)$ & $(0.0086)$ \\
\hline \multirow[t]{2}{*}{ Job Tenure } & & $0.0084^{*}$ & $0.0089^{*}$ & $0.0083^{*}$ & $0.0088^{*}$ & $0.0086^{*}$ \\
\hline & & $(0.0006)$ & $(0.0007)$ & $(0.0006)$ & $(0.0007)$ & $(0.0008)$ \\
\hline \multirow[t]{2}{*}{ Job Tenure ${ }^{2}$} & & $-0.0001^{*}$ & $-0.0001^{*}$ & $-0.0001^{*}$ & $-0.0001^{*}$ & $-0.0001^{*}$ \\
\hline & & $(0.0000)$ & $(0.0000)$ & $(0.0000)$ & $(0.0000)$ & $(0.0000)$ \\
\hline \multirow[t]{2}{*}{ Tenure * immst } & & & $-0.0065^{*}$ & & $-0.0066^{*}$ & $-0.0063^{*}$ \\
\hline & & & $(0.0024)$ & & $(0.0024)$ & $(0.0027)$ \\
\hline \multirow[t]{2}{*}{ Tenure $^{2} *$ immst } & & & 0.0002 & & 0.0002 & 0.0002 \\
\hline & & & $(0.0001)$ & & $(0.0001)$ & $(0.0001)$ \\
\hline \multirow[t]{2}{*}{ uc } & & & & $0.0072^{*}$ & $0.0080^{*}$ & $0.0128^{*}$ \\
\hline & & & & $(0.0010)$ & $(0.0011)$ & $(0.0012)$ \\
\hline \multirow[t]{2}{*}{ ustr } & & & & & & 0.0077 \\
\hline & & & & & & $(0.0050)$ \\
\hline \multirow[t]{2}{*}{ ulow } & & & & & & $-0.0270^{*}$ \\
\hline & & & & & & $(0.0050)$ \\
\hline \multirow[t]{2}{*}{$\mathrm{uc} * \mathrm{immst}$} & & & & & $-0.0098^{*}$ & $-0.0117^{*}$ \\
\hline & & & & & $(0.0038)$ & $(0.0040)$ \\
\hline \multirow[t]{2}{*}{ ustr * immst } & & & & & & -0.0177 \\
\hline & & & & & & $(0.0175)$ \\
\hline \multirow[t]{2}{*}{ ulow * immst } & & & & & & -0.0250 \\
\hline & & & & & & $(0.0170)$ \\
\hline
\end{tabular}

Note: 1 . U stands for the current unemployment rate. immst represents a foreign-born indicator.

2. Standard errors are in parentheses. The dependent variable is the log of the real composite hourly wage. The independent variables include years since immigration and years since immigration squared, years of schooling, years of experience, years of experience squared, tenure, tenure squared, macroeconomic measure, controls for industry, marital status, province of residence, urban/rural status, interactions of a foreign-born indicator with tenure variables and three macroeconomic measures.

$3 . * 5 \%$. 
By adopting the random effects approach, we have found a distinct gender effect in immigrant wage profiles. Alternatively, we repeat the gender analysis using fixed effects estimation to examine whether gender still matters in explaining immigrant wage assimilation, as well as returns to tenure and macroeconomic conditions. As shown earlier in Table 6.1, the male group differs from the female group in some of the individual characteristics, especially in hourly wage rate, years of work experience, job tenure, and marriage rate. With potential gender and other heterogeneity embedded in the model specifications, failing to control for unobserved individual effect may result in biased estimates of immigrant wage performance.

In Table 6.9, we list groups of estimates across genders from multiple regression models. Although most YSM estimates are insignificant, it suggests that male immigrants gradually assimilate economically but at a decreasing rate. Compared to the random effects estimates, the speed of wage growth for male immigrants is at least 0.3 percent lower. On the other hand, female immigrants do not show any tendency of wage assimilation at all, which differs from our earlier findings drawn from random effects estimations in that female immigrants who arrived in the 1960 s eventually catch up economically to their native-born counterparts. Next, we examine the role of tenure variables on wage returns. Differing from what was found in the random effects approach, the wage assimilation profile for male immigrants is found to be less sensitive to the additional control. The wage growth paths for female immigrants further decline and will never converge to those of native-born counterparts. Wage returns to job tenure are found to be lower in the fixed effects wage settings for both male and female. Again, the wage gap in terms of tenure is above 0.2 percent annually between the two groups. 
By interacting tenure variables with a foreign-born indicator, it suggests that immigrants/non-immigrants earn different returns to tenure. Similar to earlier findings from the random-effects approach, the gap is larger in magnitude between male immigrants and their native-born counterparts than between female immigrants and their counterparts. Lastly, we investigate the gender effect regarding the sensitivity of wage assimilation to macroeconomic conditions. Unlike the worsening wage growth profile faced by female immigrants under the impact of business cycles, male immigrants catch up at a faster speed than they do under model specifications without macro controls. Although the unemployment rate at landing drops out in fixed effects models, we are still able to control for the current unemployment rate. Similar to earlier results on the macroeconomic measures, the estimates found on both genders suggest a positive impact of labour market variations on wages, which worth further exploration. Again, immigrants are more adversely affected by current macroeconomic fluctuations than are non-immigrants. Next, the combination of implicit contract effects and wage assimilation effects are nested into the same wage model in light of the wage responses of immigrants in relative to the native born to labour market variations. Comparing results from Columns $4 \mathrm{a}$ and $4 \mathrm{~b}$ in Table 6.9 to the same columns in Table 6.7, there are major differences between random effects estimations and fixed effects estimations in the coefficients of the interaction terms of the macroeconomic controls for both groups. Unlike the previous positive coefficient of the interaction term of the initial unemployment rate, male immigrants are found to be severely depressed in their economic returns (in comparison to the native-born workers) by the labour market conditions when they were hired. Adopting the fixed effects approach rather than the 
random effects approach finds female immigrants more affected by past labour market conditions relative to their native-born counterparts.

In summary, applying fixed effects estimations has captured unobserved heterogeneity in gender and suggests a biased-up assimilation effect for immigrants as well as biased estimates of the macroeconomic variables. 
TABLE 6.9

Coefficients of Immigrant Variables by Gender after Controlling for Fixed Effects

\begin{tabular}{|c|c|c|c|c|c|c|c|c|}
\hline Variable & $\begin{array}{c}\text { Male } \\
\text { 1a }\end{array}$ & $\begin{array}{c}\text { Female } \\
1 \mathrm{~b}\end{array}$ & $\begin{array}{c}\text { Male } \\
2 \mathrm{a}\end{array}$ & $\begin{array}{c}\text { Female } \\
2 b\end{array}$ & $\begin{array}{c}\text { Male } \\
3 \mathrm{a} \\
\end{array}$ & $\begin{array}{c}\text { Female } \\
3 \mathrm{~b} \\
\end{array}$ & $\begin{array}{c}\text { Male } \\
4 \mathrm{a} \\
\end{array}$ & $\begin{array}{c}\text { Female } \\
4 b \\
\end{array}$ \\
\hline \multirow[t]{2}{*}{ Years Since Immigration } & 0.0083 & -0.0025 & 0.0087 & -0.0034 & $0.0101^{*}$ & -0.0057 & 0.0082 & -0.0026 \\
\hline & $(0.0047)$ & $(0.0049)$ & $(0.0048)$ & $(0.0049)$ & $(0.0051)$ & $(0.0053)$ & $(0.0053)$ & $(0.0061)$ \\
\hline \multirow[t]{2}{*}{ Years Since Immigration $^{2} / 100$} & $-0.0204^{*}$ & 0.0014 & $-0.0200^{*}$ & 0.0036 & $-0.0277^{*}$ & 0.0055 & $-0.0328^{*}$ & 0.0135 \\
\hline & $(0.0099)$ & $(0.0108)$ & $(0.0099)$ & $(0.0108)$ & $(0.0111)$ & $(0.0113)$ & $(0.0112)$ & $(0.0125)$ \\
\hline \multirow[t]{2}{*}{ Job Tenure } & & & $0.0074^{*}$ & $0.0101^{*}$ & $0.0081^{*}$ & $0.0104^{*}$ & $0.0078^{*}$ & $0.0099^{*}$ \\
\hline & & & $(0.0009)$ & $(0.0009)$ & $(0.0009)$ & $(0.0010)$ & $(0.0011)$ & $(0.0011)$ \\
\hline \multirow[t]{2}{*}{ Job Tenure ${ }^{2}$} & & & 0.0000 & $-0.0002^{*}$ & 0.0000 & $-0.0002^{*}$ & -0.0001 & $-0.0002 *$ \\
\hline & & & $(0.0000)$ & $(0.0000)$ & $(0.0000)$ & $(0.0000)$ & $(0.0000)$ & $(0.0000)$ \\
\hline \multirow[t]{2}{*}{ Job Tenure * immst } & & & & & $-0.0101 *$ & -0.0018 & $-0.0074^{*}$ & -0.0043 \\
\hline & & & & & $(0.0031)$ & $(0.0035)$ & $(0.0035)$ & $(0.0043)$ \\
\hline \multirow[t]{2}{*}{ Job Tenure ${ }^{2} *$ immst } & & & & & $0.0004^{*}$ & -0.0001 & $0.0004^{*}$ & -0.0002 \\
\hline & & & & & $(0.0002)$ & $(0.0001)$ & $(0.0001)$ & $(0.0002)$ \\
\hline \multirow[t]{2}{*}{ uc } & & & & & $0.0038^{*}$ & $0.0124^{*}$ & $0.0083^{*}$ & $0.0175^{*}$ \\
\hline & & & & & $(0.0015)$ & $(0.0015)$ & $(0.0016)$ & $(0.0017)$ \\
\hline \multirow[t]{2}{*}{ ustr } & & & & & & & 0.0137 & 0.0017 \\
\hline & & & & & & & $(0.0078)$ & $(0.0064)$ \\
\hline \multirow[t]{2}{*}{ ulow } & & & & & & & $-0.0295^{*}$ & $-0.0239^{*}$ \\
\hline & & & & & & & $(0.0072)$ & $(0.0069)$ \\
\hline \multirow[t]{2}{*}{ uc * immst } & & & & & -0.0058 & $-0.0132^{*}$ & -0.0064 & $-0.0172^{*}$ \\
\hline & & & & & $(0.0050)$ & $(0.0057)$ & $(0.0052)$ & $(0.0062)$ \\
\hline \multirow[t]{2}{*}{ ustr * immst } & & & & & & & $-0.0524^{*}$ & 0.0157 \\
\hline & & & & & & & $(0.0261)$ & $(0.0218)$ \\
\hline \multirow[t]{2}{*}{ ulow $*_{\text {immst }}$} & & & & & & & -0.0153 & -0.0293 \\
\hline & & & & & & & $(0.0218)$ & $(0.0262)$ \\
\hline
\end{tabular}

Note: 1 . U stands for the current unemployment rate. immst represents a foreign-born indicator.

2. Standard errors are in parentheses. The dependent variable is the log of the real composite hourly wage.

The independent variables include years since immigration and years since immigration squared, years of schooling, years of experience, years of experience squared, tenure, tenure squared, macroeconomic measures, controls for industry, marital status, province of residence, urban/rural status, and interactions of a foreign-born indicator with tenure variables and the three macroeconomic measures.

$3 . *=5 \%$. 


\section{Conclusion}

We have employed pooled panel data from the Survey of Labour and Income Dynamics (SLID) to investigate whether immigrants have experienced initial wage disadvantage in comparison to their native-born counterparts and whether they will eventually integrate into the local labour market through their wage growth paths since immigration. Model specifications with and without tenure variables are examined separately. Approximation of using age as a proxy for actual years of work experience is also investigated. This chapter provides a further look at the gender effect on immigrants' wage outcomes. Macroeconomic measures are added to the conventional immigrant wage model to identify the differences in labour market outcomes between immigrants and their native-born counterparts arising from labour market fluctuations. Also importantly, an issue of individual unobserved heterogeneity is addressed through using fixed effects estimations.

The major findings of this chapter are as follows: First, the initial economic disadvantage faced by immigrants has been found to be smaller in magnitude than in previous research especially when tenure variables are included. Second, the empirical evidence suggests that a declining pattern of cohort quality exists. Recent cohorts of immigrants seem to experience a larger wage gap at the time of immigration than earlier cohorts. Wage convergence is extremely weak in most specifications, although immigrants do exhibit an improved economic performance along the growth paths. Third, job tenure plays an important role in analyzing immigrant wage dynamics. Biases arising from omitted tenure variables are implied. It is found that approximately a two to three percent entry wage gap between immigrants and non-immigrants can be explained by job 
tenure differences. Immigrants having less return to years of tenure may partly explain the slow rate of assimilation found in this chapter. Fourth, employing the age proxy for actual work experience leads to an enlarged wage gap between immigrants and nativeborn workers. This may provide a sound explanation for the higher magnitude of cohort effects found in earlier studies that use conventional proxies for the unavailable experience variable. Fifth, testing for group differences by gender reveals that the initial wage gap at arrival faced by female immigrants is smaller than the one faced by male immigrants. Declining patterns of cohort quality are found between genders in both random effects approach and fixed effects approach. Sixth, the integration of macroeconomic variables leads to an increase in the entry effect for immigrants. Evidence suggests that the minimum unemployment rate has a larger adverse effect on earnings outcomes than other macroeconomic measures, which represents the dominant position of the implicit contract effect. It also reveals that the wage performance in business cycles differentiates across genders. For immigrant men, it is the unemployment rate at the start of the job that seems most important rather than the minimum unemployment rate over the job tenure. Immigrants are also found to earn lower wages than the native-born when facing fluctuating macroeconomic conditions. These findings on immigrant initial performance and adjustment process shed light on immigration policy regarding admission classes, social welfare cost of immigration, and linking immigration policy adjustment to labour market conditions. Finally, the fixed effects estimation results suggest that unobserved individual heterogeneity is responsible for the enlarged assimilation estimates, and failing to control for individual characteristics therefore biases up the true rate of assimilation. 


\section{Chapter 7}

\section{Conclusions}

Introducing current and past macroeconomic variables into the human capital wage model allows us to test the effect of business cycle variations on the earnings performance of Canadian workers. Implicit contracts with costless mobility capture how wages respond to the best labour market conditions when employees do not commit to the contracts and have unconstrained mobility to switch to new jobs. Implicit contracts with costly mobility, on the other hand, restrict the mobility level of workers and impose binding contracts on both firms and workers. The earnings outcomes of workers are, under this circumstance, more determined by the labour market conditions at the time of hiring. In contrast to the implicit contract view which claims the importance of the past macroeconomic conditions on wage variations, the spot market view states that the contemporaneous macro conditions are the determinant factor in affecting the wage outcomes of workers.

In the previous literature, researchers mainly rely on unemployment rates to measure the labour market fluctuations. We follow this approach by employing three macroeconomic indicators, i.e., the current unemployment rate, the unemployment rate at the time when an individual starts his job and the minimum unemployment rate since the start of the worker's employment with the firm to capture their individual and joint effect on workers' earnings performance at different stages of the job tenure. Using a pooled sample from the Survey of Labour and Income Dynamics (SLID), we carry out implicit contract analysis in the first two research chapters. We not only focus on the native-born 
workers but extend the literature to immigrants as the target group. It fills the void of implicit contract wage studies related to immigrants as well as the earnings differences between immigrants and the native born in facing business cycle fluctuations. Our main findings indicate that the implicit contract model with costless mobility gives a better explanation for wage dynamics than does either the spot market model or the implicit contract model with full commitment. Evidence suggests a wage discrepancy between immigrants and native-born workers in response to macroeconomic conditions. For native-born workers, a one percent increase in the minimum unemployment rate leads to a 1.37 percent decrease in the wage. A 3.08 percent further wage drop is witnessed on immigrants to this change in the labour market conditions. Moreover, we find that differences in the wage sensitivity to the macro conditions vary by gender. Native-born female workers are more sensitive to current labour market conditions and less affected by the best labour market conditions since the start of employment with the firm compared to native-born male workers, which seems to suggest that implicit contract effects are more common for male workers. On the other hand, female immigrants are found to respond less to labour market conditions than male immigrants.

The large number of observations in the native-born sample in the SLID allows us to examine the implicit contact effect across industries and different age groups. The empirical results suggest that the effect of macroeconomic variables varies by industry. The model is also estimated allowing the effects on wages of the macroeconomic variables to vary with age. Unlike a hill-shaped implicit contracting effect found in the earlier literature, past labour market conditions are found to affect the current wage rate of different age groups without a clear pattern. We also examine the implicit contracting 
effects by union status. Unionized members include those who are either: 1) a union member or 2) covered by a collective agreement. Non-unionized members are treated as the comparison group. Evidence suggests that the union group and the non-union group have differing wage reactions to labour market conditions. Non-union members seem to be unable to avoid the scarring effect of past macroeconomic variations. In particular, for both men and women, non-union workers have wage responses that are consistent with an implicit contract model with costless mobility. Union workers seem to be insulated from most of the wage effects of macroeconomic variation.

Chapter 6 examines the initial wage discrepancies between immigrants and native-born workers at the time of immigration, and the rate of wage assimilation of immigrants since their arrival in the hosting country. This literature also focus on the earnings outcomes of immigrants in relation to those of the native born, but from a different perspective in that it emphasizes on looking at the initial wage performance and the gradual wage convergence paths of immigrants. Based on the analysis of the pooled data sets from the SLID, we study nine cohorts of immigrants who arrived in Canada between 1960 and 2004 using the native born as the comparison group. Our study suggests that the initial wage differences between immigrants and the native born are smaller in magnitude than previous findings, albeit a declining cohort quality that is captured by the weaker wage performance. Wage differences are found to be less severe between female immigrants and comparable natives than between male immigrants and comparable natives. In addition, the empirical results show little evidence of wage convergence except for immigrants who arrived before 1975 . Those who immigrated after the mid-70s could gradually reduce the wage gap to the native-born workers but 
never completely catch up. We compare the wage specification that uses age as a proxy for actual work experience and the wage specification that instead uses actual work experience, and find exaggerated immigrant-native wage differentials relative in the former case.

A major contribution of this thesis chapter is the fact that a thorough investigation is carried out on the wage returns to job tenure for immigrants. Biases arising from omitted tenure are suggested. After controlling for job tenure, we find empirical support for a declining entry wage gap between immigrants and their native-born counterparts as well as a drop in the rate of wage growth assimilation. An approximately 0.8 percent lower wage return to job tenure for immigrants is found in comparison to their nativeborn counterparts, which may partly attribute to the wage inequality between immigrants and non-immigrants.

We also adopt a novel approach by integrating the implicit contract literature into immigrants' wage cohort-assimilation literature. The innovation allows us to examine the sensitivity of workers' wage reaction to labour market conditions at different stages of their employment. The minimum unemployment rate over an individual's entire job tenure is found to be the most important macroeconomic determinant of the wage outcomes of workers. Evidence also suggests that immigrants typically have lower wages during business cycle shocks than their native-born counterparts.

Immigrant-native earnings differences and the empirical evidence that immigrants do not converge economically to the native born further raise the issue of the improvement of immigrants' economic status. In addition, the analysis of this thesis indicates that labour market conditions are important in analyzing immigrant wages if the 
goal is to evaluate the performance of immigrants in the labour market since ignoring macroeconomic conditions may lead to a biased interpretation of the success of a particular group of immigrants. 


\section{Appendix A:}

Tables

\section{Table A1. Definition of Variables in Regressions for Implicit Contract Effects}

\section{Dependent Variable}

$\ln (w) \quad$ logarithm of composite hourly wage rate

\section{Independent Variables}

\begin{tabular}{|c|c|}
\hline uc & current national unemployment rate \\
\hline ustr & unemployment rate at the start of the worker's current job \\
\hline \multirow[t]{2}{*}{ ulow } & minimum unemployment rate during the worker's current \\
\hline & job spell \\
\hline immst & foreign-born indicator. 1 for immigrant, 0 otherwise \\
\hline ysm, $\mathrm{ysm}^{2}$ & years since immigration and its quadratic form \\
\hline yrschl & total years of schooling \\
\hline yrxfte, yrxfte ${ }^{2}$ & total years of labour market experience and its quadratic form \\
\hline jobyr, jobyr ${ }^{2}$ & job tenure and its quadratic form \\
\hline marst & marital status. 1 for married, 0 otherwise \\
\hline pvres & province of residence, Newfoundland, Prince Edward Island, \\
\hline \multirow{11}{*}{$\begin{array}{l}\text { urbrur } \\
\text { nic }\end{array}$} & Nova Scotia, New Brunswick, Quebec, Ontario (default), \\
\hline & Manitoba, Saskatchewan, British Columbia and Alberta \\
\hline & urban or rural residence. 1 for urban residence, 0 otherwise \\
\hline & dummy variables for industry group. Agriculture, logging \& \\
\hline & forestry, fishing, hunting \& trapping, mining \& oil \& gas extraction, \\
\hline & utilities, construction, durables, non-durables, wholesale trade, \\
\hline & retail trade, transportation \& warehousing, finance/insurance, real \\
\hline & estate and leasing, professional, scientific \& technical services, \\
\hline & business, building and other support services, educational service, \\
\hline & health care and social assistance, information, culture and \\
\hline & recreation, accommodation \& food services, public administration \\
\hline
\end{tabular}




\section{Table A2. Definition of Variables in Regressions for Cohort Effects and Assimilation Effects}

\section{Dependent Variable}

In(w) logarithm of composite hourly wage rate

\section{Independent Variables}

c1 - c9 cohort dummy variables representing the time of immigration

1-9 for immigration in 1960-64, 1965-69, 1970-74, 1975-79, 1980-

$84,1985-89,1990-94,1995-99$ and 2000-04, respectively

immst foreign-born indicator. 1 for immigrant, 0 otherwise

ysm, $\mathrm{ysm}^{2} \quad$ years since immigration and its quadratic form

uc current national unemployment rate

ue unemployment rate at time of arrival

ustr unemployment rate at the start of the worker's current job

ulow minimum unemployment rate during the worker's current

job spell

yrschl total years of schooling

yrxfte, $\mathrm{yrxfte}^{2}$ total years of labour market experience and its quadratic form (age is also used as a proxy for work experience)

jobyr, jobyr ${ }^{2}$ job tenure and its quadratic form

urbrur urban or rural residence. 1 for urban residence, 0 otherwise

marst marital status. 1 for married, 0 otherwise

pvres dummy variables for province of residence, Newfoundland, Prince Edward Island, Nova Scotia, New Brunswick, Quebec, Ontario (default), Manitoba, Saskatchewan, British Columbia and Alberta

nic dummy variables for industry group. Agriculture, logging \& forestry, fishing, hunting \& trapping, mining \& oil \& gas extraction, utilities, construction, durables, non-durables, wholesale trade, retail trade, transportation \& warehousing, finance/insurance, real estate and leasing, professional, scientific \& technical services, 
business, building and other support services, educational service, health care and social assistance, information, culture and recreation, accommodation $\&$ food services, public administration 
Appendix B:

Consumer Price Index, historical summary (1993 to 2006)

\begin{tabular}{ccc}
\hline \hline \multirow{2}{*}{ Year } & \multicolumn{2}{c}{ CPI } \\
\cline { 2 - 3 } & $2002=100$ & $2004=100$ \\
\hline 1993 & 85.6 & 81.8 \\
1994 & 85.7 & 81.9 \\
1995 & 87.6 & 83.7 \\
1996 & 88.9 & 84.9 \\
1997 & 90.4 & 86.3 \\
1998 & 91.3 & 87.2 \\
1999 & 92.9 & 88.7 \\
2000 & 95.4 & 91.1 \\
2001 & 97.8 & 93.4 \\
2002 & 100 & 95.5 \\
2003 & 102.8 & 98.2 \\
2004 & 104.7 & 100.0 \\
2005 & 107 & 102.2 \\
2006 & 109.1 & 104.2 \\
\hline
\end{tabular}

Source: Statistics Canada, http://www40.statcan.gc.ca/101/cst01/econ46a-eng.htm 


\section{Appendix C:}

Tables with clustered standard errors (three examples from each research chapters)

Table C.1

Coefficient Estimates of Implicit Contracting Effects

from Fixed Effects Estimation

(Native-born Group)

\begin{tabular}{|c|c|c|c|c|c|c|c|}
\hline \multirow{2}{*}{ Macroeconomic Measures } & \multicolumn{7}{|c|}{ Regression Results for the Pooled Panel 93-06 $(\mathrm{N}=74,038)$} \\
\hline & 1 & 2 & 3 & 4 & 5 & 6 & 7 \\
\hline \multirow[t]{2}{*}{ Current Unemployment Rate } & $0.0098^{*}$ & & & $0.0113^{*}$ & $0.0130^{*}$ & & $0.0129 *$ \\
\hline & $(0.0016)$ & & & $(0.0016)$ & $(0.0016)$ & & $(0.0016)$ \\
\hline \multirow[t]{2}{*}{ Unemployment Rate at Start of Job } & & -0.0064 & & $-0.0123 *$ & & 0.0095 & 0.0077 \\
\hline & & $(0.0046)$ & & $(0.0046)$ & & $(0.0069)$ & $(0.0068)$ \\
\hline \multirow[t]{2}{*}{ Minimum Rate Since Start of Job } & & & $-0.0137^{*}$ & & $-0.0214 *$ & $-0.0207^{*}$ & $-0.0271^{*}$ \\
\hline & & & $(0.0042)$ & & $(0.0043)$ & $(0.0064)$ & $(0.0064)$ \\
\hline
\end{tabular}

Note: 1. Clustered standard errors in parentheses are in comparison with standard errors from Table 4.2.

2. $*=5 \%$. 
Table C.2

\section{Implicit Contracting Effects from Fixed Effects Estimation} (Immigrant Group)

\begin{tabular}{|c|c|c|c|c|c|c|c|}
\hline & \multicolumn{7}{|c|}{$\begin{array}{l}\text { Regression Results without Instruments for the Pooled Panel 93-06 } \\
\qquad(\mathrm{N}=6,887)\end{array}$} \\
\hline & 1 & 2 & 3 & 4 & 5 & 6 & 7 \\
\hline \multirow[t]{2}{*}{ Current Unemployment Rate } & -0.0048 & & & -0.0014 & 0.0013 & & 0.0013 \\
\hline & $(0.0048)$ & & & $(0.0048)$ & $(0.0048)$ & & $(0.0048)$ \\
\hline \multirow[t]{2}{*}{ Unemployment Rate at Start of Job } & & $-0.0410^{*}$ & & $-0.0404^{*}$ & & -0.0055 & -0.0055 \\
\hline & & $(0.0158)$ & & $(0.0158)$ & & $(0.0200)$ & $(0.0200)$ \\
\hline \multirow[t]{2}{*}{ Minimum Rate Since Start of Job } & & & $-0.0535^{*}$ & & $-0.0543^{*}$ & $-0.0496^{*}$ & $-0.0504^{*}$ \\
\hline & & & $(0.0152)$ & & $(0.0154)$ & $(0.0192)$ & $(0.0194)$ \\
\hline
\end{tabular}

Note: 1. Clustered standard errors in parentheses are in comparison with standard errors from Table 5.2.

2. $*=5 \%$ 
TABLE C.3

\section{Coefficients of Immigrant Variables after Controlling for Fixed Effects}

\begin{tabular}{|c|c|c|c|c|c|}
\hline \multirow{2}{*}{ Variable } & \multicolumn{5}{|c|}{$(\mathrm{N}=96,927)$} \\
\hline & 1 & 2 & 3 & 4 & 5 \\
\hline \multirow[t]{2}{*}{ Years Since Immigration } & 0.0041 & 0.0040 & 0.0064 & 0.0039 & 0.0039 \\
\hline & $(0.0050)$ & $(0.0050)$ & $(0.0053)$ & $(0.0050)$ & $(0.0054)$ \\
\hline \multirow[t]{2}{*}{ Years Since Immigration ${ }^{2} / 100$} & -0.0118 & -0.0107 & -0.0147 & -0.0112 & -0.0143 \\
\hline & $(0.0106)$ & $(0.0106)$ & $(0.0117)$ & $(0.0106)$ & $(0.0117)$ \\
\hline \multirow[t]{2}{*}{ Job Tenre } & & $0.0084^{*}$ & $0.0089^{*}$ & $0.0083^{*}$ & $0.0088^{*}$ \\
\hline & & $(0.0009)$ & $(0.0009)$ & $(0.0009)$ & $(0.0009)$ \\
\hline \multirow[t]{2}{*}{ Job Tenure ${ }^{2}$} & & $-0.0001^{*}$ & $-0.0001^{*}$ & $-0.0001^{*}$ & $-0.0001 *$ \\
\hline & & $(0.0000)$ & $(0.0000)$ & $(0.0000)$ & $(0.0000)$ \\
\hline \multirow[t]{2}{*}{ Tenure $*$ immst } & & & $-0.0065^{*}$ & & $-0.0066^{*}$ \\
\hline & & & $(0.0033)$ & & $(0.0033)$ \\
\hline \multirow[t]{2}{*}{ Tenure $^{2} *$ immst } & & & 0.0002 & & 0.0002 \\
\hline & & & $(0.0002)$ & & $(0.0002)$ \\
\hline \multirow[t]{2}{*}{ uc } & & & & $0.0072^{*}$ & $0.0080^{*}$ \\
\hline & & & & $(0.0014)$ & $(0.0015)$ \\
\hline \multirow[t]{2}{*}{ uc * immst } & & & & & $-0.0098^{*}$ \\
\hline & & & & & $(0.0052)$ \\
\hline
\end{tabular}

Note: 1 . Clustered standard errors in parentheses are in comparison with standard errors from Table 6.8.

2. ${ }^{*}=5 \%$. 
Appendix D:

Tables with regression results from using average hourly wage rate on the main job (three examples from each research chapters)

\section{Table D.1}

Coefficient Estimates of Implicit Contracting Effects

from Fixed Effects Estimation

(Native-born Group)

\begin{tabular}{|c|c|c|c|c|c|c|c|}
\hline \multirow{2}{*}{ Macroeconomic Measures } & \multicolumn{7}{|c|}{ Regression Results for the Pooled Panel 93-06 $(\mathrm{N}=73,943)$} \\
\hline & 1 & 2 & 3 & 4 & 5 & 6 & 7 \\
\hline \multirow[t]{2}{*}{ Current Unemployment Rate } & $0.0097^{*}$ & & & $0.0111 *$ & $0.0131^{*}$ & & $0.0129^{*}$ \\
\hline & $(0.0012)$ & & & $(0.0012)$ & $(0.0012)$ & & $(0.0012)$ \\
\hline \multirow[t]{2}{*}{ Unemployment Rate at Start of Job } & & -0.0054 & & $-0.0112^{*}$ & & $0.0136^{*}$ & $0.0118 *$ \\
\hline & & $(0.0036)$ & & $(0.0037)$ & & $(0.0055)$ & $(0.0055)$ \\
\hline \multirow[t]{2}{*}{ Minimum Rate Since Start of Job } & & & $-0.0146^{*}$ & & $-0.0224 *$ & $-0.0247^{*}$ & $-0.0311^{*}$ \\
\hline & & & $(0.0034)$ & & $(0.0035)$ & (0.0053) & $(0.0054)$ \\
\hline
\end{tabular}

Note: 1 . The dependent variable is log hourly wage rate which is derived by dividing the total earnings in the main job by the product of usual number of weeks and usual weekly hours that work was done. The regression results are in comparison with results from Table 4.2 .

2. Standard errors are in parentheses.

$3{ }^{*}=5 \%$. 
Table D.2

Implicit Contracting Effects from Fixed Effects Estimation:

\section{Immigrant Men and Women}

\begin{tabular}{|c|c|c|c|c|c|c|c|}
\hline & \multicolumn{7}{|c|}{$\begin{array}{l}\text { Regression Results without Instruments for the Pooled Panel 93-06 } \\
\qquad(\mathrm{N}=6,883)\end{array}$} \\
\hline & 1 & 2 & 3 & 4 & 5 & 6 & 7 \\
\hline \multirow[t]{2}{*}{ Current Unemployment Rate } & -0.0053 & & & -0.0016 & 0.0011 & & 0.0012 \\
\hline & $(0.0036)$ & & & $(0.0035)$ & $(0.0035)$ & & $(0.0035)$ \\
\hline \multirow[t]{2}{*}{ Unemployment Rate at Start of Job } & & $-0.0455^{*}$ & & $-0.0449^{*}$ & & -0.0098 & -0.0099 \\
\hline & & $(0.0121)$ & & $(0.0120)$ & & $(0.0157)$ & $(0.0157)$ \\
\hline \multirow[t]{2}{*}{ Minimum Rate Since Start of Job } & & & $-0.0568^{*}$ & & $-0.0575^{*}$ & $-0.0498^{*}$ & $-0.0504 *$ \\
\hline & & & $(0.0118)$ & & $(0.0119)$ & $(0.0153)$ & $(0.0155)$ \\
\hline
\end{tabular}

Note: 1. The dependent variable is log hourly wage rate which is derived by dividing the total earnings in the main job by the product of usual number of weeks and usual weekly hours that work was done. The regression results are in comparison with results from Table 5.2.

2. Standard errors are in parentheses.

$3{ }^{*}=5 \%$. 
TABLE D.3

Coefficient Estimates of Immigrant Variables (without Tenure Controls)

\begin{tabular}{|c|c|c|}
\hline Variable & $\begin{array}{c}\text { Actual Work Experience } \\
1\end{array}$ & $\begin{array}{c}\text { Age Proxy } \\
2 \\
\end{array}$ \\
\hline \multirow[t]{2}{*}{ Year 1960-64 } & $-0.0224^{*}$ & $-0.1564^{*}$ \\
\hline & $(0.0019)$ & $(0.0019)$ \\
\hline \multirow[t]{2}{*}{ Year 1965-69 } & $-0.0605^{*}$ & $-0.1757^{*}$ \\
\hline & $(0.0016)$ & $(0.0016)$ \\
\hline \multirow[t]{2}{*}{ Year 1970-74 } & $-0.0591^{*}$ & $-0.1658^{*}$ \\
\hline & $(0.0015)$ & $(0.0015)$ \\
\hline \multirow[t]{2}{*}{ Year 1975-79 } & $-0.1198^{*}$ & $-0.2303^{*}$ \\
\hline & $(0.0015)$ & $(0.0015)$ \\
\hline \multirow[t]{2}{*}{ Year 1980-84 } & $-0.1288^{*}$ & $-0.2397^{*}$ \\
\hline & $(0.0014)$ & $(0.0014)$ \\
\hline \multirow[t]{2}{*}{ Year 1985-89 } & $-0.1222 *$ & $-0.2320^{*}$ \\
\hline & $(0.0012)$ & $(0.0012)$ \\
\hline \multirow[t]{2}{*}{ Year 1990-94 } & $-0.1340^{*}$ & $-0.2556^{*}$ \\
\hline & $(0.0011)$ & $(0.0011)$ \\
\hline \multirow[t]{2}{*}{ Year 1995-99 } & $-0.1291 *$ & $-0.2628^{*}$ \\
\hline & $(0.0011)$ & $(0.0011)$ \\
\hline \multirow[t]{2}{*}{ Year 2000-04 } & $-0.0790^{*}$ & $-0.2264^{*}$ \\
\hline & $(0.0019)$ & $(0.0019)$ \\
\hline \multirow[t]{2}{*}{ Years Since Immigration } & $0.0058^{*}$ & $0.0095^{*}$ \\
\hline & $(0.0001)$ & $(0.0001)$ \\
\hline \multirow[t]{2}{*}{ Years Since Immigration $^{2} / 100$} & $-0.0115^{*}$ & $-0.0108^{*}$ \\
\hline & $(0.0002)$ & $(0.0001)$ \\
\hline No. of Observations & 96,927 & 96,927 \\
\hline
\end{tabular}

Note: 1 . The dependent variable is log hourly wage rate which is derived by dividing the total earnings in the main job by the product of usual number of weeks and usual weekly hours that work was done. The regression results are in comparison with results from In comparison with regression results from Table 6.3. 2. Standard errors are in parentheses.

3 . $*=5 \%$. 


\section{Appendix E:}

Tables with implicit contracting estimates obtained from random effects estimation

Results shown in Table E.1 and Table E.2 are obtained from the following

random effects models.

$\ln w(i, t)=\mathrm{X}_{i, t} \Omega_{1}+\left\{\begin{array}{l}\beta_{1} u c_{t}+\varepsilon_{1, i t} \\ \beta_{2} u s t r_{i, t}+\varepsilon_{2, i t} \\ \beta_{3} u l o w_{i, t}+\varepsilon_{3, i t} \\ \beta_{4} u c_{1}+\beta_{5} u s t r_{i, t}+\beta_{6} u l o w_{i, t}+\varepsilon_{i, t}\end{array}\right.$

Table E.1

Coefficient Estimates of Implicit Contracting Effects

from Random Effects Estimation

(Native-born Group)

\begin{tabular}{|c|c|c|c|c|c|c|c|}
\hline \multirow{2}{*}{ Macroeconomic Measures } & \multicolumn{7}{|c|}{ Regression Results for the Pooled Panel 93-06 $(\mathrm{N}=74,038)$} \\
\hline & 1 & 2 & 3 & 4 & 5 & 6 & 7 \\
\hline \multirow[t]{2}{*}{ Current Unemployment Rate } & $0.0065^{*}$ & & & $0.0072^{*}$ & $0.0099^{*}$ & & $0.0099^{*}$ \\
\hline & $(0.0000)$ & & & $(0.0000)$ & $(0.0000)$ & & $(0.0000)$ \\
\hline \multirow[t]{2}{*}{ Unemployment Rate at Start of Job } & & $-0.0029^{*}$ & & $-0.0051^{*}$ & & $0.0068 *$ & $0.0067^{*}$ \\
\hline & & $(0.0000)$ & & $(0.0000)$ & & $(0.0001)$ & $(0.0001)$ \\
\hline \multirow[t]{2}{*}{ Minimum Rate Since Start of Job } & & & $-0.0151^{*}$ & & $-0.0214^{*}$ & $-0.0212^{*}$ & $-0.0274^{*}$ \\
\hline & & & $(0.0001)$ & & $(0.0001)$ & $(0.0001)$ & $(0.0001)$ \\
\hline
\end{tabular}

Note: 1 . Standard errors are in parentheses. The dependent variable is the log of the real composite hourly wage. The independent variables include macroeconomic measures, years of schooling, years of experience, years of experience squared, tenure, tenure squared, and controls for industry, marital status, province of residence and urban/rural status. The random effects estimation results are in comparison with results from fixed effects estimation shown in Table 4.2.

2. $*=5 \%$. 
Table E.2

Implicit Contracting Effects from Fixed Effects Estimation: Immigrant Men and Women

\begin{tabular}{|c|c|c|c|c|c|c|c|}
\hline & \multicolumn{7}{|c|}{$\begin{array}{l}\text { Regression Results for the Pooled Panel 93-06 } \\
\qquad(\mathrm{N}=6,887)\end{array}$} \\
\hline & 1 & 2 & 3 & 4 & 5 & 6 & 7 \\
\hline \multirow[t]{2}{*}{ Current Unemployment Rate } & $-0.0004 *$ & & & $0.0008^{*}$ & $0.0042 *$ & & $0.0042^{*}$ \\
\hline & $(0.0001)$ & & & $(0.0001)$ & $(0.0001)$ & & $(0.0001)$ \\
\hline \multirow[t]{2}{*}{ Unemployment Rate at Start of Job } & & $-0.0125^{*}$ & & $-0.0127^{*}$ & & $0.0032 *$ & $0.0034^{*}$ \\
\hline & & $(0.0002)$ & & $(0.0002)$ & & $(0.0002)$ & $(0.0002)$ \\
\hline \multirow[t]{2}{*}{ Minimum Rate Since Start of Job } & & & $-0.0347^{*}$ & & $-0.0371^{*}$ & $-0.0375^{*}$ & $-0.0401^{*}$ \\
\hline & & & $(0.0002)$ & & $(0.0002)$ & $(0.0002)$ & $(0.0003)$ \\
\hline
\end{tabular}

Note: 1. Standard errors are in parentheses. The dependent variable is the log of the real composite hourly wage. The independent variables include macroeconomic measures, years since migration and years since migration squared, years of schooling, years of experience, years of experience squared, tenure, tenure squared, and controls for industry, marital status, province of residence and urban/rural status. The random effects estimation results are in comparison with results from fixed effects estimation shown in Table 5.2. 2 . $*=5 \%$. 


\section{Appendix F:}

A table with estimates representing individual characteristics

Estimates of an $\mathrm{X}$ vector representing individual characteristics shown in Table

F.1 are obtained from the following random effects model.

$$
\ln w(i, t)=\mathrm{X}_{i, t} \Omega_{1}+\beta_{1} u c_{t}+\beta_{2} u s t r_{i, t}+\beta_{3} u l o w_{i, t}+\varepsilon_{i, t}
$$

Table F.1

Coefficient Estimates Representing Individual Characteristics from Implicit Contracting Models: Men and Women

\begin{tabular}{ccc}
\hline Variable & Native-born & Immigrant \\
& 1 & 2 \\
\hline Years of schooling & $0.0494^{*}$ & $0.0440^{*}$ \\
Years of full-time experience & $(0.0000)$ & $(0.0001)$ \\
Years of experience squared & $0.0268^{*}$ & $0.0230^{*}$ \\
& $(0.0000)$ & $(0.0001)$ \\
Job tenure & $-0.0004^{*}$ & $-0.0003^{*}$ \\
& $(0.0000)$ & $(0.0000)$ \\
Job tenure squared & $0.0126^{*}$ & $0.0061^{*}$ \\
& $(0.0000)$ & $(0.0001)$ \\
Marital status & $-0.0002^{*}$ & $0.0000^{*}$ \\
& $(0.0000)$ & $(0.0000)$ \\
Urban/rural status & $0.0497^{*}$ & $0.0406^{*}$ \\
& $(0.0001)$ & $(0.0004)$ \\
Agriculture & $0.0278^{*}$ & $-0.0382^{*}$ \\
& $(0.0001)$ & $(0.0006)$ \\
Forestry \& logging & $-0.0567^{*}$ & $0.1341^{*}$ \\
& $(0.0005)$ & $(0.0024)$ \\
Fishing, hunting \& trapping & $0.1515^{*}$ & $0.2510^{*}$ \\
Mining, oil \&gas & $(0.0006)$ & $(0.0031)$ \\
Utilities & $0.1478^{*}$ & 0.0000 \\
Construction & $(0.0008)$ & $(0.0000)$ \\
& $0.2937^{*}$ & $0.3961^{*}$ \\
& $(0.0005)$ & $(0.0016)$ \\
& $0.2896^{*}$ & $0.3271^{*}$ \\
& $(0.0006)$ & $(0.0024)$ \\
& $0.1431^{*}$ & $0.2579^{*}$ \\
& &
\end{tabular}




\begin{tabular}{|c|c|c|}
\hline & $(0.0004)$ & $(0.0014)$ \\
\hline \multirow[t]{2}{*}{ Durables } & $0.1411^{*}$ & $0.2812^{*}$ \\
\hline & $(0.0003)$ & $(0.0012)$ \\
\hline \multirow[t]{2}{*}{ Non-durables } & $0.1085^{*}$ & $0.1371^{*}$ \\
\hline & $(0.0003)$ & $(0.0012)$ \\
\hline \multirow[t]{2}{*}{ Wholesale trade } & $0.0728^{*}$ & $0.1267^{*}$ \\
\hline & $(0.0004)$ & $(0.0013)$ \\
\hline \multirow[t]{2}{*}{ Retail trade } & $-0.0977^{*}$ & $0.0117^{*}$ \\
\hline & $(0.0003)$ & $(0.0011)$ \\
\hline \multirow[t]{2}{*}{ Transportation and warehousing } & $0.1324^{*}$ & $0.2104^{*}$ \\
\hline & $(0.0004)$ & $(0.0014)$ \\
\hline \multirow[t]{2}{*}{ Finance and insurance } & $0.1200^{*}$ & $0.1990^{*}$ \\
\hline & $(0.0004)$ & $(0.0013)$ \\
\hline \multirow[t]{2}{*}{ Real estate and leasing } & $0.0132 *$ & $0.3227^{*}$ \\
\hline & $(0.0005)$ & $(0.0018)$ \\
\hline \multirow[t]{2}{*}{ Professional, Scientific and Technical Services } & $0.1572 *$ & $0.1793^{*}$ \\
\hline & $(0.0004)$ & $(0.0012)$ \\
\hline \multirow[t]{2}{*}{ Business, building, and other support services } & $0.0159^{*}$ & $0.1571^{*}$ \\
\hline & $(0.0004)$ & $(0.0013)$ \\
\hline \multirow[t]{2}{*}{ Educational services } & $0.1825^{*}$ & $0.2464^{*}$ \\
\hline & $(0.0003)$ & $(0.0012)$ \\
\hline \multirow[t]{2}{*}{ Health care and social assistance } & $0.1292 *$ & $0.1816^{*}$ \\
\hline & $(0.0003)$ & $(0.0012)$ \\
\hline \multirow[t]{2}{*}{ Information, Culture, and Recreation } & $0.0652 *$ & $0.2231^{*}$ \\
\hline & $(0.0004)$ & $(0.0014)$ \\
\hline \multirow[t]{2}{*}{ Accommodation and food services } & $-0.1715^{*}$ & $-0.0349^{*}$ \\
\hline & $(0.0004)$ & $(0.0013)$ \\
\hline \multirow[t]{2}{*}{ Public Administration } & $0.1977^{*}$ & $0.3571^{*}$ \\
\hline & $(0.0003)$ & $(0.0012)$ \\
\hline \multirow[t]{2}{*}{ Newfoundland and Labrador } & $-0.1836^{*}$ & $-0.0697^{*}$ \\
\hline & $(0.0004)$ & $(0.0027)$ \\
\hline \multirow[t]{2}{*}{ Prince Edward Island } & $-0.2223 *$ & $-0.1448^{*}$ \\
\hline & $(0.0004)$ & $(0.0026)$ \\
\hline \multirow[t]{2}{*}{ Nova Scotia } & $-0.1891^{*}$ & $-0.2035^{*}$ \\
\hline & $(0.0003)$ & $(0.0016)$ \\
\hline \multirow[t]{2}{*}{ New Brunswick } & $-0.1783^{*}$ & $-0.1119^{*}$ \\
\hline & $(0.0003)$ & $(0.0017)$ \\
\hline \multirow[t]{2}{*}{ Quebec } & $-0.0718^{*}$ & $-0.1009^{*}$ \\
\hline & $(0.0002)$ & $(0.0011)$ \\
\hline
\end{tabular}




$\begin{array}{ccc}\text { Manitoba } & -0.0964^{*} & -0.1752^{*} \\ \text { Saskatchewan } & (0.0003) & (0.0011) \\ \text { Alberta } & -0.1311^{*} & -0.1220^{*} \\ & (0.0003) & (0.0016) \\ \text { British Columbia } & -0.0095^{*} & -0.0468^{*} \\ \text { Constant } & (0.0003) & (0.0009) \\ & 0.0459^{*} & 0.0003 \\ \text { No. of Observations } & (0.0003) & (0.0008) \\ & 1.7990^{*} & 2.0431^{*} \\ \end{array}$

Note: 1 . Standard errors are in parentheses.

2. Random effects estimation is employed.

3. Column 1 combined with Column 7 of Table E.1 makes the full table of estimates from Model (F.1) for the native-born group. Column 2 combined with Column 7 of Table E. 2 is for the immigrant group. 4. $*=5 \%$. 


\section{References}

Abbott, Michael G and Charles M Beach (1993) "Immigrant Earnings Differentials and Birth-Year Effects for Men in Canada: Post-war-1972," Canadian Journal of Economics, 26(3): 505-524.

Abraham, Katharine G and Haltiwanger, John C (1995) "Real Wages and the Business Cycle," Journal of Economic Literature, 33(3): 1215-1264.

Allensworth, Elaine M (1997) "Earnings Mobility of First and '1.5' Generation Mexican-Origin Women and Men: A Comparison with U.S.-Born Mexican Americans and Non-Hispanic Whites," International Migration Review, 31(2): 386-410.

Altonji, Joseph G and Robert A Shakotko (1987) "Do Wages Rise with Job Seniority?" Review of Economic Studies, 54(3): 437-459.

Altonji, Joseph G and Nicolas Williams (2005) "Do Wages Rise with Job Seniority A Reassessment," Industrial and Labour Relations Review, 58(3): 370397.

Ashenfelter, Orley and David Card (1986) "Why have Unemployment Rates in Canada and the U.S. Diverged?" Economia, 53(210): S171-S195.

Aydemir, Abdurrahman (2003) "Effects of Business Cycles on the Labour Market Assimilation of Immigrants," Analytical Studies Research Paper Series, Catalogue No. 11F0019MIE2003203. Ottawa: Statistics Canada.

Azariadis, Costas (1975) "Implicit Contracts and Underemployment Equilibria," Journal of Political Economy, 83(6): 1183-1202.

Baily, Martin N (1974) "Wages and Employment Under Uncertain Demand," Review of Economic Studies, 41(1): 37-50.

Baker, Michael and Dwayne Benjamin (1994) "The Performance of Immigrants in the Canadian Labor Market," Journal of Labor Economics, 12(3): 369405.

(1997) "The Role of the Family in Immigrants' Labor-Market Activity: An Evaluation of Alternative Explanations," American Economic Review, 87(4): 705-727.

Beach, Charles M and Christopher Worswick (1993) "Is There a Double-negative Effect on the Earnings of Immigrant Women?" Canadian Public Policy, 19(1): 36-53. 
Beaudry, Paul and John E DiNardo (1991) "The Effect of Implicit Contracts on the Movement of Wages over the Business Cycle: Evidence from Micro Data," Journal of Political Economy, 99(4): 665-688.

Beaudry, Paul and David A Green (2000) "Cohort patterns in Canadian earnings: assessing the role of skill premia in inequality trends," Canadian Journal of Economics, 33(4): 907-936.

Becker, Gary S (1964) "Investment in Human Capital: A Theoretical Analysis," Journal of Political Economy, 70(5): 9-49.

Bils, Mark J (1985) "Real Wages over the Business Cycle: Evidence from Panel Data," Journal of Political Economy, 93(4): 666-689.

Borjas, George J (1982) "The Earnings of Male Hispanic Immigrants in the United States," Industrial and Labour Relations Review, 35(3): 343-353. (1985) "Assimilation, Changes in Cohort Quality, and Earnings of Immigrants," Journal of Labor Economics, 3(4): 463-489. (1987) "Self-Selection and the Earnings of Immigrants," American Economic Review, 77(4): 531-553.

(1993) "Immigration Policy, National Origin, and Immigrant Skills: A Comparison of Canada and the United States," In David Card and Richard B Freeman (Ed.), Small Differences That Matter: Labor Markets and Income Maintenance in Canada and the United States. Chicago: University of Chicago Press, (1993): 21-44.

(1996) "The earnings of Mexican immigrants in the United States," Journal of Development Economics, 51(1): 69-98.

Brown, James N and Orley Ashenfelter (1986) "Testing the Efficiency of Employment Contracts," Journal of Political Economy, 94(3): S40-S87.

Butcher, Kristin F (1994) "Black Immigrants in the United States: A Comparison with Native Blacks and Other Immigrants," Industrial and Labor Relations Review, 47(2): 265-284.

Card, David and William C Riddell (1993) "A Comparative Analysis of Unemployment in Canada and the United States," in David Card and Richard B Freeman (Ed.) Small Differences That Matter: Labor Markets and Income Maintenance in Canada and the United States. Chicago: University of Chicago Press, (1993): 149-190.

Carliner, Geoffrey (1980) "Wages, Earnings and Hours of First, Second and Third 
Generation American Males," Economic Enquiry, 18(1): 87-102.

Chiswick, Barry R (1978) "The Effect of Americanization on the Earnings of Foreign-Born Men," Journal of Political Economy, 86(5): 897-921.

Chiswick, Barry R, Yinon Cohen and Tzippi Zach (1997) "The Labor Market Status of Immigrants: Effects of the Unemployment Rate at Arrival and Duration of Residence," Industrial and Labour Relations Review, 50(2): 289-303.

Chiswick, Barry R and Paul W Miller (2002) "Immigrant Earnings: Language Skills, Linguistic Concentrations and the Business Cycle," Journal of Population Economics, 15(1): 31-57.

(2007) "Modeling Immigrants' Language Skills," IZA Discussion Paper, No. 2974. Available at SSRN: http://ssrn.com/abstract=1011140

Christiano, Lawrence J and Martin Eichenbaum (1992) "Current Real Business Cycle Theories and Aggregate Labor Market Fluctuations," American Economic Review, 82(3): 430-450.

Cobb-Clark, Deborah A (1993) "Immigrant Selectivity and Wages: The Evidence for Women," American Economic Review, 83(4): 986-993.

Collard, Fabrice and David de la Croix (2000) "Gift Exchange and the Business Cycle: The Fair Wage Strikes Back," Review of Economic Dynamics, 3(1): 166-193.

Devereux, Paul J and Robert A Hart (2005) "The Spot Market Matters: Evidence on Implicit Contracts from Britain," IZA Discussion Paper, No. 1497. Available at SSRN: http://ssrn.com/abstract $=673426$

Duleep, Harriet O. and Mark C Regets (1997) "Immigrant Entry Earnings and Human Capital Growth: Evidence from the 1960-80 Censuses," In Solomon W Polachek (Ed.) Research in Labor Economics, 16: 297-317.

Fang, Tony and Morley Gunderson (2009) "Minimum Wage Impacts on Older Workers: Longitudinal Estimates from Canada," British Journal of Industrial Relations, 47(2): 371-387.

Friedman, Milton (1968) "The Role of Monetary Policy," American Economic Review, 58(1): 1-17.

Funkhauser, Edward and Stephen J Trejo (1995) "The Labor Market Skills of Recent Male Immigrants: Evidence from the Current Population Survey," Industrial and Labor Relations Review, 48(4): 792-811. 
Gomme, Paul and Jeremy Greenwood (1995) "On the Cyclical Allocation of Risk," Journal of Economic Dynamics and Control, 19(1-2): 91-124.

Grant, Darren (2003) "The Effect of Implicit Contracts on the Movement of Wages over the Business Cycle: Evidence from the National Longitudinal Surveys," Industrial and Labor Relations Review, 56(3): 393-408.

Grant, Mary L (1999) "Evidence of New Immigrant Assimilation in Canada," Canadian Journal of Economics, 32(4): 930-955.

Green, David A and James Townsend (2010) "Understanding the Wage Patterns of Canadian Less Skilled Workers: The Role of Implicit Contracts," Canadian Journal of Economics, 43(1): 373-403.

Harris, Milton and Bengt Holmstrom (1982) "A Theory of Wage Dynamics," Review of Economic Studies, 49(3): 315-333.

Hogan, Chad (2001) "Enforcement of Implicit Employment Contracts Through Unionization," Journal of Labor Economics, 19(1): 171-195.

Holmstrom, Bengt (1981) "Contractual Models of the Labor Market," American Economic Review, 71(2): 308-313.

$\mathrm{Hu}$, Wei-Yin (2000) "Immigrant Earnings Assimilation: Estimates from Longitudinal Data," American Economic Review, 90(2): 368-372.

Hum, Derek and Wayne Simpson (2000) "Closing the Wage Gap: Economic Assimilation of Canadian Immigrants Reconsidered," Journal of International Migration and Integration, 1(4): 427-441. (2002) "Selectivity and immigration in Canada," Journal of International Migration and Integration, 3(1): 107-127.

(2004) "Reinterpreting the performance of immigrant wages from panel data," Empirical Economics, 29 (1): 129-147.

Jovanovic. Boyan (1979) "Job Matching and the Theory of Turnover," Journal of Political Economy, 87 (5): 972-990.

Juhn. Chinhui, Kevin M Murphy and Brooks Pierce (1993) "Wage Inequality and the Rise in Returns to Skill," Journal of Political Economy, 101(3): 410442.

Knight, Frank H (1921) "Risk, Uncertainty and Profit," Hart, Schaffner and Marx Prize Essays, No. 31. Boston and New York: Houghton Mifflin. 
Long, James E (1980) "The Effect of Americanization on Earnings: Some Evidence for Women," Journal of Political Economy, 88(3): 620-629.

MaCurdy, Thomas E and John H Pencavel (1986) "Testing between Competing Models of Wage and Employment Determination in Unionized Markets," Journal of Political Economy, 94(3): S3-S39.

McDonald, James T and Christopher Worswick (1997) "Unemployment Incidence of Immigrant Men in Canada," Canadian Public Policy, 23(4): 353-373.

(1998) "The Earnings of Immigrant Men in Canada: Job Tenure, Cohort, and Macroeconomic Conditions," Industrial and Labor Relations Review, 51(3): 465-482.

(1999) "The Earnings of Immigrant Men in Australia: Assimilation, Cohort Effects, and Macroeconomic Conditions," The Economic Record, 75(228): 49-62.

(1999) "Wages, Implicit Contracts and the Business Cycle: Evidence from Canadian Micro Data," Journal of Political Economy, 107(4): 884892.

Miller, P. (1992) "The Earnings of Asian Male Immigrants in the Canadian Labor Market," International Migration Review, 26(4): 1222-1247.

Mincer, Jacob (1958) "Investment in Human Capital and Personal Income Distribution," Journal of Political Economy, 66(4): 281-302.

Mincer, Jacob and Boyan Jovanovic (1981) "Labor Mobility and Wages," In Sherwin Rosen (Ed.) Studies in Labor Markets. New York: National Bureau of Economic Research, (1981): 21-63.

Nakamura, Alice O and Masao Nakamura. (1992) "Wage Rates of Immigrant and Native Men in Canada and the United States," in Barry R Chiswick (Ed.) Immigration, Language and Ethnicity: Canada and the United States. Washington, D.C.: American Enterprise Institute, (1992): 145-166.

Phillips, Alban W (1958) "The Relationship Between Unemployment and the Rate of Change of Money Wages in the United Kingdom 1861-1957," Economica, 25 (100): 283-99.

Reimers, Cordelia W (1997) "The Progress of Mexican and White Non-Hispanic Immigrants in California and Texas, 1980 to 1990," Quarterly Review of Economics and Finance, 37(Supplement 1): 315-343. 
Reitz, Jeffrey G (2001) "Immigrant Skill Utilization in the Canadian Labour Market: Implications of Human Capital Research," Journal of International Migration and Integration, 2(3): 347-378.

Rosen, Sherwin (1985) "Implicit Contract: A Survey," Journal of Economic Literature, 23(3): 1144-1175.

Shamsuddin, Abul F M (1998) "The Double-negative Effect on the Earnings of Foreign-born Females in Canada," Applied Economics, 30(9): 1187-1201.

Skuterud, Mikal and Mingcui Su (2009) "Immigrant Wage Assimilation and the Return to Foreign and Host-Country Sources of Human Capital," CLSRN Working Papers, clsrn_admin-2009-38, UBC Department of Economics. Available at: http://econrsss.anu.edu.au/pdf/seminars/skuterud.pdf.

Statistics Canada (1993-2006) Survey of Labour and Income Dynamics, Ottawa: Statistics Canada.

Topel, Robert H (1991) "Specific Capital, Mobility, and Wages: Wages Rise with Job Seniority," Journal of Political Economy, 99(1): 145-176.

Wald, Steven and Tony Fang (2008) "Overeducated Immigrants in the Canadian Labour Market: Evidence from the Workplace and Employee Survey," Canadian Public Policy, 34 (4): 457-79. 